\title{
THE VARIABILITY OF THE EL NIÑO SOUTHERN OSCILLATION AND MODOKI MODE AND THEIR IMPACTS ON NEW YORK STATE \\ CLIMATE
}

A Thesis Presented to the Faculty of the Graduate School at the University of Missouri

In Partial Fulfillment of the Requirements for the Degree

Master of Science

by

THOMAS CAIN

Dr. Anthony Lupo, Thesis Advisor

JULY 2021 
The undersigned, appointed by the dean of the Graduate School, have examined the

thesis entitled

\section{THE VARIABILITY OF THE EL NINO SOUTHERN OSCILLATION AND MODOKI MODE}

\section{AND THEIR IMPACTS ON NEW YORK STATE CLIMATE}

Presented by Thomas Cain

a candidate for the degree of Master of Science,

and hereby certify that, in their opinion, it is worthy of acceptance.

Professor Anthony Lupo

Associate Extension Professor Patrick Guinan

Assistant Teaching Professor Clayton Blodgett 


\section{ACKNOWLEDGMENTS}

First and foremost, I'd like to thank Dr. Anthony Lupo for his advisement and guidance throughout my student career. His patience and wisdom helped show me the way forward countless times, and he has been a fantastic mentor throughout my time here. In addition, I would like to thank Dr. Fox and Dr. Guinan for their teachings and guidance, as well as Dr. Blodgett. I would also like to recognize the graduate and undergraduate students here that have welcomed me into the department with open arms, and made Missouri feel just like home. Last but certainly not least, I would like to thank my friends and family for their unwavering support, without which I would not have been able to accomplish this. 


\section{Table of Contents}

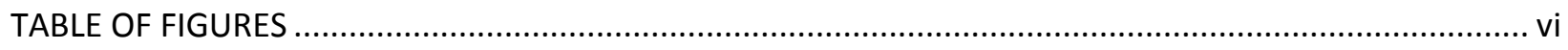

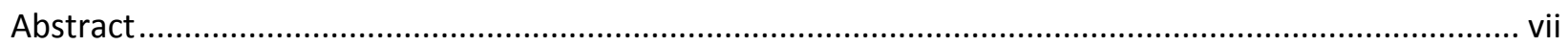

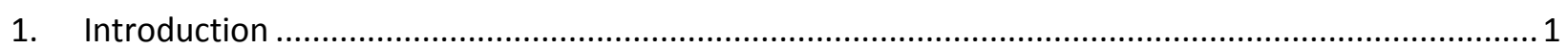

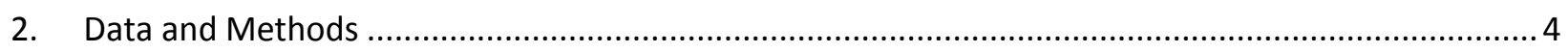

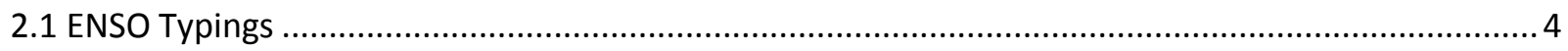

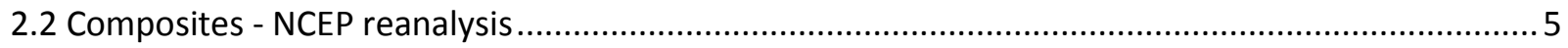

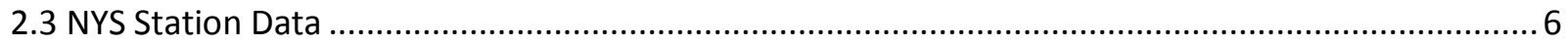

Figure 1: Locations (starred) of data points used for analysis. Any gaps in data were filled by co-op stations within 30 miles of their respective locations .................................................................. 6

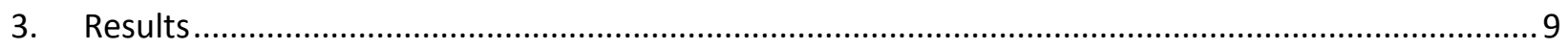

3.1 Signal Strength: Conventional El Niño vs Modoki......................................................................... 9

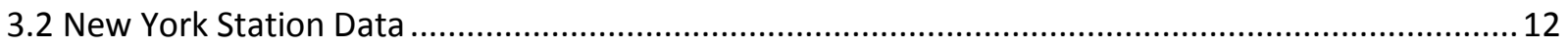

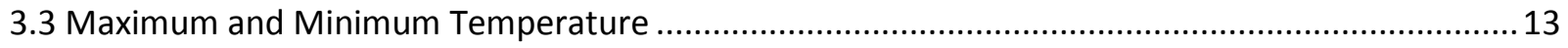

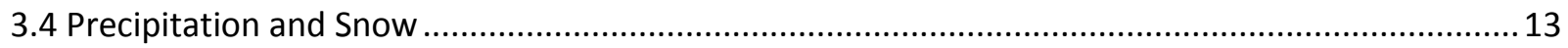

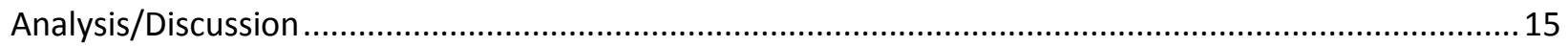

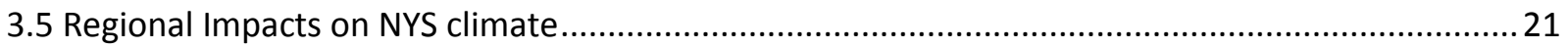

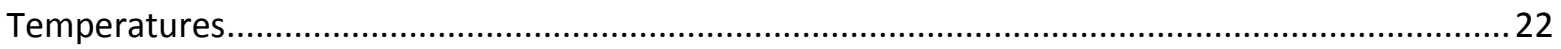

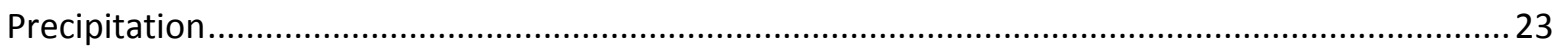

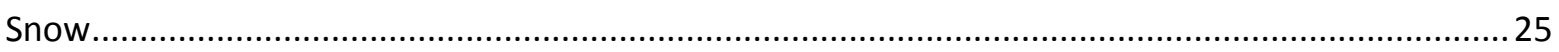

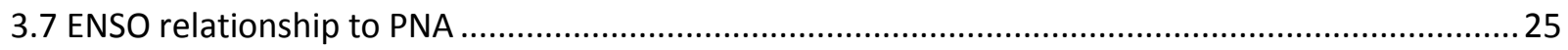

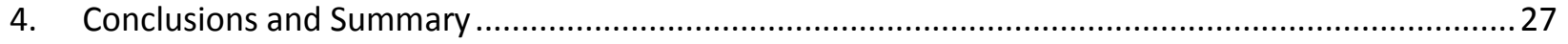

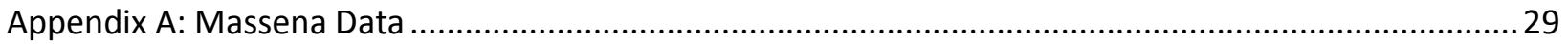

A.1 - Comparison of Maximum Temperature Anomalies - Conventional El Niño vs Modoki ...............29

A.2 - Comparison of Minimum Temperature Anomalies - Conventional El Niño vs Modoki.................30

A.3 - Comparison of Precipitation Anomalies - Conventional El Niño vs Modoki ................................31

A.4 - Comparison of Snow Anomalies - Conventional El Niño vs Modoki ...........................................32

A.5 - Comparison of Maximum Temperature Anomalies - La Niña vs Modoki ...................................33

A.6 - Comparison of Minimum Temperature Anomalies -La Niña vs Modoki .....................................34

A.7 - Comparison of Precipitation Anomalies - La Niña vs Modoki....................................................35

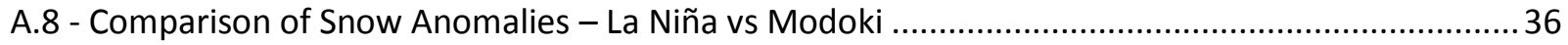

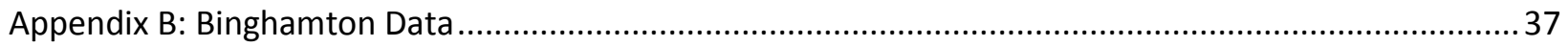

B.1 - Comparison of Maximum Temperature Anomalies - Conventional El Niño vs Modoki .................37 
B.2 - Comparison of Minimum Temperature Anomalies - Conventional El Niño vs Modoki. 38

B.3 - Comparison of Precipitation Anomalies - Conventional El Niño vs Modoki..................................39

B.4 - Comparison of Snow Anomalies - Conventional El Niño vs Modoki........................................... 40

B.5 - Comparison of Maximum Temperature Anomalies - La Niña vs Modoki.................................... 41

B.6 - Comparison of Minimum Temperature Anomalies - La Niña vs Modoki ....................................42

B.7 - Comparison of Precipitation Anomalies - La Niña vs Modoki.....................................................4 43

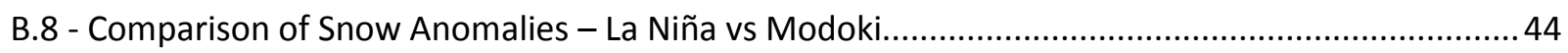

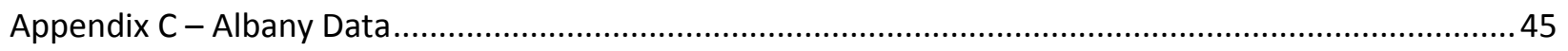

C.1 - Comparison of Maximum Temperature Anomalies - Conventional El Niño vs Modoki .................45

C.2 - Comparison of Minimum Temperature Anomalies - Conventional El Niño vs Modoki................46

C.3 - Comparison of Precipitation Anomalies - Conventional El Niño vs Modoki................................47

C.4 - Comparison of Snow Anomalies - Conventional El Niño vs Modoki............................................48

C.5 - Comparison of Maximum Temperature Anomalies - La Niña vs Modoki.....................................49

C.6 - Comparison of Minimum Temperature Anomalies - La Niña vs Modoki ....................................50

C.7 - Comparison of Precipitation Anomalies - La Niña vs Modoki....................................................51

C. 8 - Comparison of Snow Anomalies - La Niña vs Modoki.............................................................52

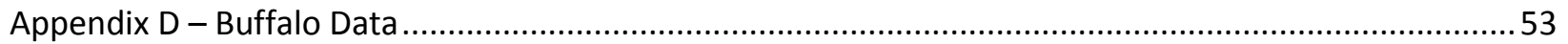

D.1 - Comparison of Maximum Temperature Anomalies - Conventional El Niño vs Modoki................53

D.2 - Comparison of Minimum Temperature Anomalies - Conventional El Niño vs Modoki ................54

D.3 - Comparison of Precipitation Anomalies - Conventional El Niño vs Modoki.................................55

D.4 - Comparison of Snow Anomalies - Conventional El Niño vs Modoki ..........................................56

D.5 - Comparison of Maximum Temperature Anomalies - La Niña vs Modoki...................................57

D.6 - Comparison of Minimum Temperature Anomalies - La Niña vs Modoki ....................................58

D.7 - Comparison of Precipitation Anomalies - La Niña vs Modoki ....................................................59

D.8 - Comparison of Snow Anomalies - La Niña vs Modoki .............................................................60

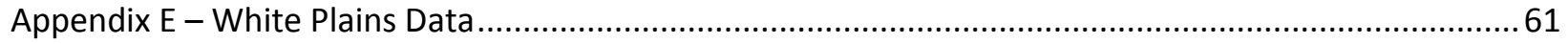

E.1 - Comparison of Maximum Temperature Anomalies - Conventional El Niño vs Modoki ................61

E.2 - Comparison of Minimum Temperature Anomalies - Conventional El Niño vs Modoki.................62

E.3 - Comparison of Precipitation Anomalies - Conventional El Niño vs Modoki .................................63

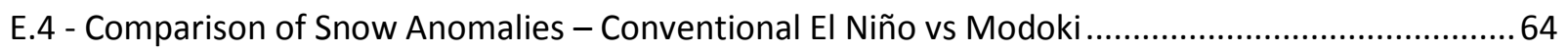

E.5 - Comparison of Maximum Temperature Anomalies - La Niña vs Modoki .....................................65

E.6 - Comparison of Minimum Temperature Anomalies - La Niña vs Modoki....................................66

E.7 - Comparison of Precipitation Anomalies - La Niña vs Modoki ...................................................67 
E.8 - Comparison of Snow Anomalies - La Niña vs Modoki. .68

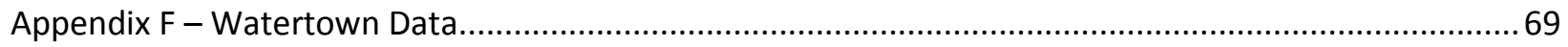

F.1 - Comparison of Maximum Temperature Anomalies - Conventional El Niño vs Modoki ................69

F.2 - Comparison of Minimum Temperature Anomalies - Conventional El Niño vs Modoki.................70

F.3 - Comparison of Precipitation Anomalies - Conventional El Niño vs Modoki ..................................71

F.4 - Comparison of Snow Anomalies - Conventional El Niño vs Modoki ...........................................72

F.5 - Comparison of Maximum Temperature Anomalies - La Niña vs Modoki .....................................73

F.6 - Comparison of Minimum Temperature Anomalies - La Niña vs Modoki....................................74

F.7 - Comparison of Precipitation Anomalies - La Niña vs Modoki ...................................................... 75

F.8 - Comparison of Snow Anomalies - La Niña vs Modoki.............................................................. 76

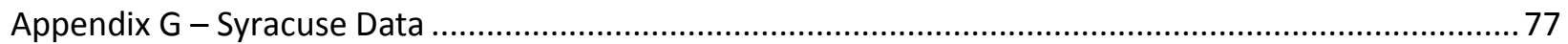

G.1 - Comparison of Maximum Temperature Anomalies - Conventional El Niño vs Modoki................77

G.2 - Fig G.2: As in Figure G.1, except for Minimum Temperature (F) ............................................ 78

G.3 - Comparison of Precipitation Anomalies - Conventional El Niño vs Modoki ................................79

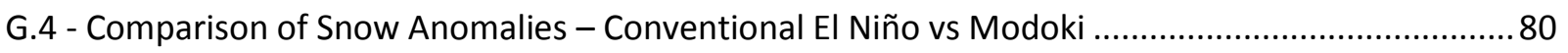

G.5 - Comparison of Maximum Temperature Anomalies - La Niña vs Modoki ...................................81

G.6 - Comparison of Minimum Temperature Anomalies - La Niña vs Modoki .....................................8 82

G.7 - Comparison of Precipitation Anomalies - La Niña vs Modoki ..................................................83

G.8 - Comparison of Snow Anomalies - La Niña vs Modoki .............................................................. 84

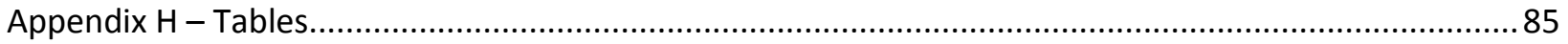

Table H.1 - Results of El Niño City Result comparisons to the overall average curves (Figures 8-11).

Maximum and Minimum Temperature results were combined due to similarity of results. .................85

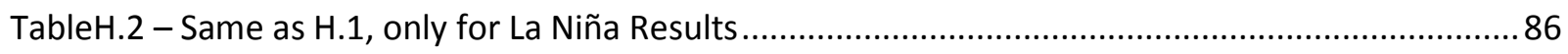



Table H.4 - Analysis of all city-based autocorrelation results...................................................... 88

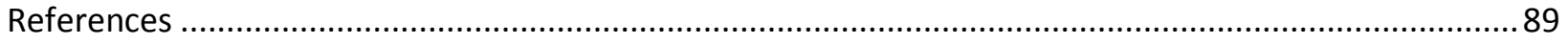




\section{TABLE OF FIGURES}

Figure 1: Locations (starred) of data points used for analysis. Any gaps in data were filled by co-op stations within 30 miles of their respective locations.

Figure 2: The Skin Surface Temperature(SST) (K) Composite Anomalies for: a) Conventional El Niño periods, b) La Niña periods, c) All El Niño Periods, and d) Modoki El Niño periods, compiled from the

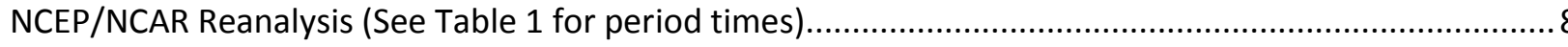

Figure 3: As in Figure 1, except for surface temperature composite anomalies (C)..............................9 Figure 4: As in Figure 1, except for precipitation $(\mathrm{mm})$ composite anomalies, compiled from GPCC

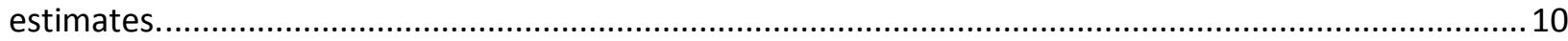

Figure 5: As in Figure 1, except for Geopotential Height $(500 \mathrm{mb})(\mathrm{m})$ Composite Anomalies. ................11

Figure 6: As in Figure 1, except for Zonal Wind $(500 \mathrm{mb})$ composite anomalies $(\mathrm{m} / \mathrm{s})$. ........................15

Figure 7: As in Figure 1, except for Meridional Wind $(850 \mathrm{mb})$ composite anomalies $(\mathrm{m} / \mathrm{s})$...................16

Figure 8: Maximum Surface Temperature (F) Daily Averaged Anomalies for all seven locations for: a) Conventional El Niño periods, b) La Niña periods, c) All El Niño Periods, and d) Modoki El Niño periods.

Warm (positive) anomalies are shown as red bars, and cold

Figure 9: As in Figure 8, except for Minimum Surface Temperature (F) Daily Averaged Anomalies. ........18

Figure 10: As in Figure 8, except for Precipitation (in) Daily Averaged Anomalies. ...................................19

Figure 11: As in Figure 8, except for Snowfall (in) Daily Averaged Anomalies. .......................................20

Figure 12: Autocorrelation of Maximum Surface Temperature (F) Daily Averaged Anomalies for all seven locations for: a) Conventional El Niño periods, b) La Niña periods, c) All El Niño Periods, and d) Modoki El Niño periods. The $X$ axis is the relationship strength .....................................................................2

Figure 13: As in Figure 8, except for Minimum Surface Temperature (F) Daily Averaged Anomalies. ......22

Figure 14: As in Figure 8, except for Precipitation (in) Daily Averaged Anomalies. ..................................23

Figure 15: As in Figure 8, except for Snowfall (in) Daily Averaged Anomalies. .......................................24 


\section{Abstract}

The El Niño Southern Oscillation (ENSO) has long been an influential climate and weather driver for many regions. Many studies have examined the variability of the phases of ENSO, leading to discovery of a separate mode of El Niño dubbed the El Niño Modoki, featuring a tripole Walker circulation. However, few studies have examined the variability of El Niño with Modoki separated from regular El Niño events. The goals of this study were to demonstrate that the El Niño signal was stronger separate from Modoki (thus leading to higher predictability), and to examine the effect of the Modoki on both a national and regional level, showing the connection between other teleconnections such as the Pacific North American teleconnection (PNA), the Arctic Oscillation (AO), and the North American Oscillation teleconnection (NAO). Using NCEP/NCAR composites, conventional El Niño events were found to have a stronger signal, with persistent features being easier to identify. Similarly, the Modoki showed a pattern that was similar but different to the regular El Niño. Using New York State for the area of regional analysis, all ENSO phases were found to modify the effect of the PNA, but the effect was different depending on location. Both of these results indicate that it is possible to generate a clearer picture of the impacts of ENSO by properly classifying these events. 


\section{Introduction}

For as long as we have had the ability to properly measure sea surface temperatures, a steady stream of studies on the El Niño Southern Oscillation (ENSO) have shed light on its impacts and dynamics, both external and internal. Some of those studies have explored the cause of impacts during its positive phase (El Niño) that deviated from the established normal effects. Examinations of the effect of this mode on Pacific climates and regions farther out have been carried out, however, few examinations have been done on its effect on Northeast winter weather. Furthermore, few have examined the effect of removing the Modoki signal from El Niño, to strengthen or "clean up" the El Niño signal. The main driver behind the differing effect

of the Modoki is that regular El Niño phases have their temperature maximum farther east in the Pacific, while Modoki have theirs nearer the dateline. (Ashok et al. 2007, Wang et al. 2018, Larkin and Harrison 2005)

Studies performed by Birk et al.(2010) and Ashok et al. (2007) found that this mode featured a westward-shifted, decentralized SSTa maximum, and neutral to weakly negative SSTas near both the Indonesian archipelago and the South American coast. The defining characteristic of a Modoki El Niño is a tripole in the tropical equatorial Pacific, as opposed to a dipole created by the other two ENSO modes, resulting in dual Walker circulations in the region. This new configuration changes the dynamics of persistent weather features and creates a separate pattern from the normal El Niño. This mode was dubbed the El Niño Modoki (henceforth referred to as the Modoki), meaning "pseudo" or "similar but different" in Japanese. Once the Modoki mode is past peak, both equatorial upwelling and easterlies in the Eastern 
Pacific are amplified, and this weakens the westerlies in the western pacific and brings warmer ocean waters via oceanic Rossby waves to that region, killing the cold anomaly previously present. This is the herald of the end of the mode and may explain both a) the very strict longevity of most Modoki events, lasting almost always around six months, and b) the lack of longevity the mode has compared to the other phases. The periodicity of the Modoki is currently thought to be anywhere from 10 to 12 years, though that frequency could possibly be changing. (Ashok et al. 2007; Dogar et al. 2019) The Modoki can affect weather and climate on a large scale, as it has been shown that the Modoki's impacts on the lower 48 states were different by region, both in polarity and amplitude, shown with both anomaly and significance maps. In addition, the Modoki has been shown to have different effects on differing teleconnections, such as the North Pacific Oscillation/West Pacific teleconnection, hereafter referred to as the NPO/WP. (Larkin and Harrison 2005; Kim, Choi, and Byung 2011) This teleconnection affects persistent features such as the Aleutian Low and is indicative of a change in precipitation in the Pacific Northwest and the southern Great Plains. (Wang et al. 2018) As well as the extratropical Northern Hemisphere and greater Pacific, the Modoki can also influence rainfall in tropical Africa. The effects in this region, while similar to conventional El Niño in some regards, was shown to be especially different during astral winter. (Preethi et al. 2015) There are also instances where the Modoki may not affect a teleconnection, as is the case with the NAO, although it could "spoof" an NAO-like response due to tropical-induced Rossby waves. (Dogar et al. 2019) It is likely that the two new patterns observed by doing this will look different in terms of the general circulation, but it is also important to examine the impacts of this on a regional level as well. 
To that end, a study done by Straus and Shukla (2002) explored the possibility that the Pacific/North American teleconnection pattern (PNA) was forced by ENSO. While the study did not make a conclusive argument for this hypothesis, it was observed that the strength (or lack thereof) of the ENSO signal modified the efficacy of the study itself. Also, ENSO's effects were found to be amplified (specifically in Missouri) when in phase with the Pacific Decadal Oscillation, or PDO. (Birk et al.2010) In addition, the relationship between the AO and ENSO has been found to be a two-way street, with one affecting the other depending on conditions. (L'Heureux et al. 2017; Chen et al. 2018) Given that the Modoki and conventional El Niño signal are potentially a product of both external and internal variability, it is a worthwhile venture to explore the effect this separation has on these and other teleconnections, and by proxy, the impacts on seasonal and mid-range weather patterns, in this case, for New York State.

This study will make use of seasonal composites to identify persistent features within these altered signals and use the similarities/differences to infer teleconnections and other dynamic relationships. In addition, it will use regional climate anomalies and signal processing to establish a relationship between these modes and existing teleconnections such as the AO, NAO, and PNA. The case for strengthening the El Niño signal by separating out the Modoki mode, as well as the case for examining the effect of ENSO on other teleconnections in the New York State (NYS) region, will be examined. 


\section{Data and Methods}

The study is focusing on the winter months (December, January, February) due to the ENSO signal overall being strongest during the winter months at that time in the Northern Hemisphere. (Dogar et al. 2019) This is also the period of time where any fluctuations in the AO or PNA would have the greatest impact on weather in the NYS region. The data for determining the length (start month/year and end month/year) of the El Niño and La Niña phases was obtained from the CPC, based on the three-month running average of SSTa within the equatorial tropical Pacific running +/- 0.5 degrees Celsius, also known as the Oceanic Nino Index(ONI).

To determine ENSO phase periods, since they use three-month running averages, the start of a phase was determined by using the first month and last month of the phase. However, exceptions were made when there were three months or less between phases - this is because ENSO phases would have been represented as ending on one month and another beginning on the same month, which is not something that happens. Therefore, at least one month of a buffer time was given in these cases. In this manner, a list of El Niño and La Niña periods were compiled.

\subsection{ENSO Typings}

Using the ENSO type classifications found in Lupo et al. (2007) as well as Kung and Chern (1995), each El Niño period was examined to determine the presence and duration of Modoki modes. As referenced, two types of SSTa configurations were similar to that of the Modoki as was discussed in Ashok et al. 2007 and Larkin and Harrison 2005. These demonstrated both a westward temperature maximum and a cooler SSTa near the South 
Table 1: Result of ENSO Typings.

\begin{tabular}{|c|c|c|}
\hline EI Niño (Conventional) & La Niña & Modoki \\
\hline 1969 & 1964 & 1963 \\
\hline 1972 & 1970 & 1965 \\
\hline 1976 & 1971 & 1968 \\
\hline 1982 & 1973 & 1977 \\
\hline 1997 & 1974 & 1979 \\
\hline 2006 & 1975 & 1986 \\
\hline 2014 & 1983 & 1987 \\
\hline \multirow[t]{13}{*}{2015} & 1984 & 1991 \\
\hline & 1988 & 1994 \\
\hline & 1995 & 2002 \\
\hline & 1998 & 2004 \\
\hline & 1999 & 2009 \\
\hline & 2000 & 2018 \\
\hline & 2005 & \\
\hline & 2007 & \\
\hline & 2008 & \\
\hline & 2010 & \\
\hline & 2011 & \\
\hline & 2016 & \\
\hline & 2017 & \\
\hline
\end{tabular}

American coast. When an El Niño period previously identified demonstrated an abundance of these typings, it was classified as a Modoki mode.

\subsection{Composites - NCEP reanalysis}

Using data available through the NCEP Reanalysis, composites for North America were compiled based on a climatology of 1981-2010. Precipitation anomalies (GPCC V2018), air temperature anomalies, geopotential height anomalies at 500mb, zonal wind anomalies at 500mb, meridional wind anomalies at $850 \mathrm{mb}$, Palmer Drought Index, and SST Composites for the equatorial Pacific were compiled. These composites would be used to identify persistent features, signal strength for ENSO phases, and to identify areas where the ENSO signal variability could be affected or effect other teleconnections. 


\subsection{NYS Station Data}

Seven sites in NY state were chosen based on availability of data and location, shown in Figure 1. Using data provided by the National Climate Data Center (NCDC), Thankfully, taking seven major and not-very-major airports gave a very good cross section of conditions - some are near the great lakes, one is close to the Atlantic, some are elevated and some are inland. This allowed for a good look at how the ENSO signal modifies climate on a regional and local level. Data from 1961-1-1 to 2019-12-31 was used for: temperature (max and min) precipitation and snow. Climate norms were also obtained from the NCDC, and the data was compared to these norms, forming anomalies. These anomalies were then averaged by day (to get 365 distinct averages, one for each day across all years). February 29th was not included in these data pools.

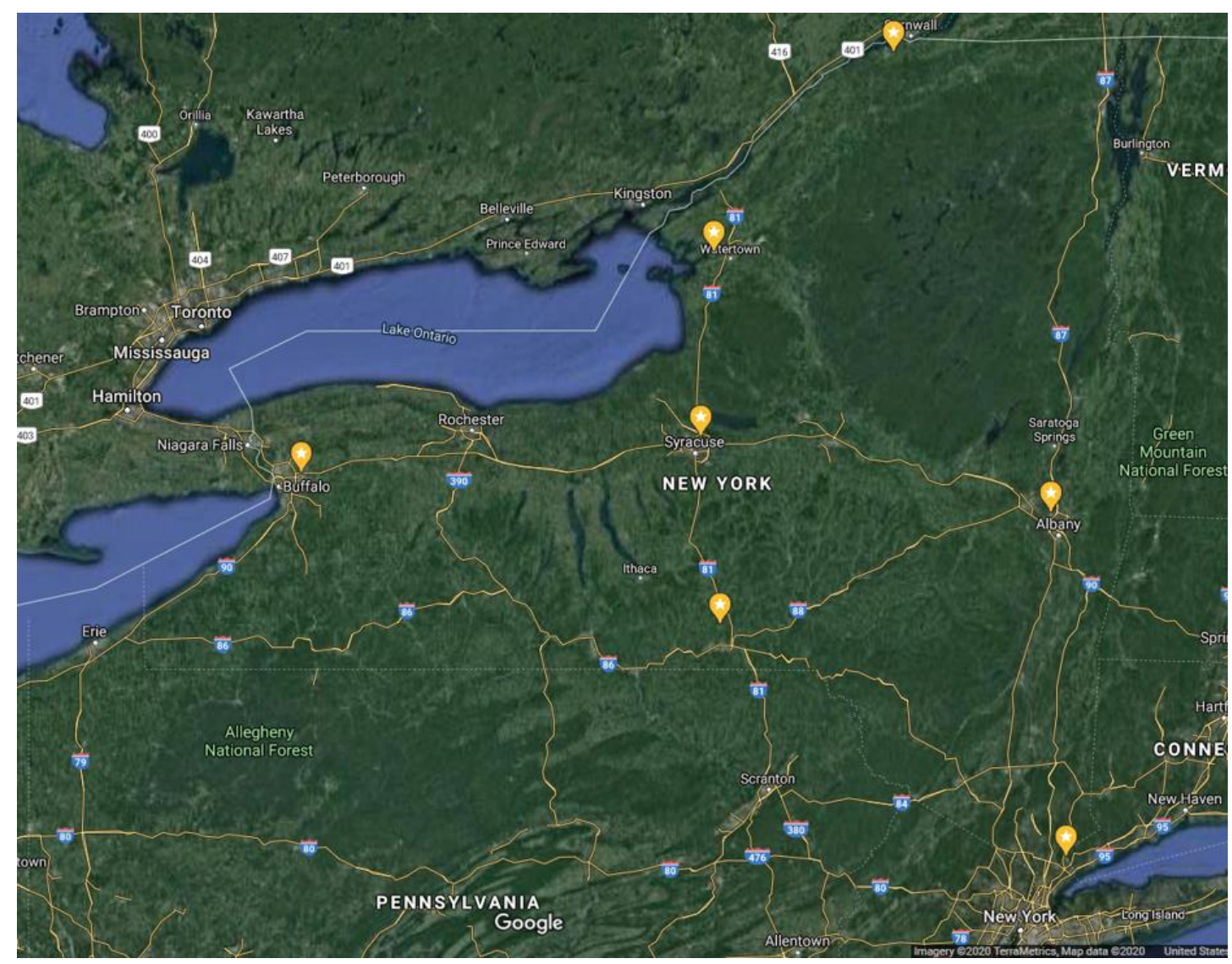

Figure 1: Locations (starred) of data points used for analysis. Any gaps in data were filled by coop stations within 30 miles of their respective locations. 
These average anomalies were calculated for each ENSO mode and filtered using a Shapiro filter in order to eliminate noise and create a smoother signal, which was calculated as:

$$
\left(\left[10 * x_{n}\right]+\left[4 * x_{n+1}\right]+\left[4 * x_{n-1}\right]-\left[x_{n+2}\right]-\left[x_{n-2}\right]\right) / 16(1)
$$

Where $\mathrm{x}$ is the current number in the set. The averaged, filtered anomalies were graphed for Max temp, min temp, snow, and precipitation for each city. In addition, autocorrelation was plotted for each of these as a means to get a power/spectrum signal from the data. Last, graphs for each variable were constructed (anomalies by day and autocorrelation) to get a glimpse at trends irrespective of location. In order to examine the prevailing weather pattern influenced by the PNA, autocorrelation was graphed. 

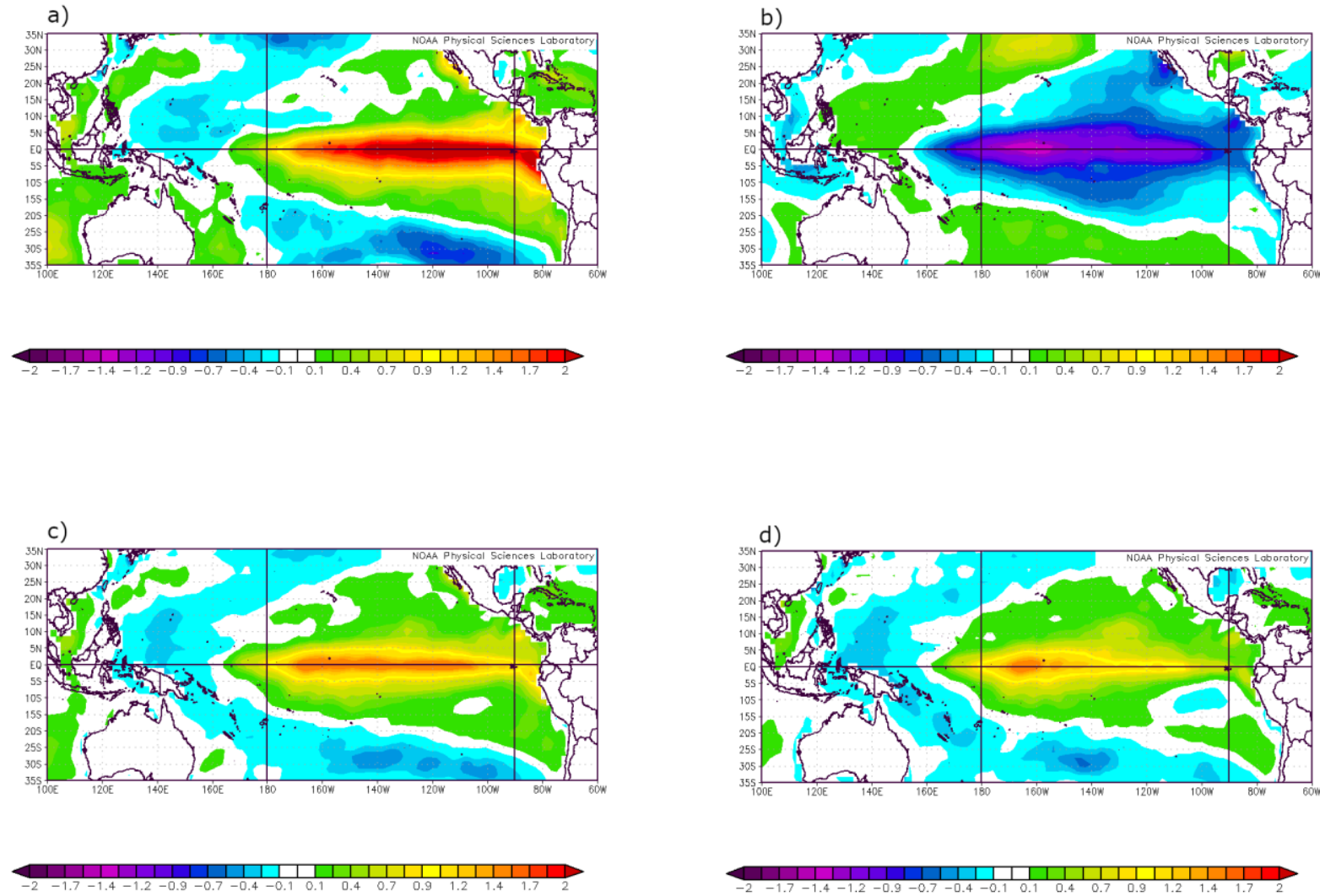

Figure 2: The Skin Surface Temperature(SST) (K) Composite Anomalies for: a) Conventional El Niño periods, b) La Niña periods, c) All El Niño Periods, and d) Modoki El Niño periods, compiled from the NCEP/NCAR Reanalysis (See Table 1 for period times).

A normally distributed pattern would see a steadily declining graph - these gives an idea of the power spectrum, of certain patterns regarding the periodicity of the peaks and valleys of the anomalies. Rather than the severity this helps discern differences in how ENSO affects the general circulation and can potentially be used to determine the effect on other teleconnections. 
a)
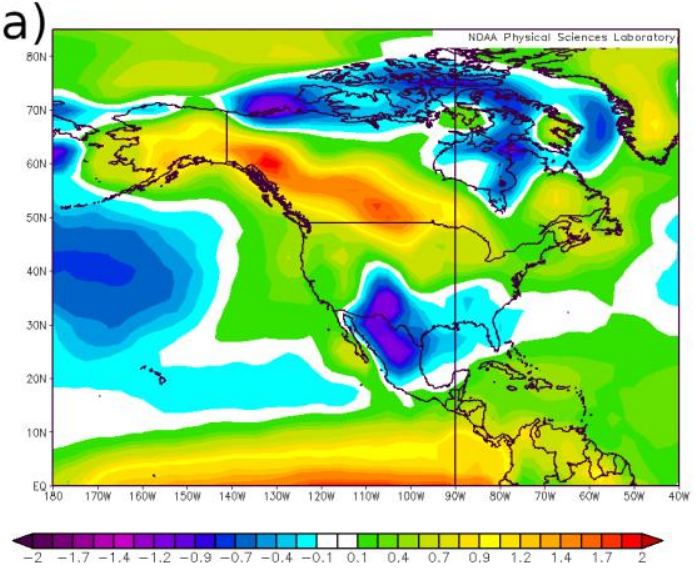

c)

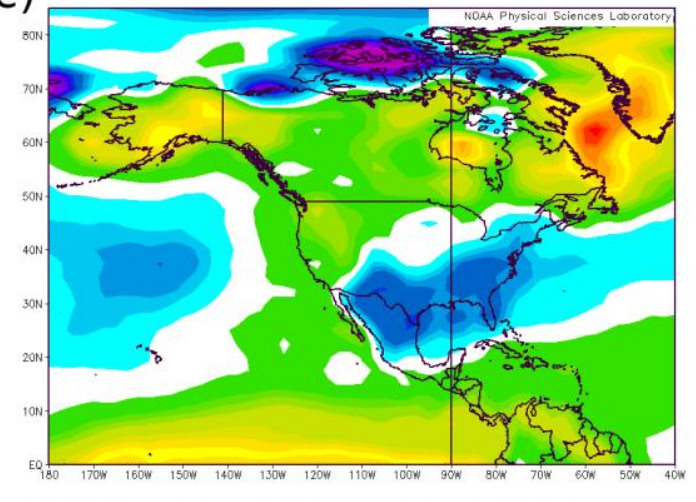

b)

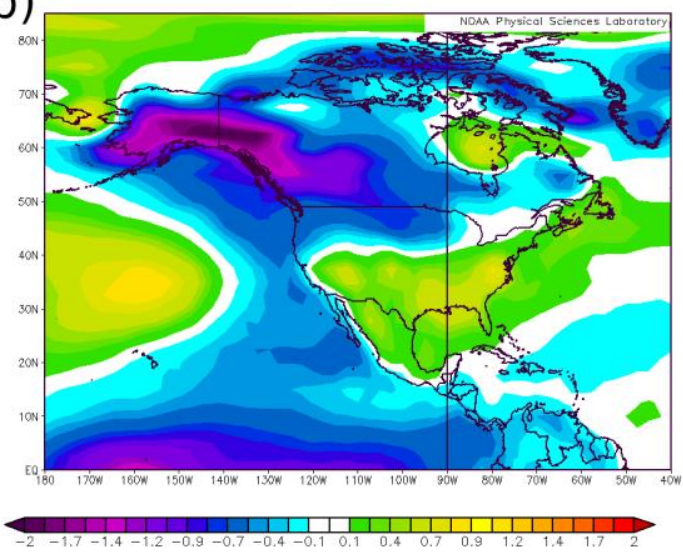

d)

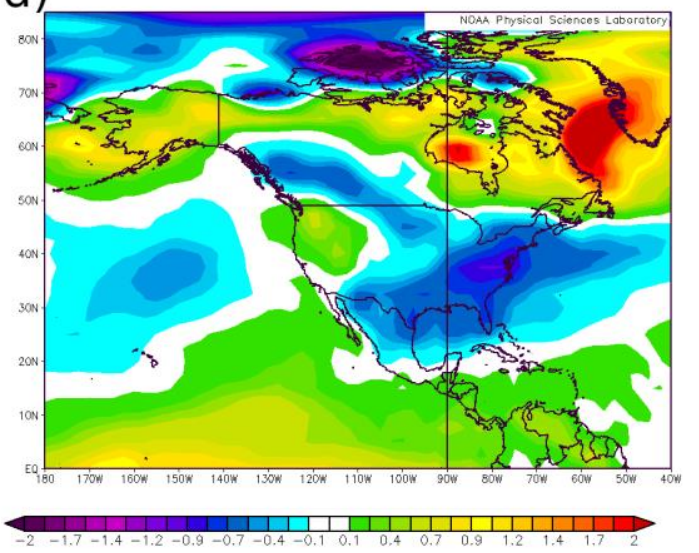

Figure 3: As in Figure 1, except for surface temperature composite anomalies (C).

\section{Results}

\subsection{Signal Strength: Conventional El Niño vs Modoki}

Starting by looking at the composite of SSTa for the equatorial tropical Pacific(Fig.2), we can accomplish two tasks: One being to verify that the SSTa shapes are as they should be for each phase or mode; two, that the signal for El Niño (conventional) is stronger when the Modoki 

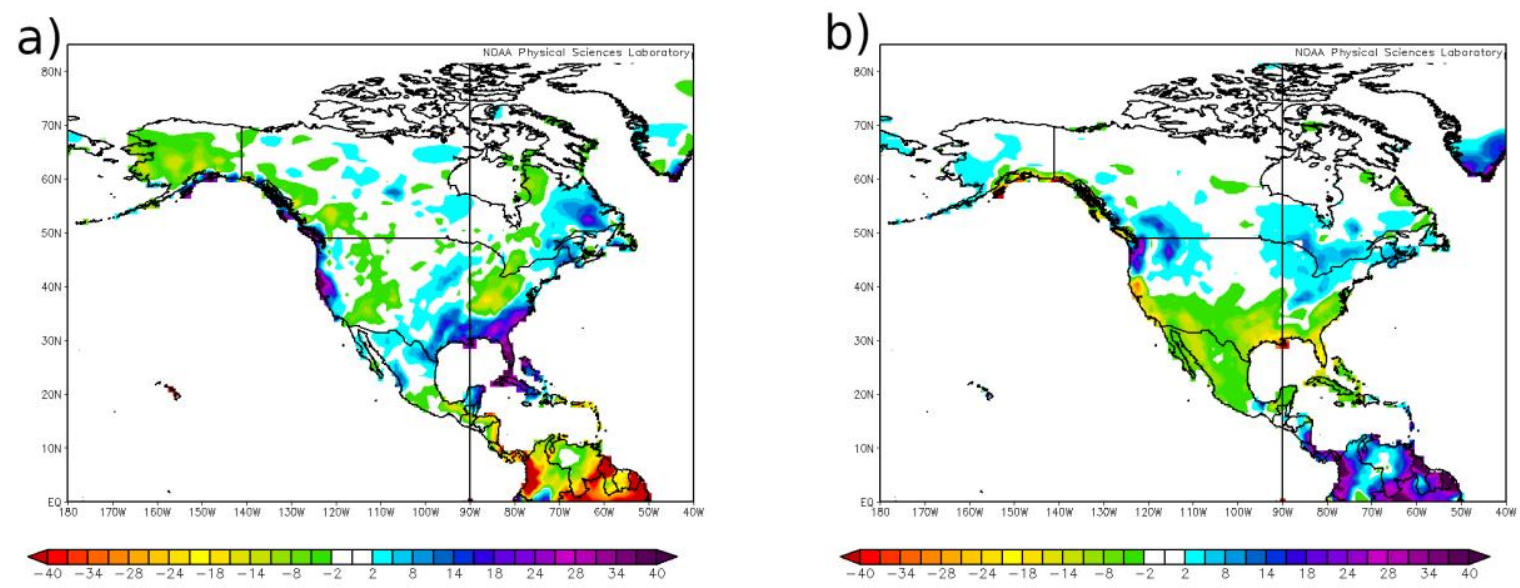

d)

C)
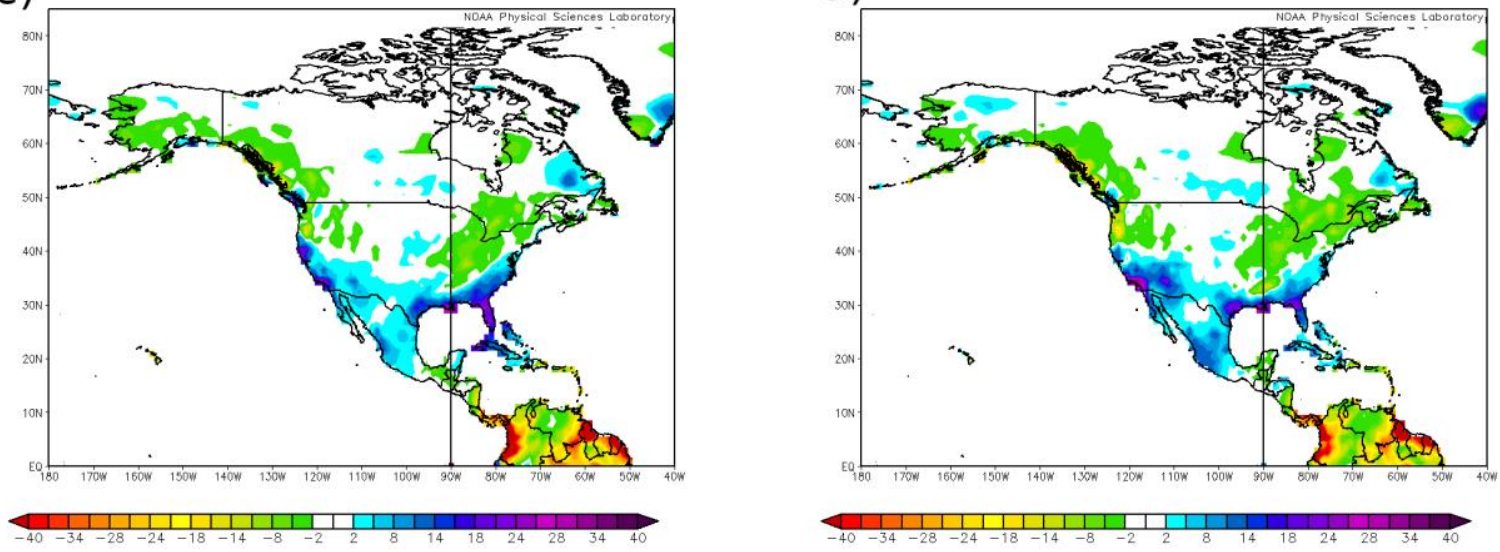

Figure 4: As in Figure 1, except for precipitation ( $\mathrm{mm}$ ) composite anomalies, compiled from GPCC estimates.

signal is removed. Looking at Fig. 2a and comparing it to 1d, the magnitude of the warm SSTa is much stronger, and the maximum in SSTa is farther to the east in 1a, as opposed to the more central location in 1d. Comparing the signal strength of 1a (just conventional El Niño) to all El Niño in 1c shows that typically conventional El Niño phases have been much stronger. Also of note is the horseshoe of negative SSTa (cooler temperatures) surrounding the temperature maximum in 1d (Modoki) that is mirrored and reversed in figure $1 \mathrm{~b}$. 
a)
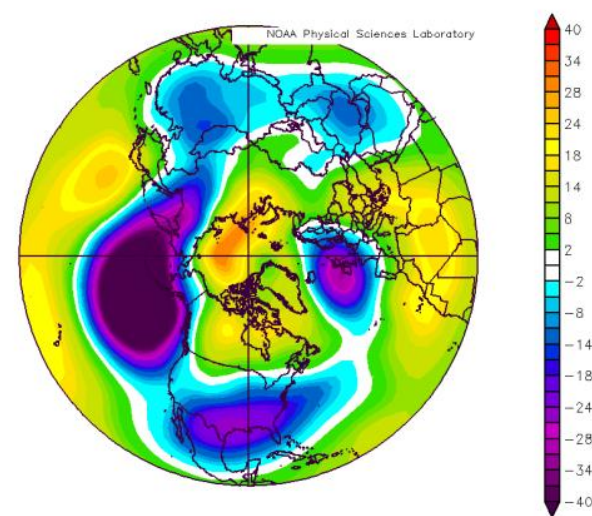

c)

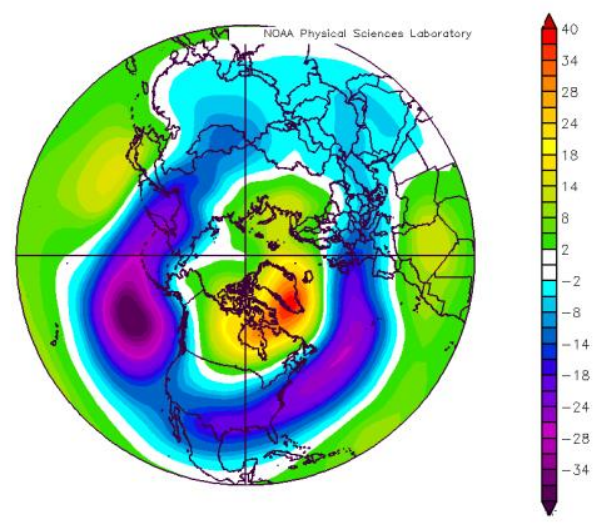

b)

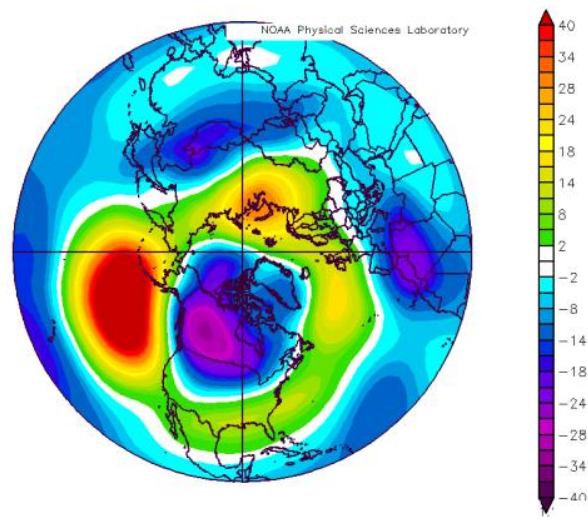

d)

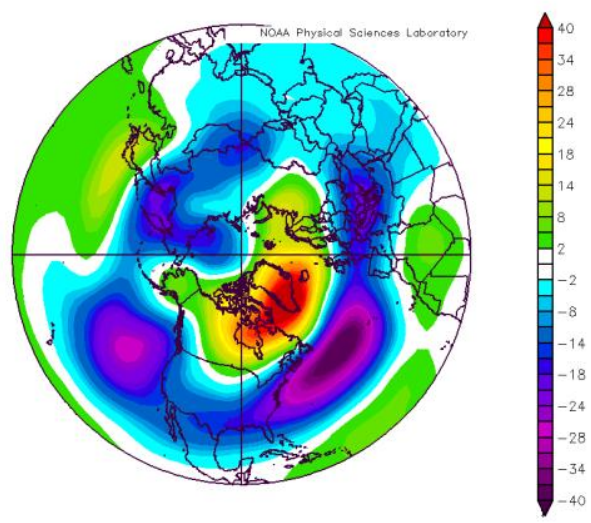

Figure 5: As in Figure 1, except for Geopotential Height (500mb) (m) Composite Anomalies.

Examining the composite of surface air temperature (Fig. 3), we see that figures 3a and 3d (Conventional El Niño and Modoki, respectively) match very well to the temperature analysis featured in Larkin and Harrison's 2005 study, as well as their precipitation analysis. Of note with precipitation anomalies is that the observed anomalies, in both region and location, were similar when comparing conventional El Niño to the Modoki (figs 4a and 4d). Once again, comparing La Niña to the Modoki reveals an almost equal and opposite pattern, most notably east of the Mississippi in the Ohio Valley, southeast, and eastern seaboard regions of the United States. 
Looking at the 500mb geopotential height anomalies in Fig. 5, comparing the pattern seen in 5d lends credence to Dogar et al. 2019, implying that the Modoki can force an NAO-like pattern, as is seen with the sweeping negative geopotential height anomaly stretching from the Eastern US to Europe, coupled with the strong positive anomaly in northern Canada. It should be noted that this pattern is of opposite phase as noted in Dogar's study. When comparing 5a to 5d, the persistent low height anomaly (Aleutian Low) is stronger for 5a, while for $5 \mathrm{~d}$ the high height anomaly over arctic Canada is stronger, as is a persistent low off the eastern seaboard. As with the previous two composites, the geopotential height map for La Niña is very similar to Modoki, only reversed in polarity.

Examining the precipitation anomalies present in figure 4, the pattern of the Modoki and La Niña being similar but opposite holds true ( $4 \mathrm{~b}$ and $4 \mathrm{~d})$. As mentioned earlier, the comparison between $4 \mathrm{a}$ and $4 \mathrm{~d}$ does not reveal too many crucial differences. The main difference with Modoki is that the Pacific Northwest is much drier than in conventional El Niño, a result consistent with Wang et al. 2018's analysis. Once again, the conventional El Niño signal appears to be marginally stronger than the signal generated from all El Niño years.

\subsection{New York Station Data}

Two types of graphs were constructed using this data: First, graphs containing filtered daily averages and autocorrelation graphs were constructed for each variable in each city, and due to their number, they will be addressed in the next section. Next, a composite of the anomalies of all cities averaged for each variable and each phase was created. Last, the same was done but for autocorrelation instead. All of these graphs can be found in Appendix B, and the resulting analysis of the autocorrelation and variables against averages can be found on Table 1. 


\subsection{Maximum and Minimum Temperature}

Maximum and minimum temperature anomalies, averaged daily and filtered, were plotted on separate graphs under the impression that different signals would emerge for different locations, however this was not the case. Therefore, for some purposes, they will be treated as one since they share the roughly the same pattern as the average. The Modoki shows a distinct signal from both El Niño and La Niña, with an oscillation period of about 20 days before cold air outbreaks dominate the signal during the latter half of the season. Conventional El Niño is typified by a warm first third of the season, followed by a roughly neutral period, ending with a cold snap. La Niña features a much lower periodicity and overall a weaker signal, featuring overall warmer temperatures near the end of the winter season and colder to start. Again, the conventional El Niño graph shows stronger values overall when compared to all El Niño years.

Delving into the autocorrelation graph for temperatures, a modest positive relationship appears for La Niña, and a modest negative relationship appears for the Modoki, both around 25 days out. This means that the same observation is more likely to occur $\mathrm{x}$ days from now, where $\mathrm{x}$ is the value in days on the $\mathrm{x}$ axis - and for the La Niña, those temperature peaks are more likely to occur again on a 12 or 13 day period (two pattern shifts, or one full cycle), whereas with the Modoki only one half cycle (one pattern shift) is likely to occur in that time period.

\subsection{Precipitation and Snow}

Looking at precipitation anomalies for Modoki and conventional El Niño, differing patterns are shown again. Pairing them with their temperature counterparts, El Niño has two precip peaks early on in the season, one appearing to be predominantly warm frontal(during warm temperature peak) and one cold frontal (during a time of transition from positive to 
negative temperature anomaly). The Modoki has one peak (cold frontal) around fifty days into the season.

Looking at the snow graphs across all phases of ENSO, and when pairing them with temperature graphs, they show a strong negative correlation to each other, as expected - it makes sense to expect more snow when negative temperature anomalies are predominant. The only other notable features for this graph is the fact that "peak snow" occurs early in the season for La Niña years and later on for El Niño.

Looking at the autocorrelations for precipitation, all three phases contain different signals. For conventional El Niño, the relationship is weak, but it cycles roughly every seven days. For La Niña precipitation, there isn't a clear emergent pattern, but the peak is a weak negative relationship almost 20 days out. With the Modoki autocorrelation, a full cycle with moderate signal from positive to negative to positive relationship occurs within $23-25$ days. This same pattern emerges with the autocorrelation graphs for snow, specifically for La Niña. A moderate negative correlation after 12 days leads into a weak to moderate positive connection after 24 days or so. With the Modoki, this relationship is inverted and lengthened significantly. 
a)

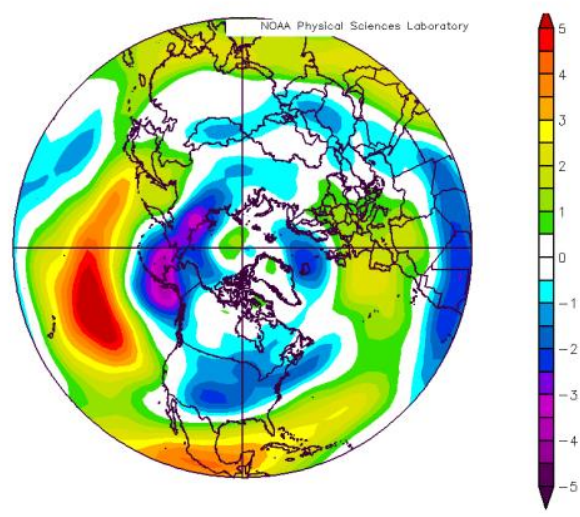

c)

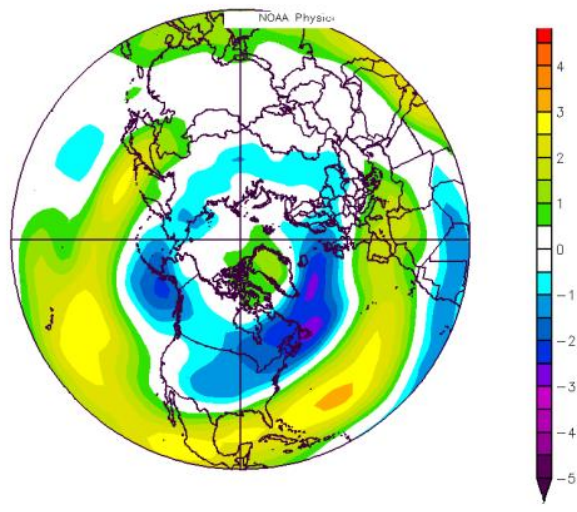

b)

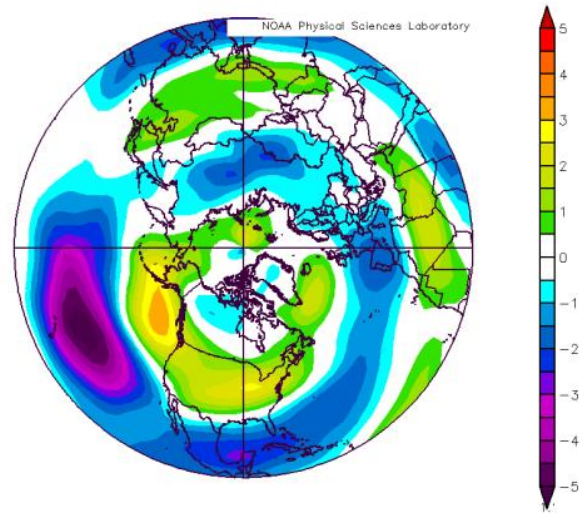

d)

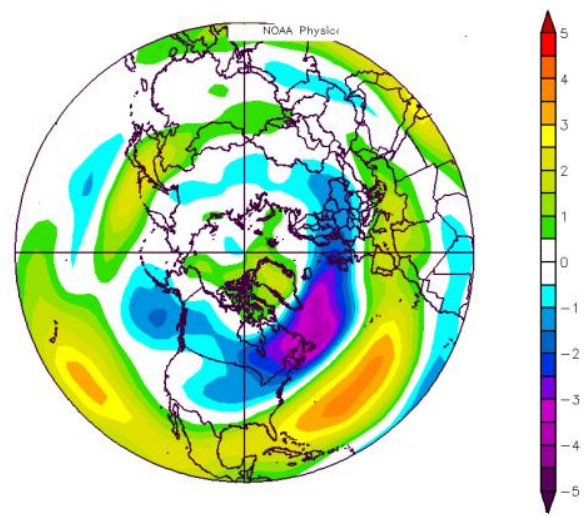

Figure 6: As in Figure 1, except for Zonal Wind (500mb) composite anomalies ( $\mathrm{m} / \mathrm{s})$.

\section{Analysis/Discussion}

Previously, we observed the linking of a strong negative correlation of the Modoki to an "NAO-like" pattern in the 500mb geopotential height field in the Northern Hemisphere. When this pattern is removed, as in figure 5a, an extremely deep low height anomaly remains near the 
a)
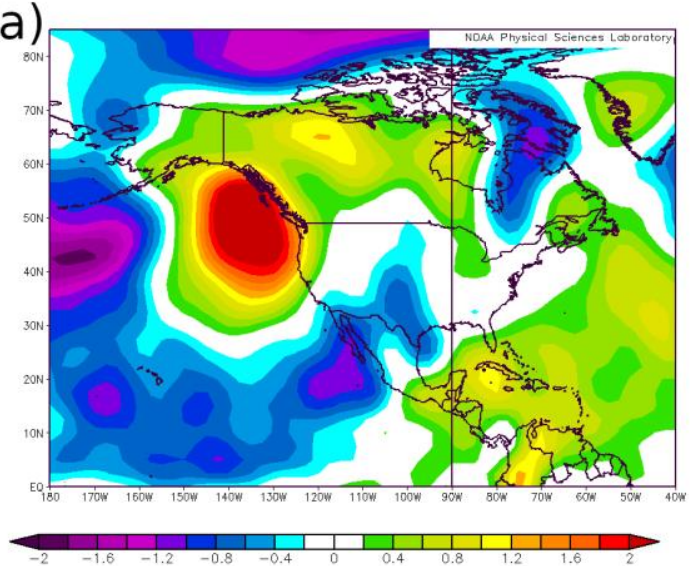

c)

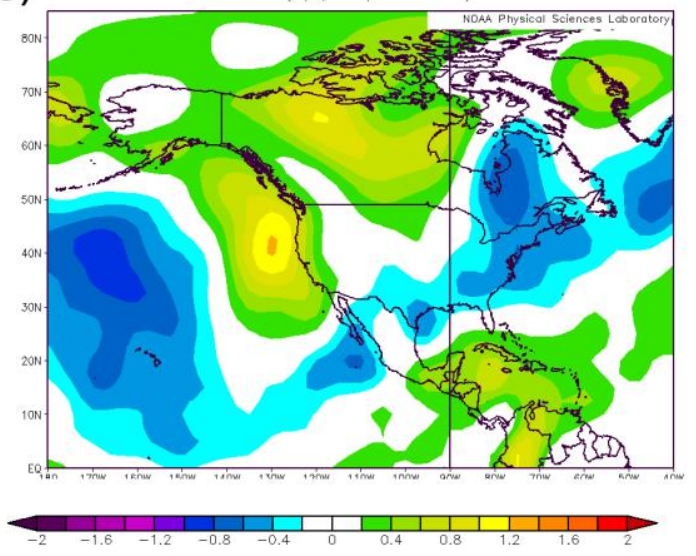

b)

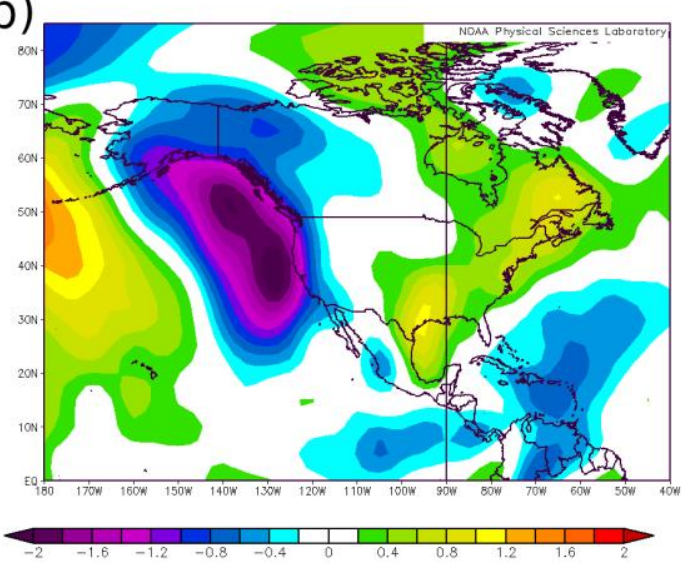

d)

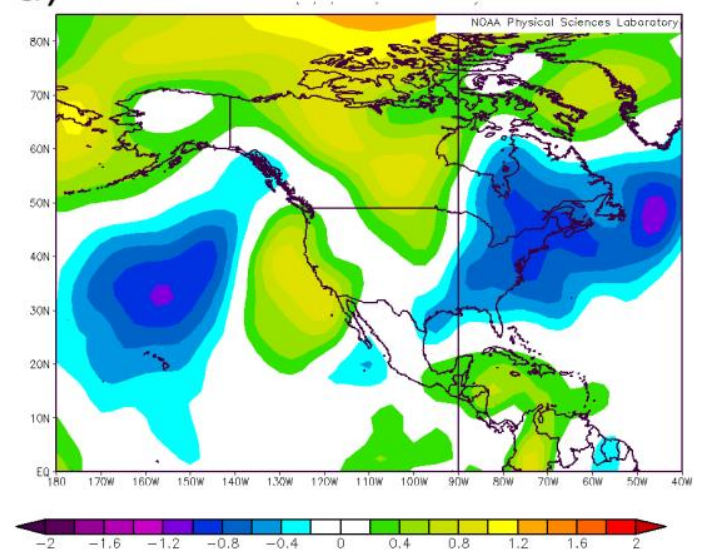

Figure 7: As in Figure 1, except for Meridional Wind (850mb) composite anomalies $(\mathrm{m} / \mathrm{s})$.

Aleutians. In addition, the positive height anomalies around the subtropical areas are more pronounced in conventional El Niño than an all-inclusive positive ENSO. This implies that El Niño has a lesser influence on height levels over the Atlantic, and an amplified effect on the storm track through the northern Pacific. In addition, a stronger dipole indicating a stronger polar jet is present in the arctic north of Alaska, whereas with the all-inclusive ENSO positive phase the jet exiting the Georgian Bay/Southern Canada region is stronger, another hallmark of the 

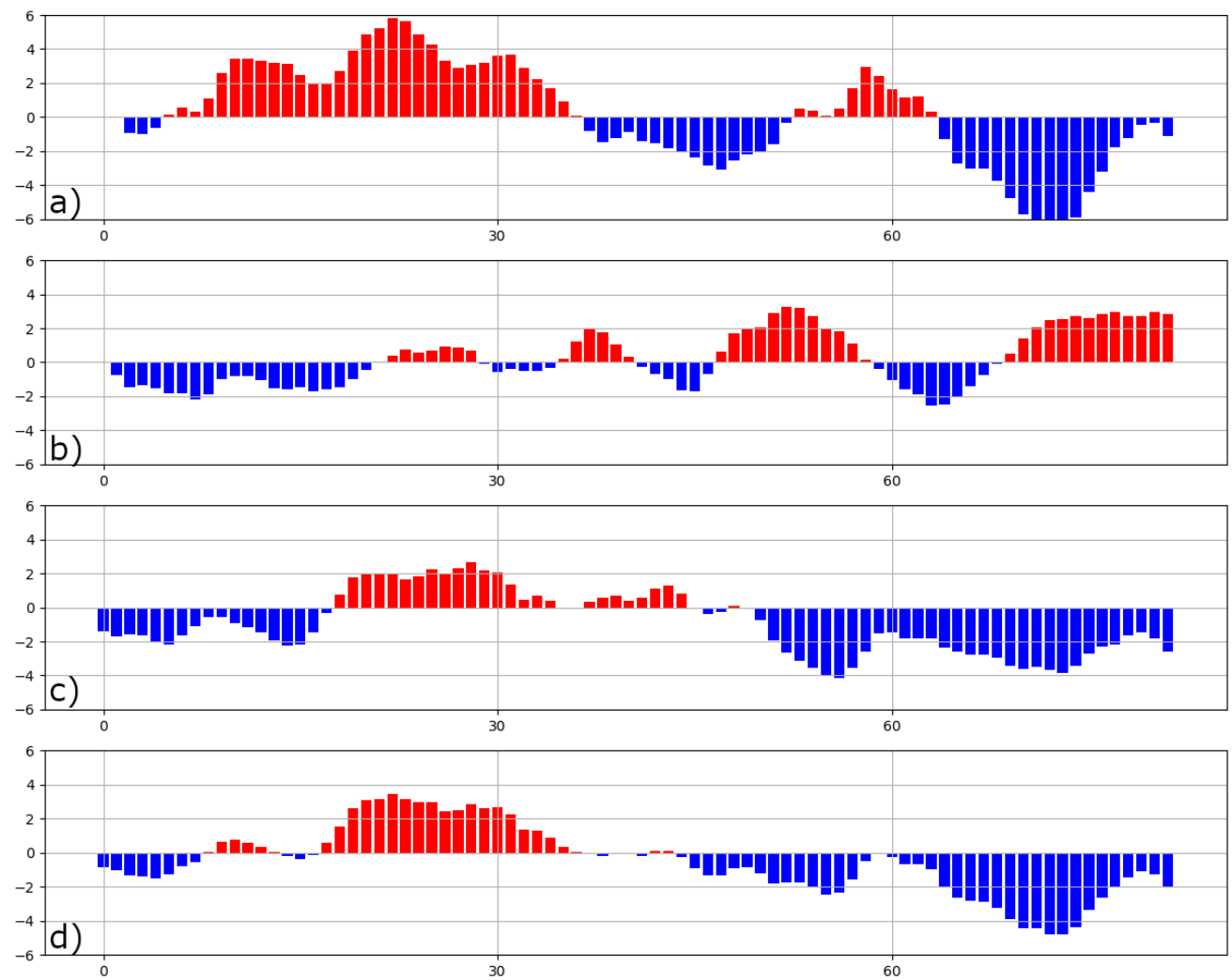

Figure 8: Maximum Surface Temperature (F) Daily Averaged Anomalies for all seven locations for: a) Conventional El Niño periods, b) La Niña periods, c) All El Niño Periods, and d) Modoki El Niño periods. Warm (positive) anomalies are shown as red bars, and cold

Modoki. Lastly, the lessening of the positive geopotential height anomaly in arctic Canada may indicate that conventional El Niño may lead to a weaker AO phase on a climatological basis. These effects on teleconnections carry over to the temperature anomalies when comparing conventional to all-inclusive El Niño, or moreover, a warmer pacific Northwest and cooler Atlantic region. Regarding precipitation, the altered storm track in the north Pacific favors more increased rainfall in northern California and less along the British Columbian coast. This trend is demonstrated by Fig. 6, which shows the zonal wind anomalies at 500mb, and as can be seen in 

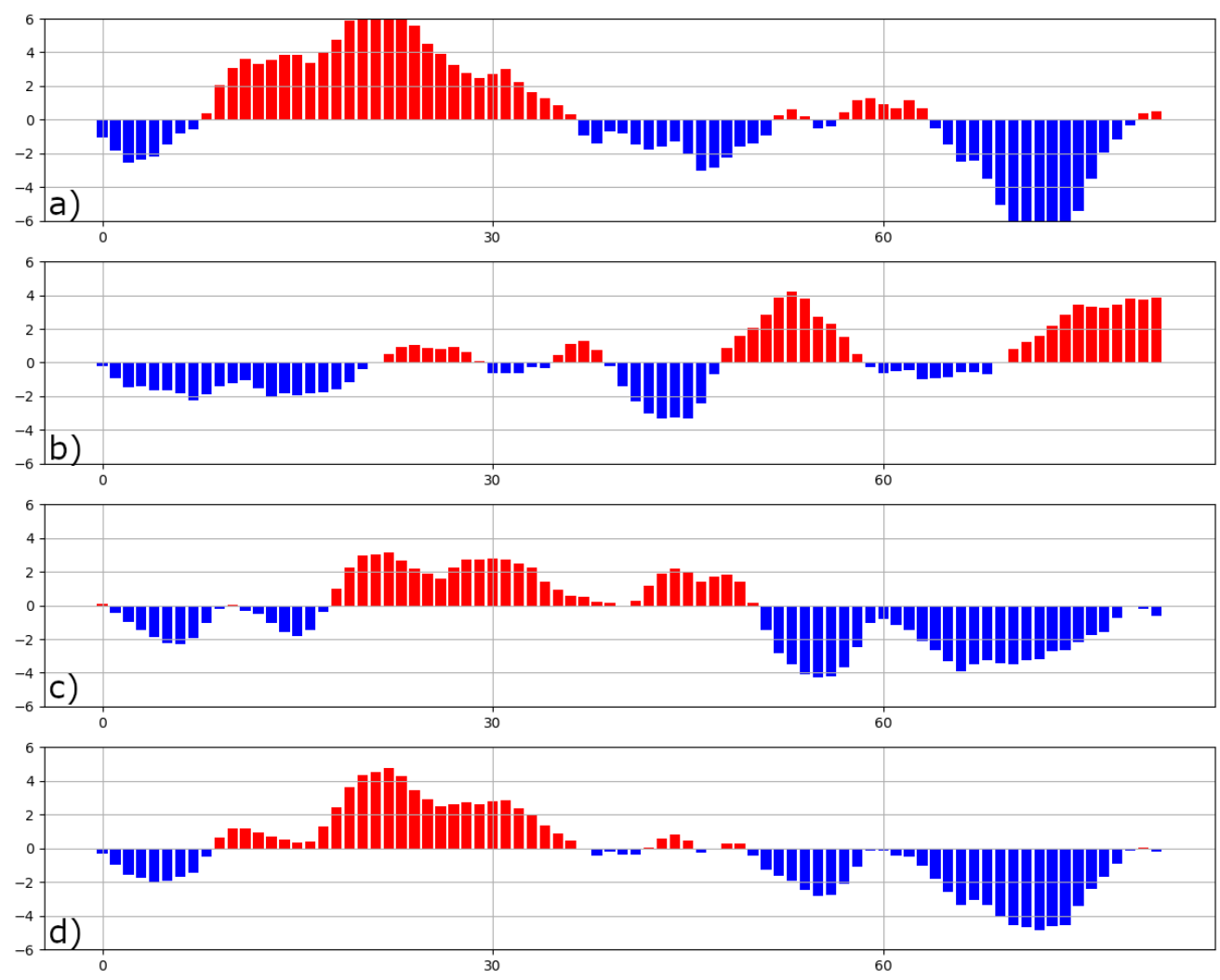

Figure 9: As in Figure 8, except for Minimum Surface Temperature (F) Daily Averaged Anomalies.

6a, the storm track toward the California coast is strengthened while the pacific NW stalls. This is further shown in the $850 \mathrm{mb}$ meridional wind (Fig. 7), showing a massive positive anomaly near the Aleutians, and taken in concert with the other composite maps indicates that the storm track is driving more precipitation and moisture southward toward the central west coast of the United States. The reasoning behind this may lie in two areas. One, the Modoki may weaken the storm track in the Southern Hemisphere during astral winter due to more frequent blocking highs over Australia during those periods. (Ashok et al. 2009) Conversely, during boreal winters in the Northern Hemisphere, it is also possible a stronger Aleutian Low coupled with a persistent high 

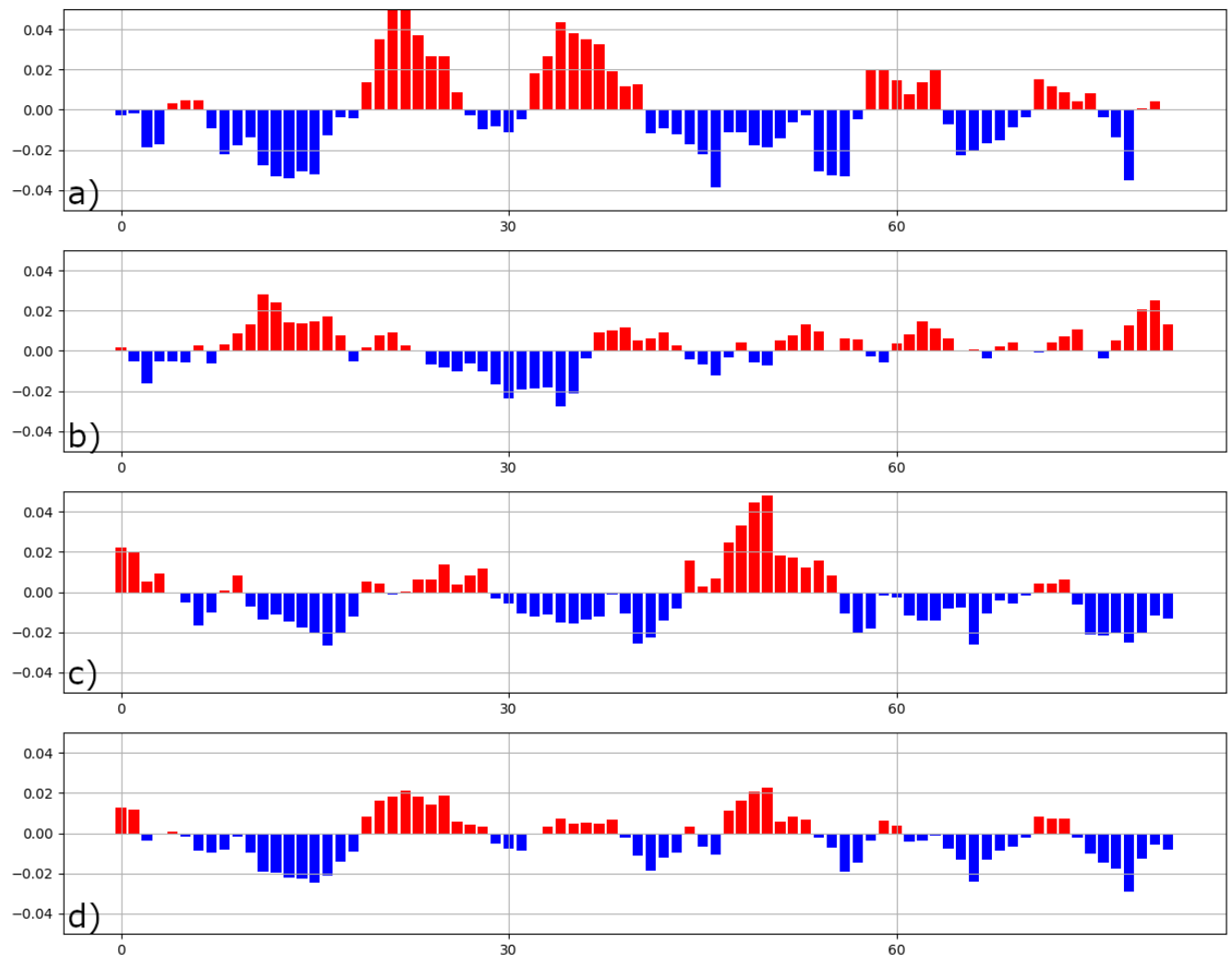

Figure 10: As in Figure 8, except for Precipitation (in) Daily Averaged Anomalies.

in the north central Pacific Ocean may intensify zonal flow in that area (shown in fig.6d) and accelerate meridional flow near the British Columbian coast (fig 7d), leading to a more "wavy" general circulation pattern overall, with the occasional blocking episode. However, this is all derived from the observations therein, and although further research on the effect of ENSO on the Aleutian Low (and its subsequent effects on the storm track) may warrant further research, it is out of the scope of this particular study. 

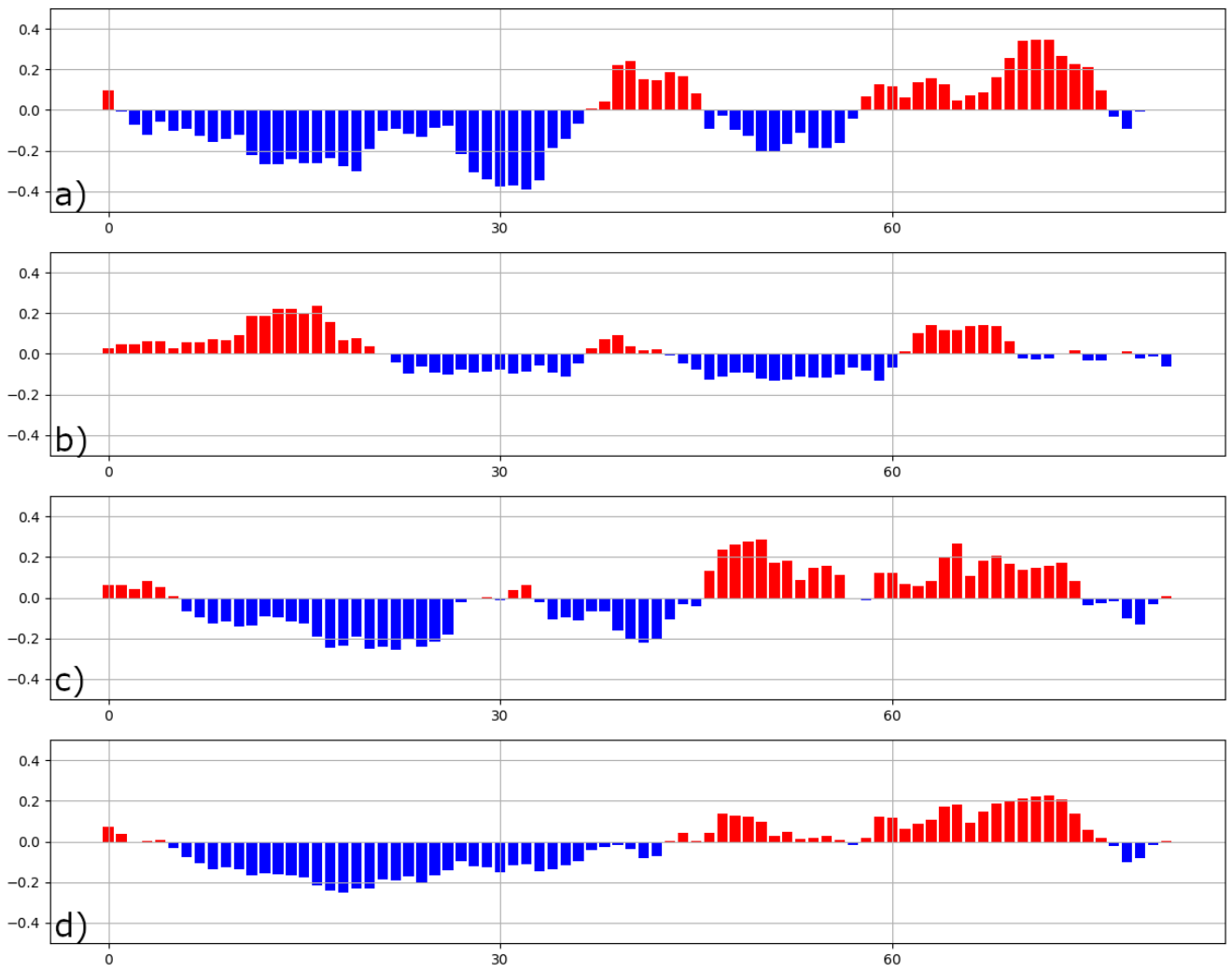

Figure 11: As in Figure 8, except for Snowfall (in) Daily Averaged Anomalies.

In addition to these differences from conventional to all-inclusive El Niño, all four anomaly graphs (figs. 8 -11) show stronger fluctuations in the conventional El Niño pattern, while roughly keeping the same basic pattern. This reveals that for New York State as a whole, the conventional El Niño signal is not only stronger than the all-inclusive El Niño, but also that the Modoki's overall impacts on all seven locations averaged is quite similar to that of conventional El Niño's. Therefore, to dig deeper into what impacts the Modoki may have on the various localized climates of New York State, we must look at each location on a case by case basis. 

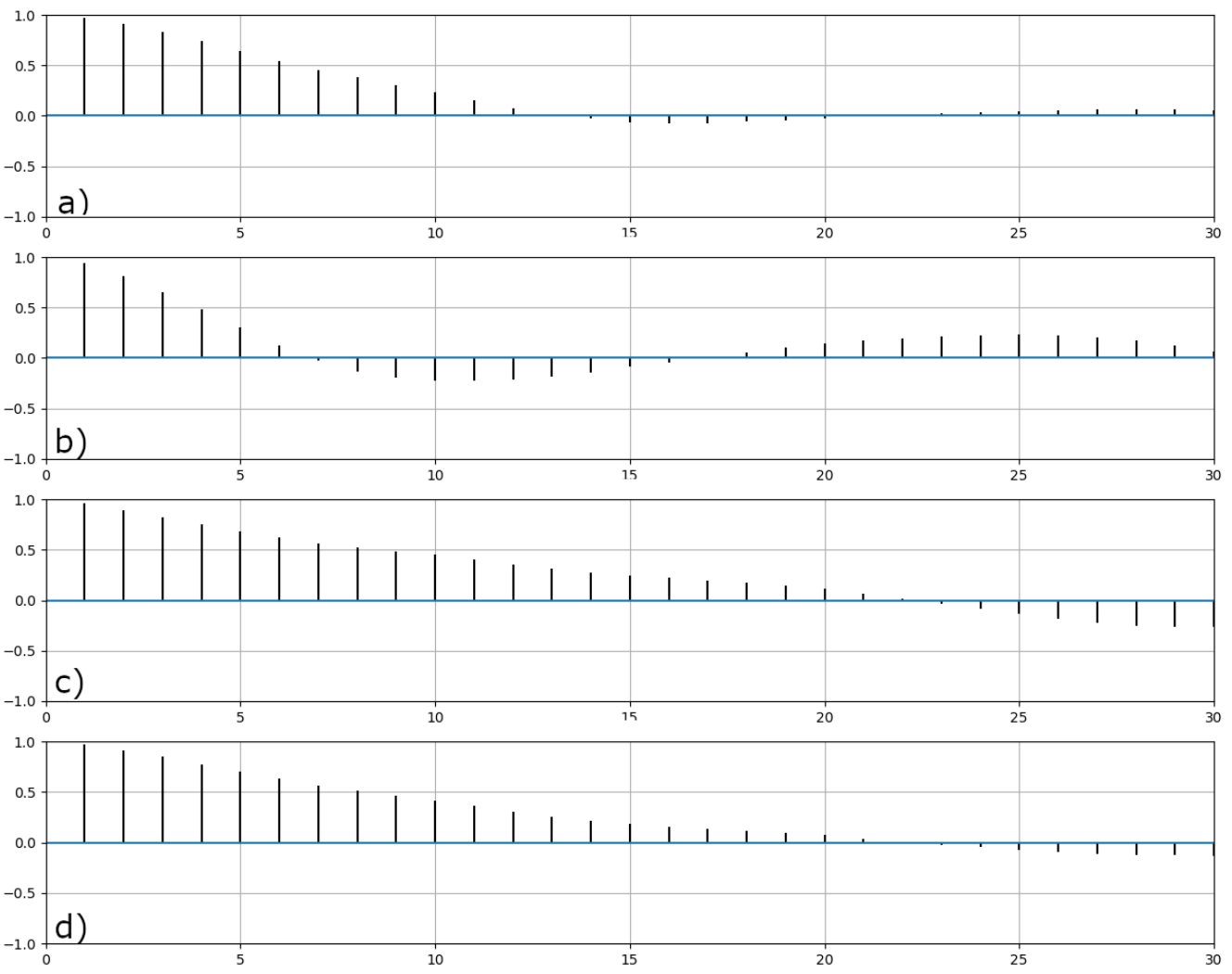

Figure 12: Autocorrelation of Maximum Surface Temperature (F) Daily Averaged Anomalies for all seven locations for: a) Conventional El Niño periods, b) La Niña periods, c) All El Niño Periods, and d) Modoki El Niño periods. The X axis is the relationship strength

\subsection{Regional Impacts on NYS climate}

While the overall effect of conventional and the Modoki El Niño modes may be similar when averaged together across all locations, when examining the variables one location at a time, more distinct patterns are visible. Throughout all of them, there are two distinct features: First, the Modoki and La Niña share a strong negative correlation in many of the graphs. Second, that there is a noticeable two to three-week gap between the maxima of most of the variables. Rather 

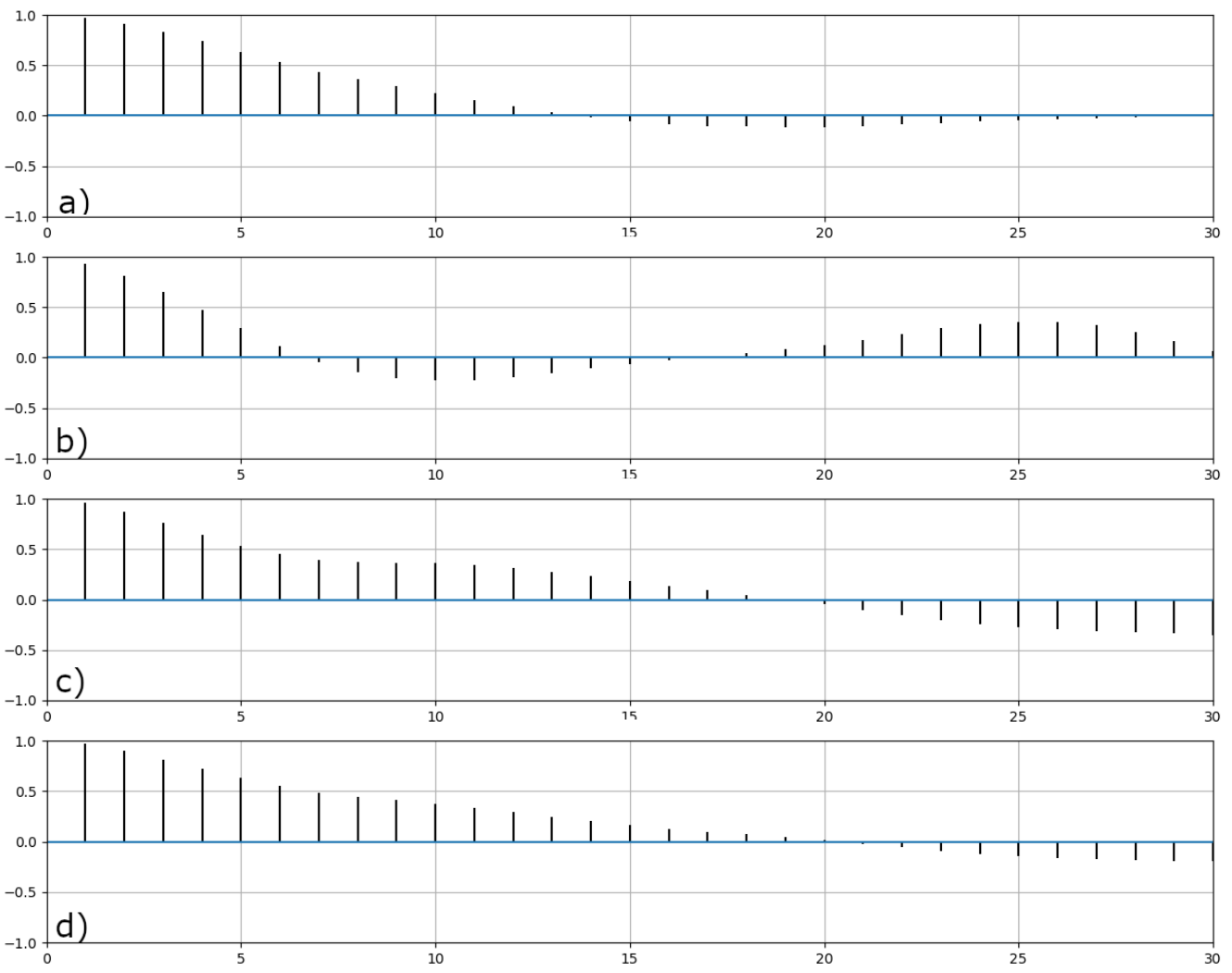

Figure 13: As in Figure 8, except for Minimum Surface Temperature (F) Daily Averaged Anomalies.

than examining the impacts over the entirety of the season, we will be looking at daily averages of temperature, precipitation, and snow.

\section{Temperatures}

For all regions and ENSO modes, there was very little deviation from the average curve. The La Niña autocorrelation cycle was consistently 20-24 days for all regions. Locations inland tended to have stronger signals than those by bodies of water. Therefore, temperatures followed very consistent patterns regardless of any variability, other than the $\mathrm{AO}$, which has a decently 

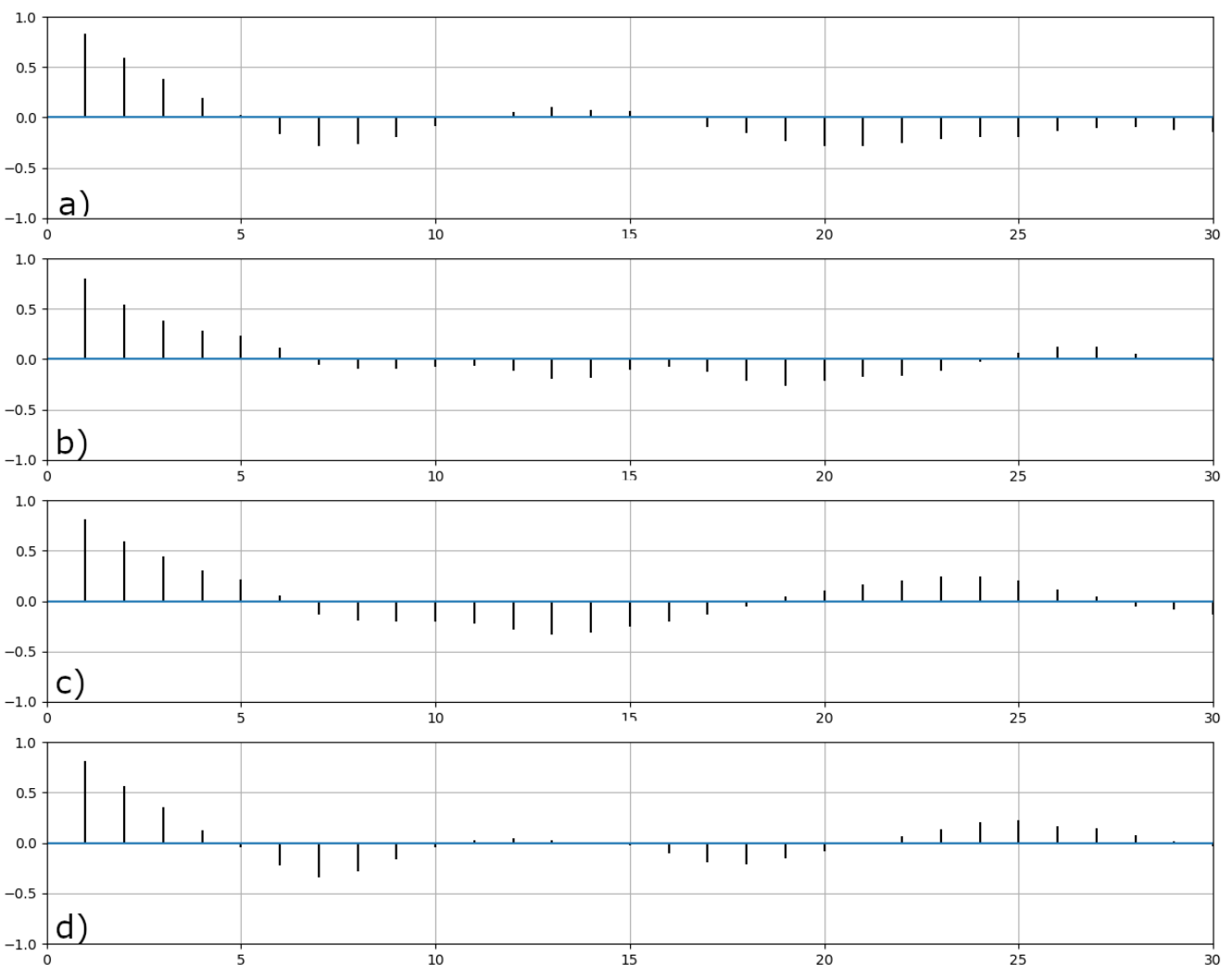

Figure 14: As in Figure 8, except for Precipitation (in) Daily Averaged Anomalies.

consistent wintertime signal of nearly a month per full cycle. This may be an indicator that the $\mathrm{AO}$ is a more effective modulator of temperatures than ENSO in this region.

Precipitation

The White Plains and Binghamton stations showed high precipitation anomalies three weeks in, and in mid-late January during conventional El Niño periods. This behavior is more consistent with the Modoki average. This could be a result of higher diurnal temperature fluctuations resulting in more rain from coastal low pressure systems. The autocorrelation results 

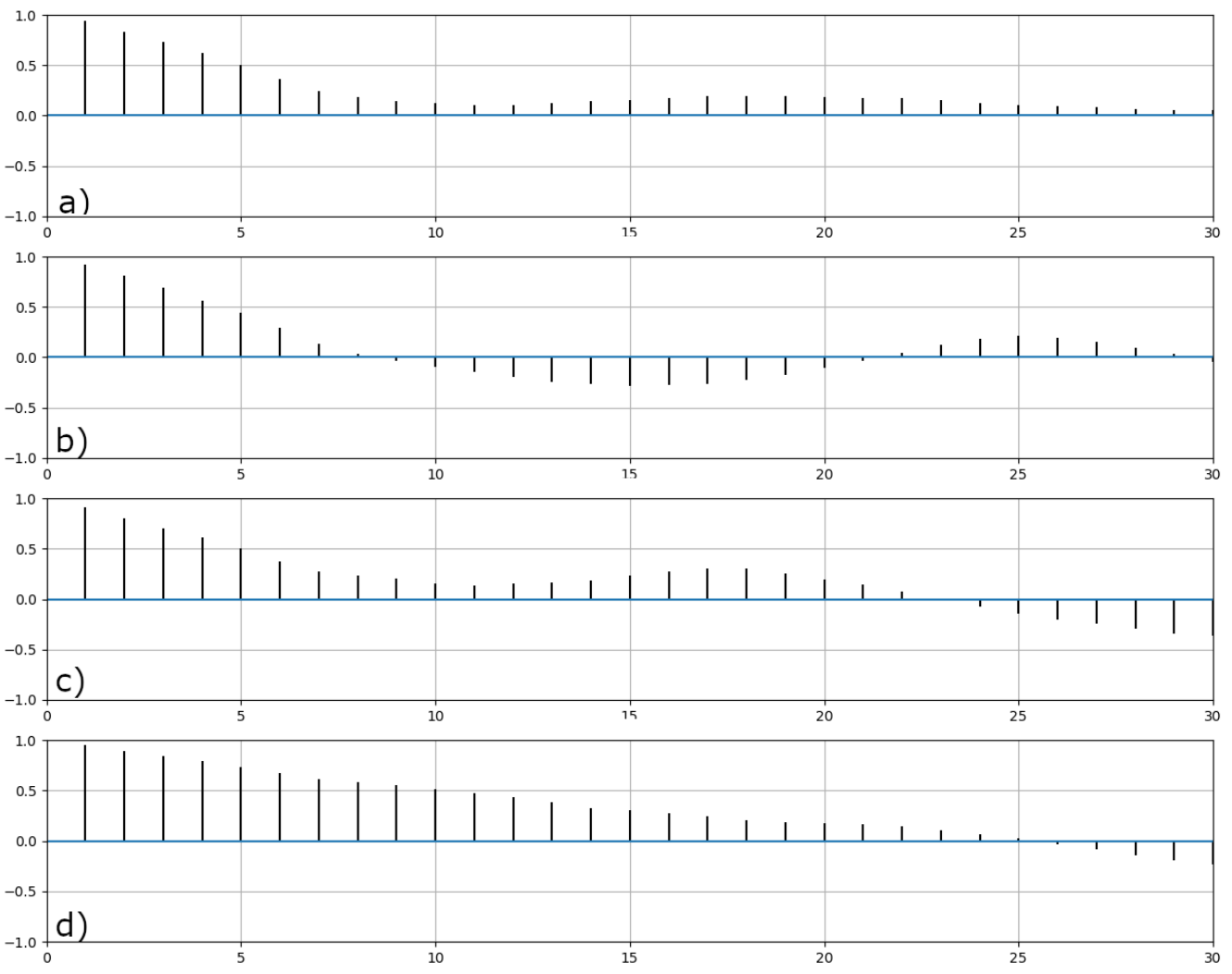

Figure 15: As in Figure 8, except for Snowfall (in) Daily Averaged Anomalies.

were widely varied. For El Niño (conventional), the results ranged from 12-day cycles to strong negatively correlated half-cycles at 26 days. All locations had an El Niño pattern, but only a few had one for La Niña. The La Niña autocorrelation cycles were absent in Watertown and White Plains. Massena's precipitation pattern turns over every 12 days or so, which adheres closest to the average curve. La Niña tended to have longer cycles, indicating the El Niño patterns brought a stronger storm track over the area. 
Snow

There was also much variability in the results when looking at snowfall. As expected, locations close to the lake experienced more snow early on in the winter due to lake influence, and locations like White Plains and Binghamton experienced more later on in the season due to coastal storms. Once again, the autocorrelation signals tended to be shorter and weaker with El Niño, with La Niña having a longer periodicity with a more robust signal usually. Massena was the only location to not have a La Niña snow cycle. One possible cause of this is that, being the northernmost location and away from lake effect and coastal snowstorms, relies only on synoptic systems to bring frozen precipitation.

\subsection{ENSO relationship to PNA}

Lin and Schubert, (2011) performed a study on the teleconnection between the AO and ENSO. It was found that they share a relationship that when in phase, tends to produce extreme warm and/or cold. The AO, of course, plays a role in extreme low temps in winter, as a negative AO means that strong cold air outbreaks are more likely due to the weakening of the polar jet stream, whereas a positive AO phase indicates a strong polar jet leading to the trapping of colder air. Their study focused on the southeast United States, looking at regional variability and interactions between ENSO and the AO.

In the study by Lim and Schubert from (2011) atmospheric blocking linked to AO was found to lead to more cold days regardless of ENSO phase, which would suggest they are somewhat independent. Furthermore, the AO had a stronger effect on diurnal temperature during the winter season than ENSO, no matter the phase. However, the effect may vary, or be reversed, depending on which region you are studying. The main takeaway from this is that two 
teleconnections may interact differently on a regional basis, and a pattern of variability within another (AO within ENSO, meaning AO having a much shorter periodicity) can be influenced by the main pattern. Thus, working with variability on a regional basis within the ENSO framework makes the most sense for trying to establish the effect of ENSO on regional weather patterns taking into account these factors will give us a clearer picture of how ENSO modulates climate and how those teleconnections interact.

It is known that the PNA typically runs on a 10-14 day cycle. However, Branstator (1987) identified a 20-24 day planetary scale wave (what he termed a long-lived traveling feature, or LLTF) that he identified during the winter of 1979/80 (a Modoki winter), and again in 1972(conventional El Niño) and 1974 (La Niña). According to the autocorrelation graphs in figures 12 through 15, the analysis of the average over all seven locations is as follows:

- La Niña: Showed a 20-24 day cycle for temperatures and snow.

- El Niño (conventional): 14-day cycle for precipitation (weak signal) - Modoki: 23-day cycle for precipitation.

Another result is, when comparing conventional El Niño autocorrelation graphs to all El Niño modes, it becomes plain that they are pushing different patterns because the Modoki mode was separated from the dataset. 


\section{Conclusions and Summary}

Examining the daily average anomalies of temperature, snow, and precipitation, it was found that all modes of ENSO presented differing looks at how they affected the regional wintertime climate. The most surprising findings were how each mode amplified the already present wave-like patterns of these variables to some extent. Despite some differences of these anomalies from their average, there were many that kept the same day to day fluctuations and varied in magnitude. These differing patterns seem to reject the idea that the AO is "more responsible" for biweekly temperature/precipitation fluctuations, although it may be strongly influential, all of the individual autocorrelations varied wildly, meaning that if the AO is responsible for the 23-day LLTF Branstator proposed, ENSO still seems to be the more powerful climate driver overall. However, in areas where ENSO impact is still lessened after separating the Modoki signal out, it may be worthwhile to examine this concept in further detail to get an idea on which teleconnection is more important when background influence is weak.

In comparing the composites of Conventional El Niño versus all modes of El Niño by separating the Modoki mode from the original signal, not only has it been made clear that the El Niño signal is much clearer without the Modoki, but that the Modoki in its own right can have a different influence on regional climate and weather. This is a clear indicator that studies regarding ENSO should take this into account when choosing which aspect of the climate driver to examine. There is more that can be done to explore this facet of ENSO that is not within the scope of this study, such as running significance tests on conventional El Niño vs Modoki and/or all El Niño modes, not to mention revisiting previous studies that didn't quite give desirable results because the El Niño signal was too weak, although some review of the precipitation data in this study may be warranted given the nature of regional precipitation and how the data is 
collected and averaged. Although it was also shown that the Modoki was not a heavyweight in terms of impacts and was indeed rather synchronous with regular El Niño at times, there are some critical differences at both the global and local levels that distinguish this mode from all others. For example, when examining the variability of precipitation within the mode, an eminently predictable cycle emerged synonymous with the LLTF studied by Branstator in 1987, which was also done on a Modoki phase. Even more possible future work would be to examine Modoki years one at a time to determine if this same pattern is present, and in this way the variability of this phase can be better examined. 


\section{Appendix A: Massena Data}

A.1 - Comparison of Maximum Temperature Anomalies - Conventional El Niño vs Modoki
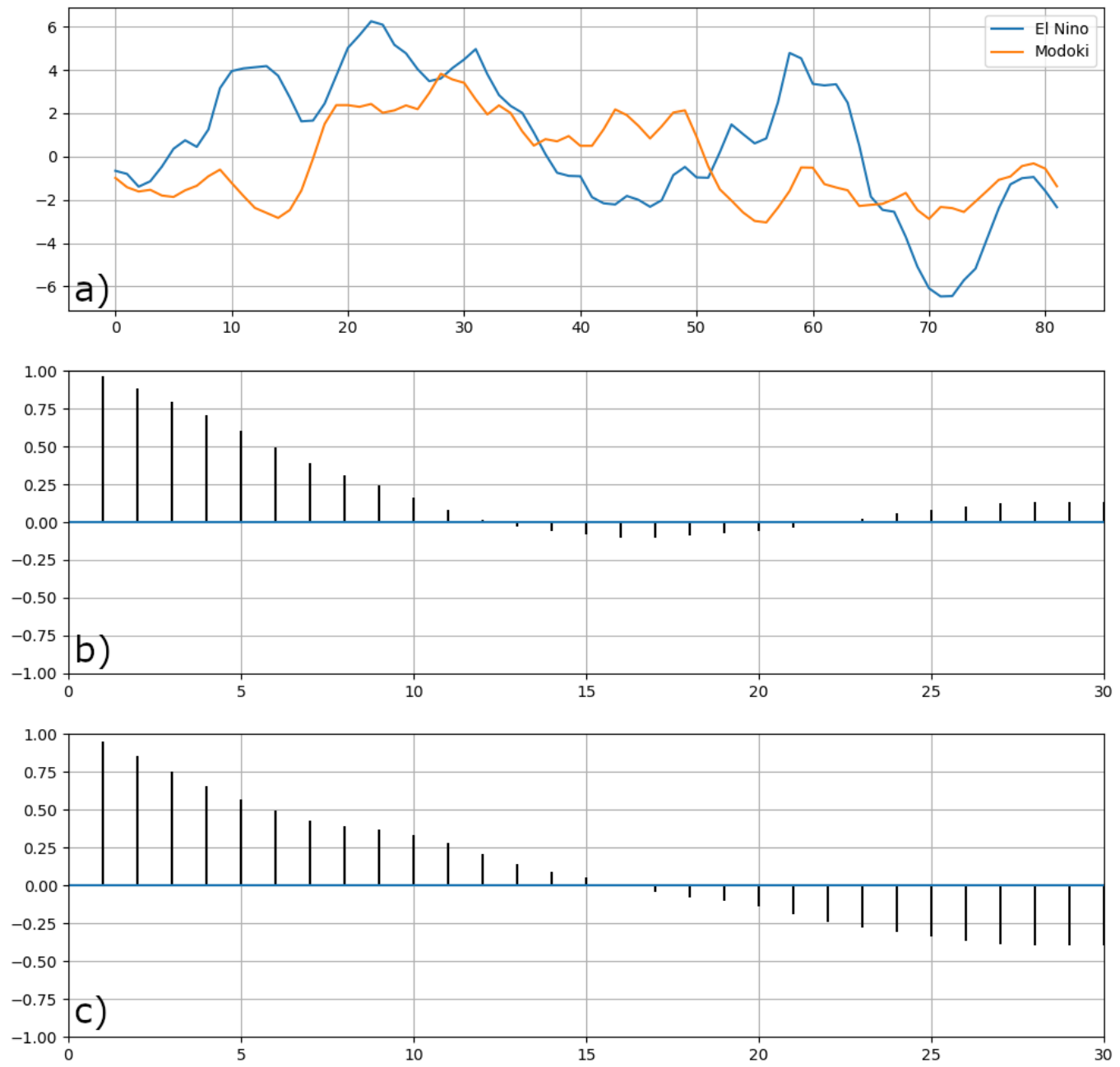

Figure A.1: a) Filtered Daily Averages of Maximum Temperature (F) for Massena, comparing conventional El Niño values(blue) against Modoki values(orange). Graphs $b$ ) and c) show the autocorrelation of Maximum Temperature for Massena for conventional El Niño and Modoki, respectively. 

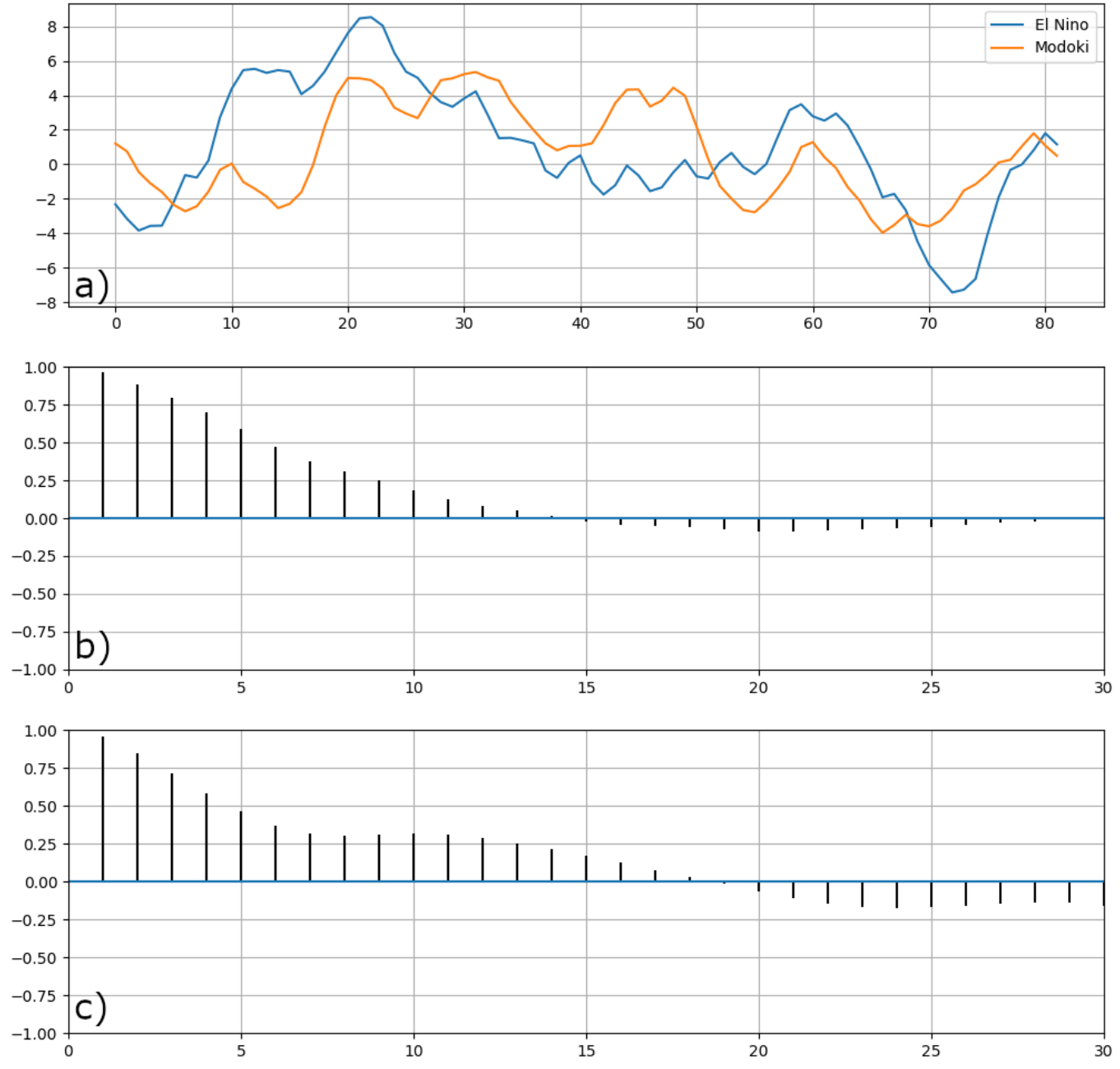

Figure A.2: As in Figure A.1, except for Minimum Temperature (F). 

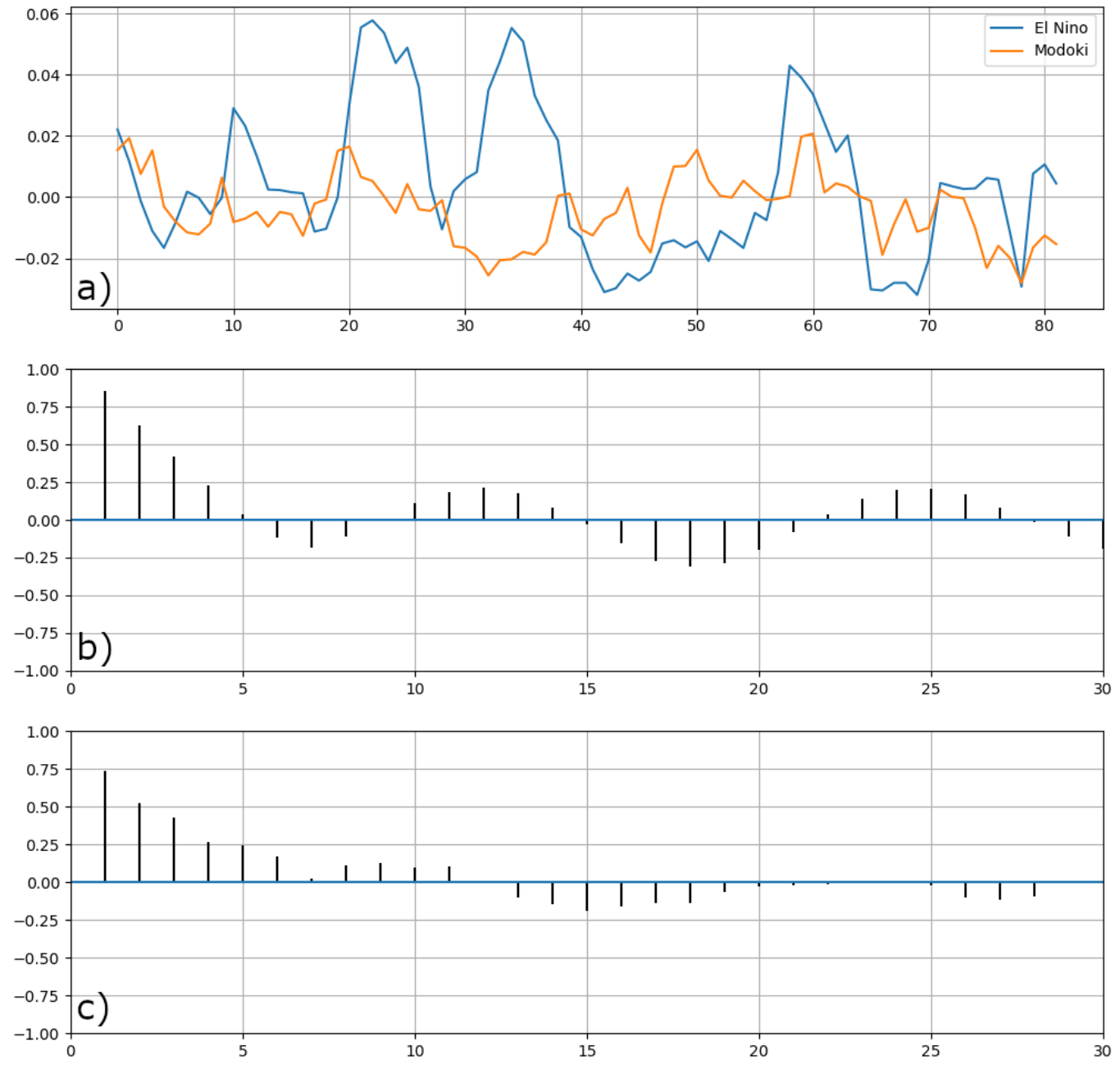

Figure A.3: As in Figure A.1, except for Precipitation (in). 
A.4 - Comparison of Snow Anomalies - Conventional El Niño vs Modoki
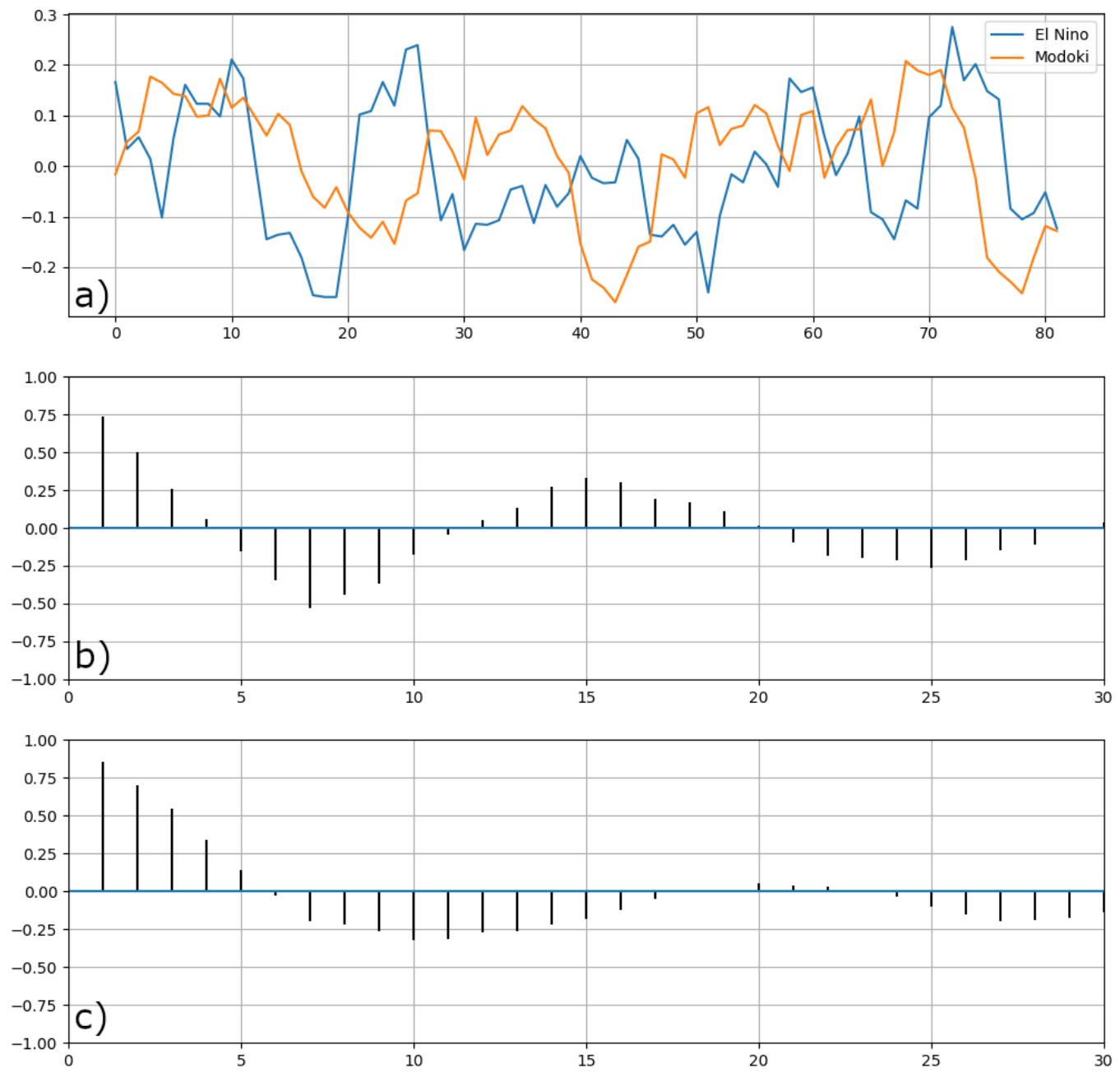

Figure A.4:: As in Figure A.1, except for Snowfall (in). 

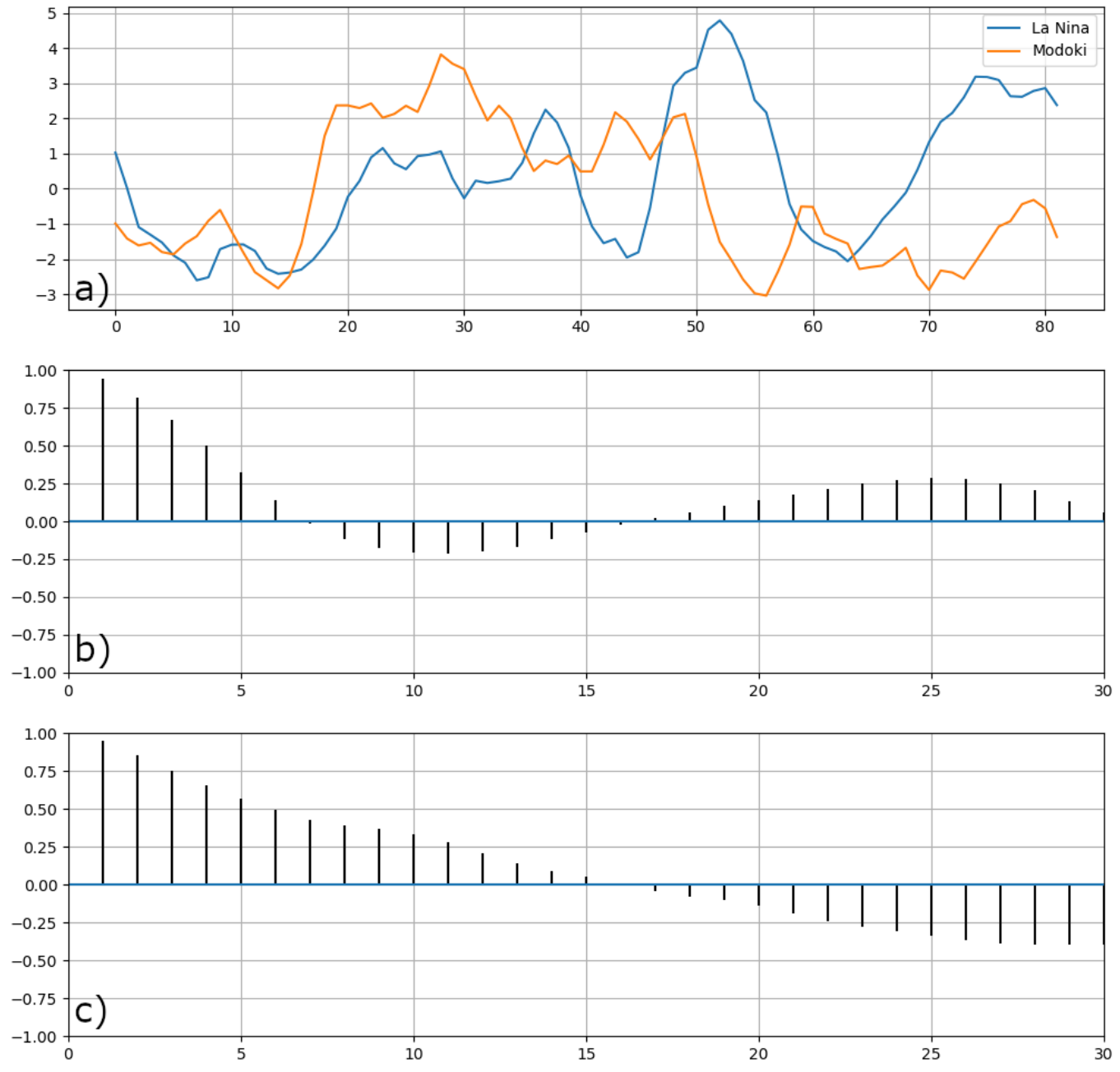

Figure A.5: As in Figure A.1, except comparing La Niña (blue) values to Modoki (orange). Graphs b) and c) show the autocorrelation of Maximum Temperature for Massena for conventional La Niña and Modoki, respectively. 

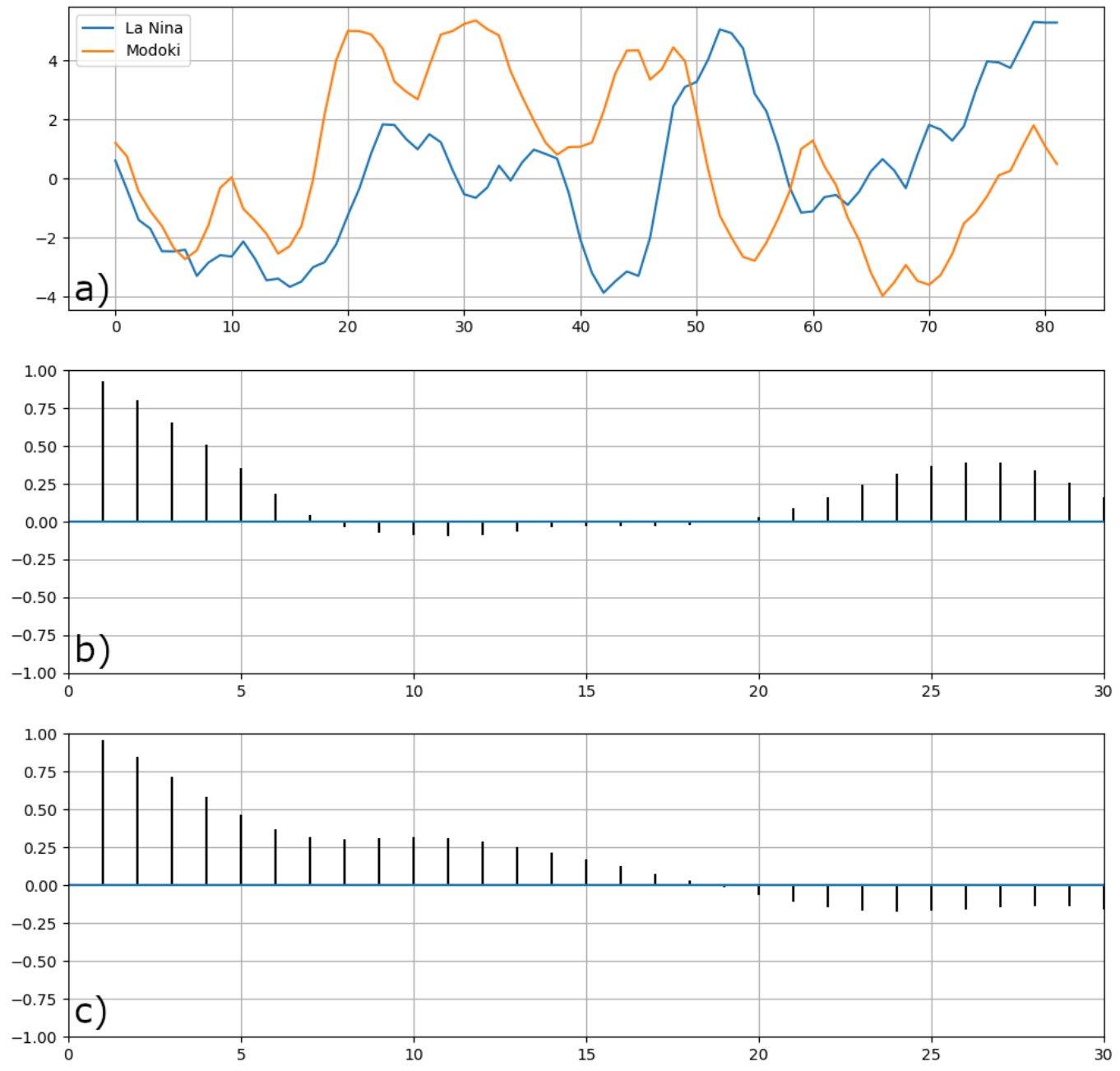

Figure A.6: As in Figure A.5, except for Minimum Temperature (F). 
A.7 - Comparison of Precipitation Anomalies - La Niña vs Modoki
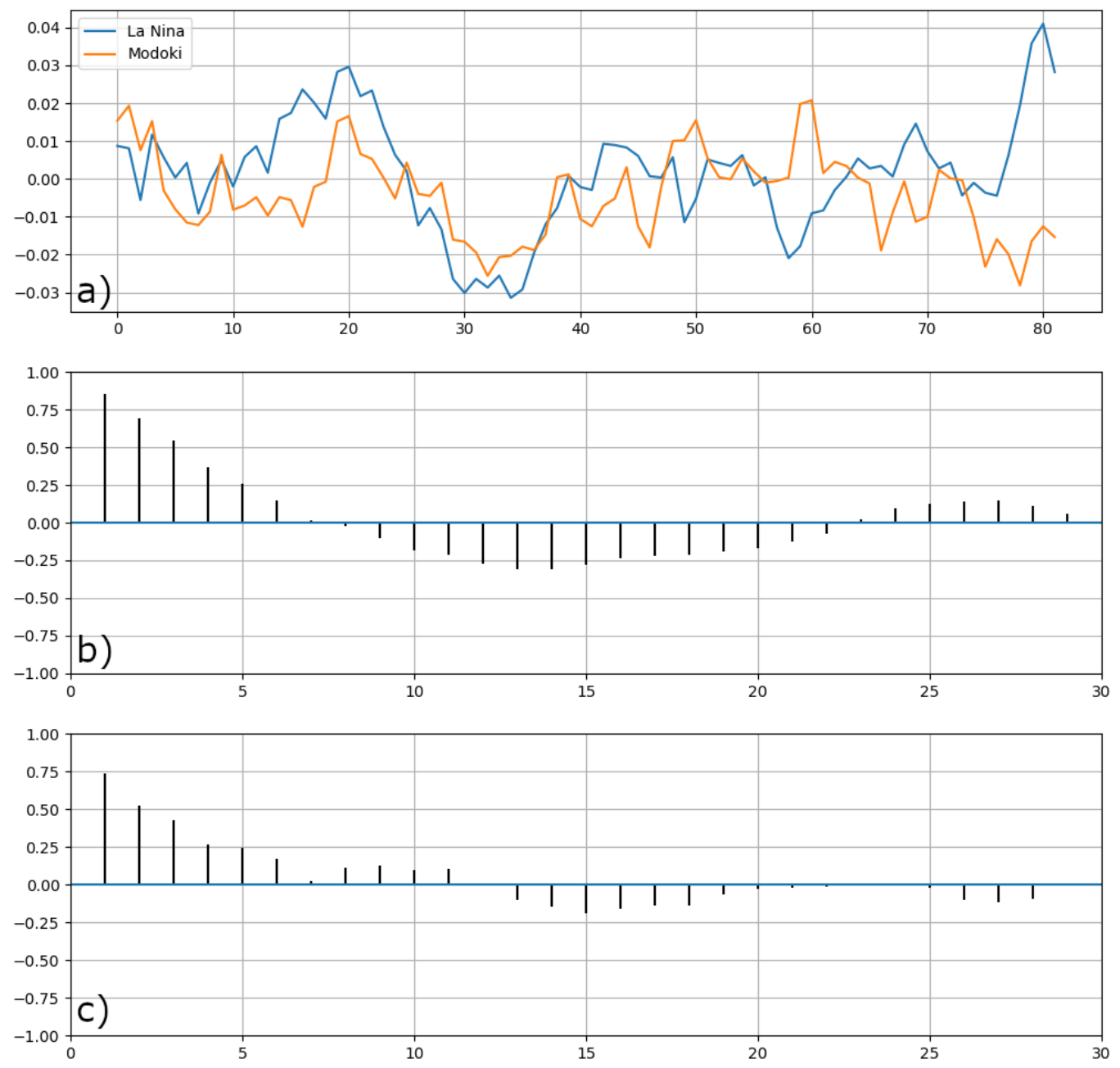

Figure A.7:as in Figure A.5, except for Precipitation (in). 
A.8 - Comparison of Snow Anomalies - La Niña vs Modoki
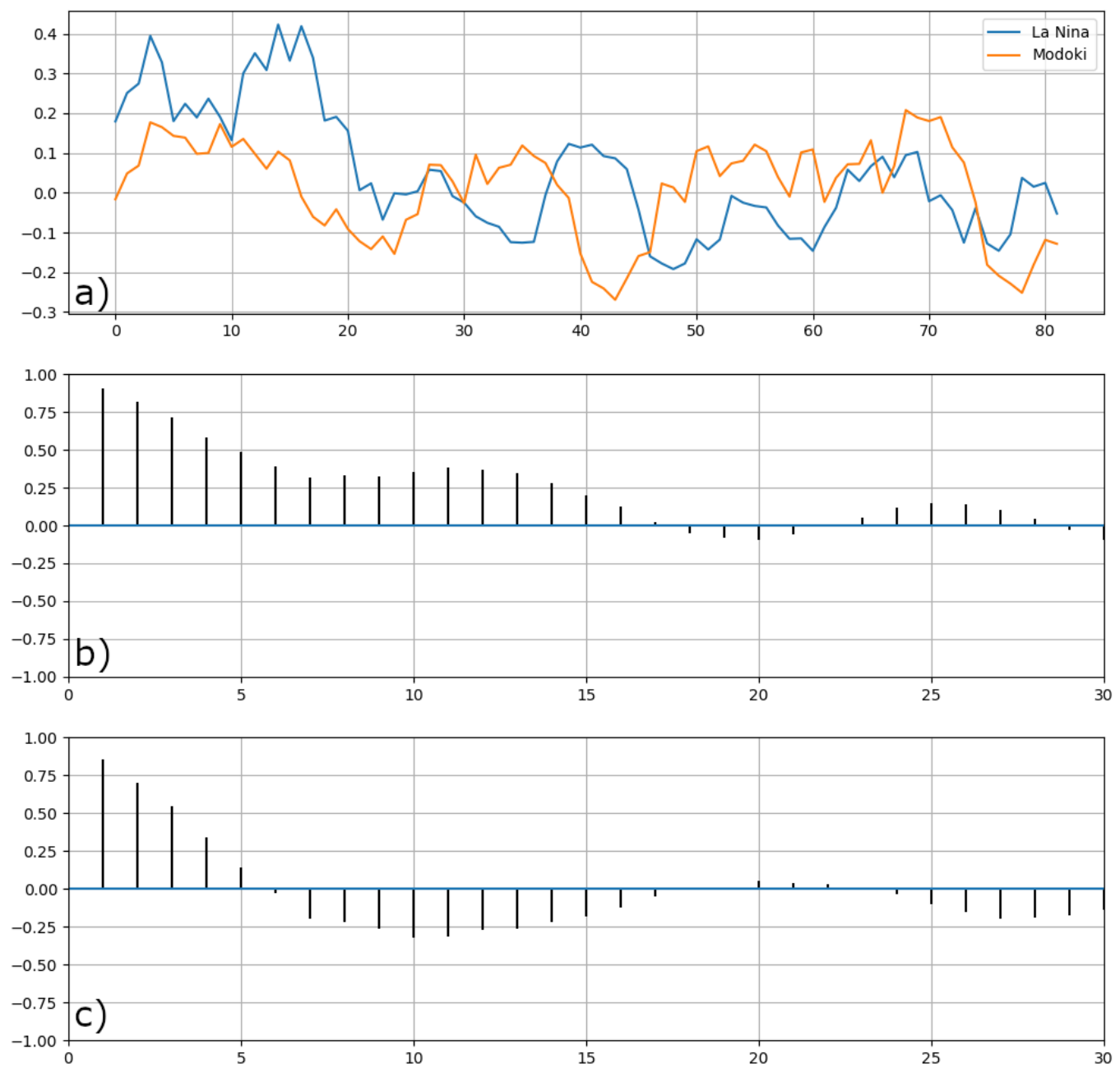

Figure A.8: As in Figure A.5, except for Snowfall (in). 


\section{Appendix B: Binghamton Data}

B.1 - Comparison of Maximum Temperature Anomalies - Conventional El Niño vs Modoki
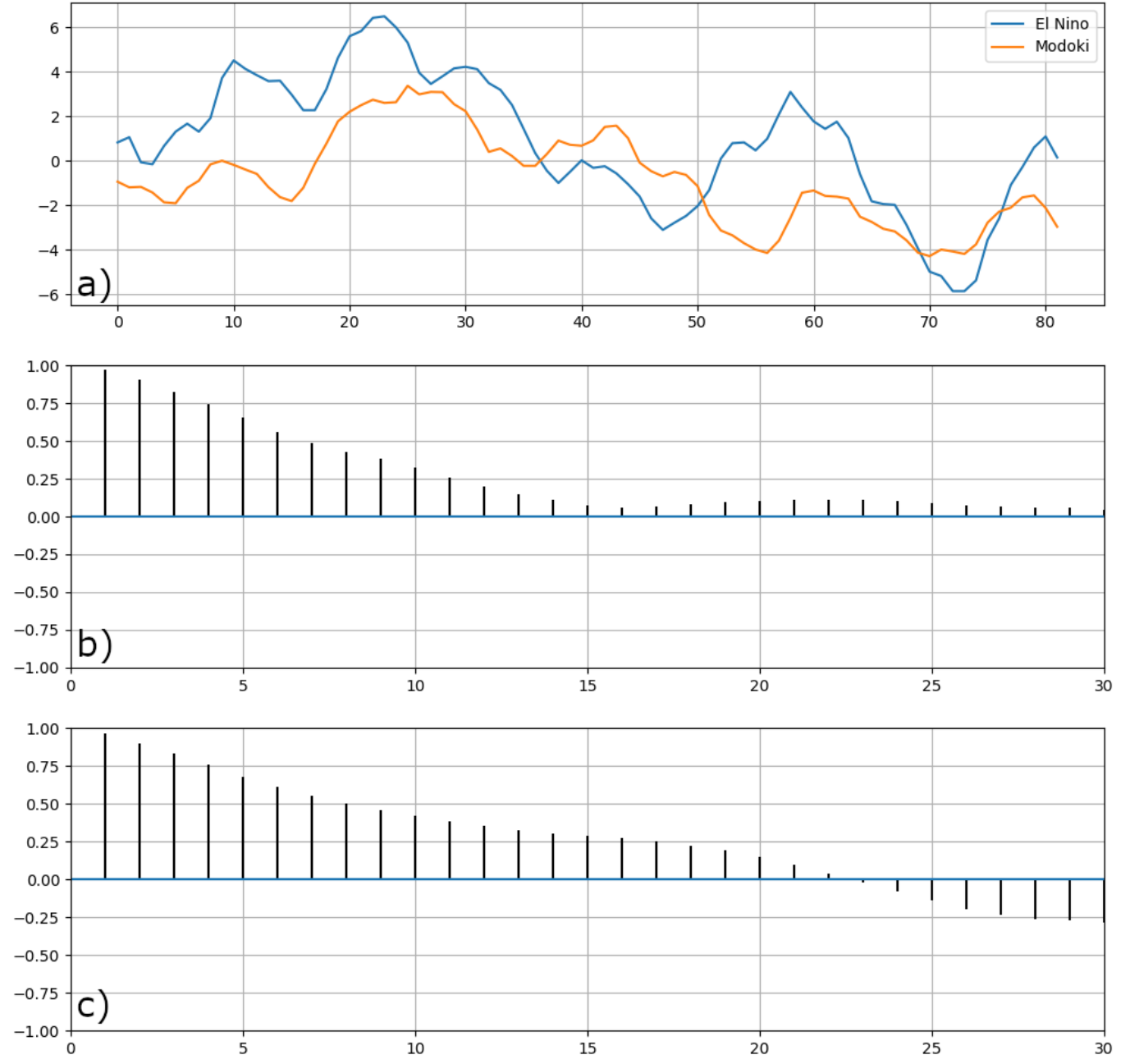

Figure B.1: a) Filtered Daily Averages of Maximum Temperature (F) for Binghamton, comparing conventional El Niño values(blue) against Modoki values(orange). Graphs b) and c) show the autocorrelation of Maximum Temperature for Binghamton for conventional El Niño and Modoki, respectively. 
B.2 - Comparison of Minimum Temperature Anomalies - Conventional El Niño vs Modoki
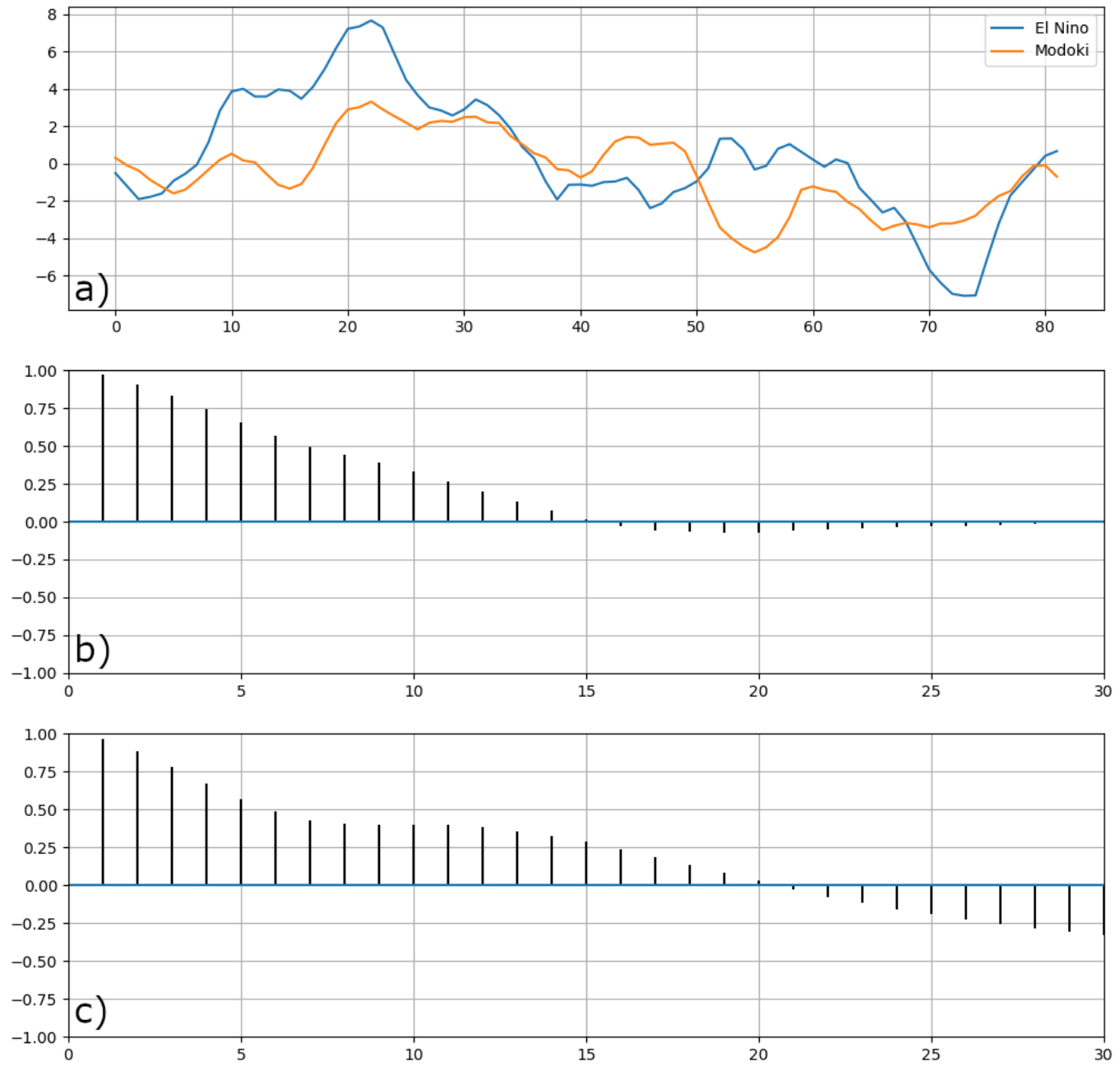

Figure B.2: As in Figure B.1, except for Minimum Temperature (F). 
B.3 - Comparison of Precipitation Anomalies - Conventional El Niño vs Modoki
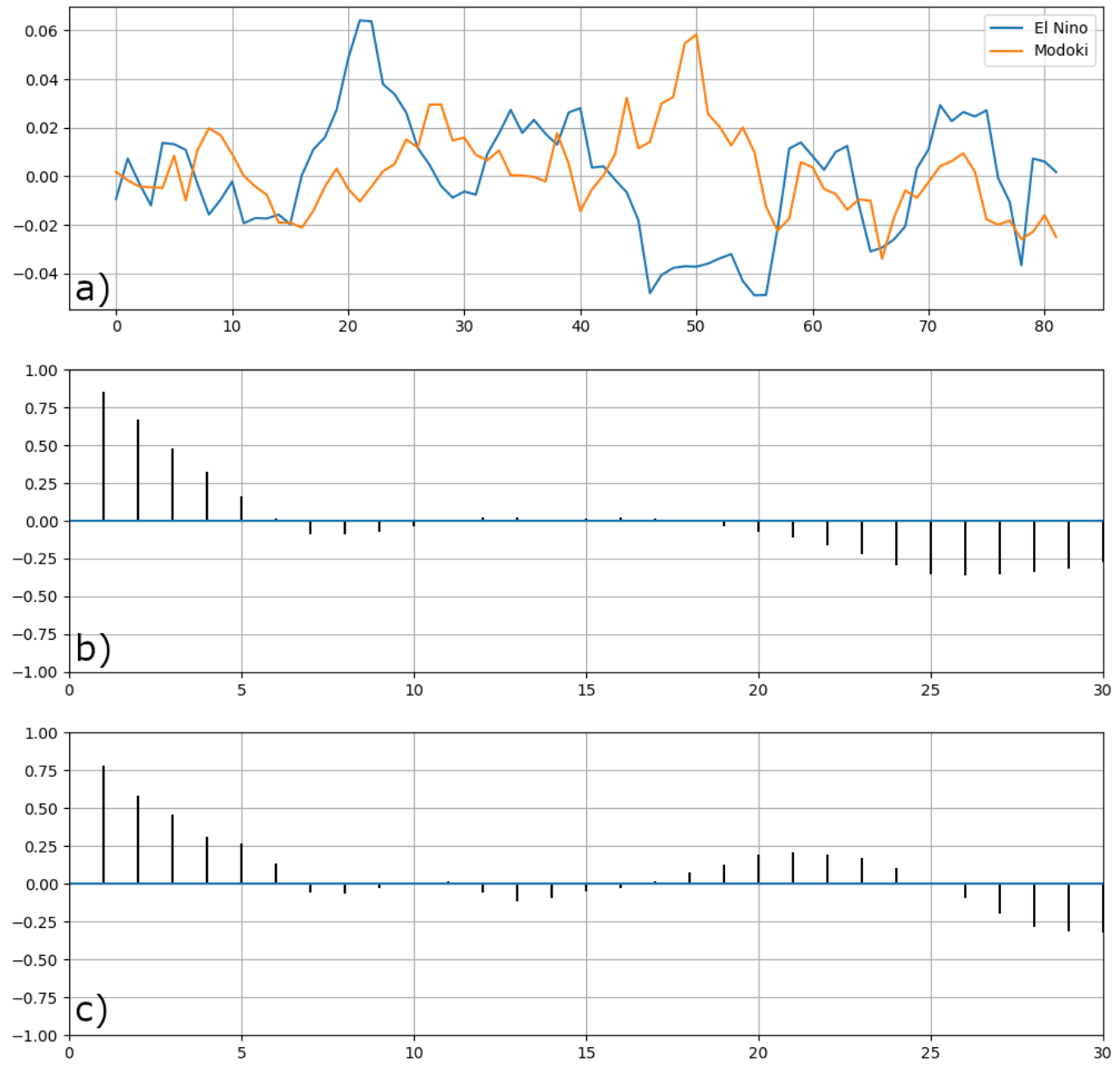

Figure B.3: As in Figure B.1, except for Precipitation (in). 
B.4 - Comparison of Snow Anomalies - Conventional El Niño vs Modoki
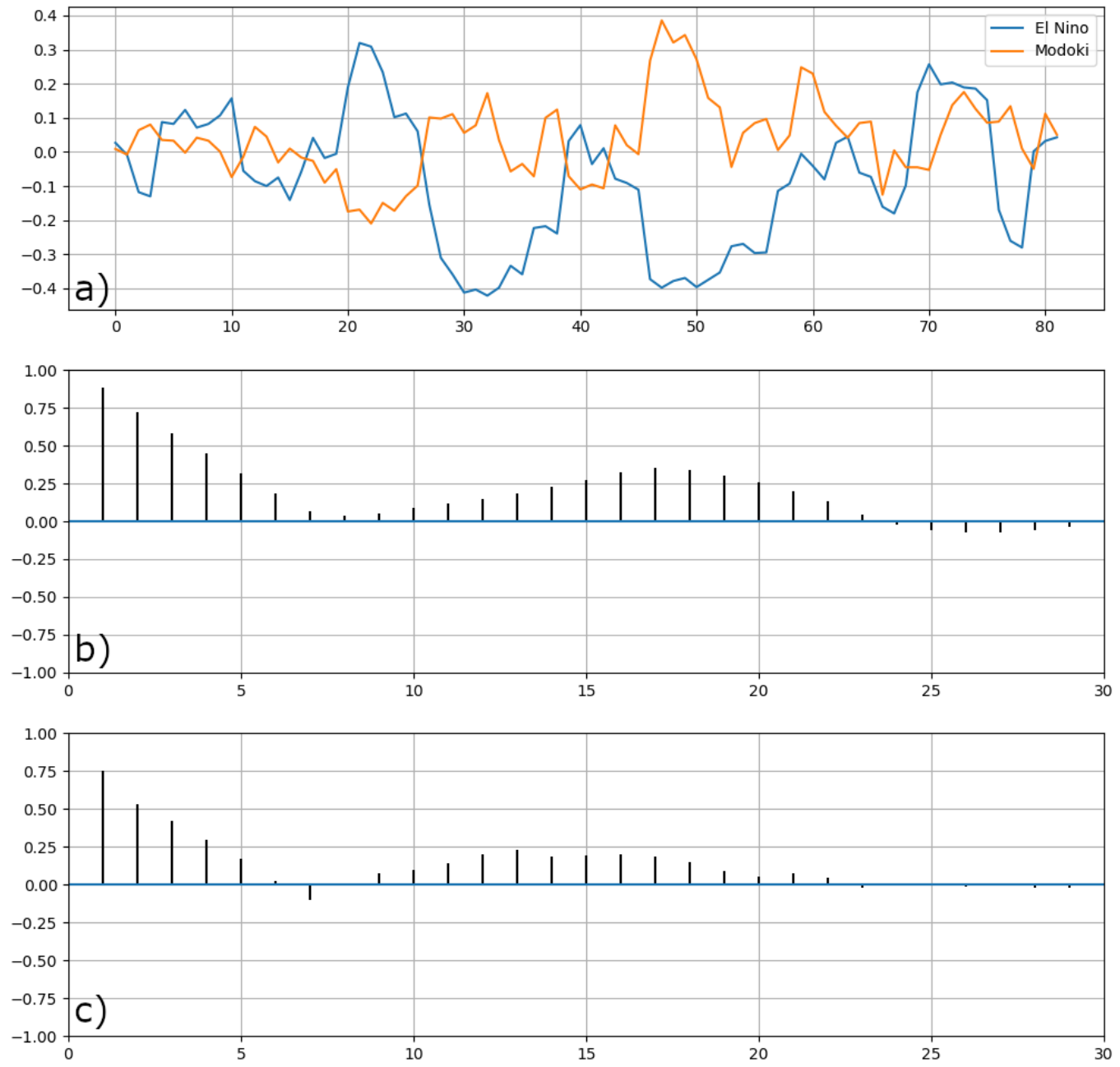

Figure B.4: As in Figure B.1, except for Snowfall (in). 

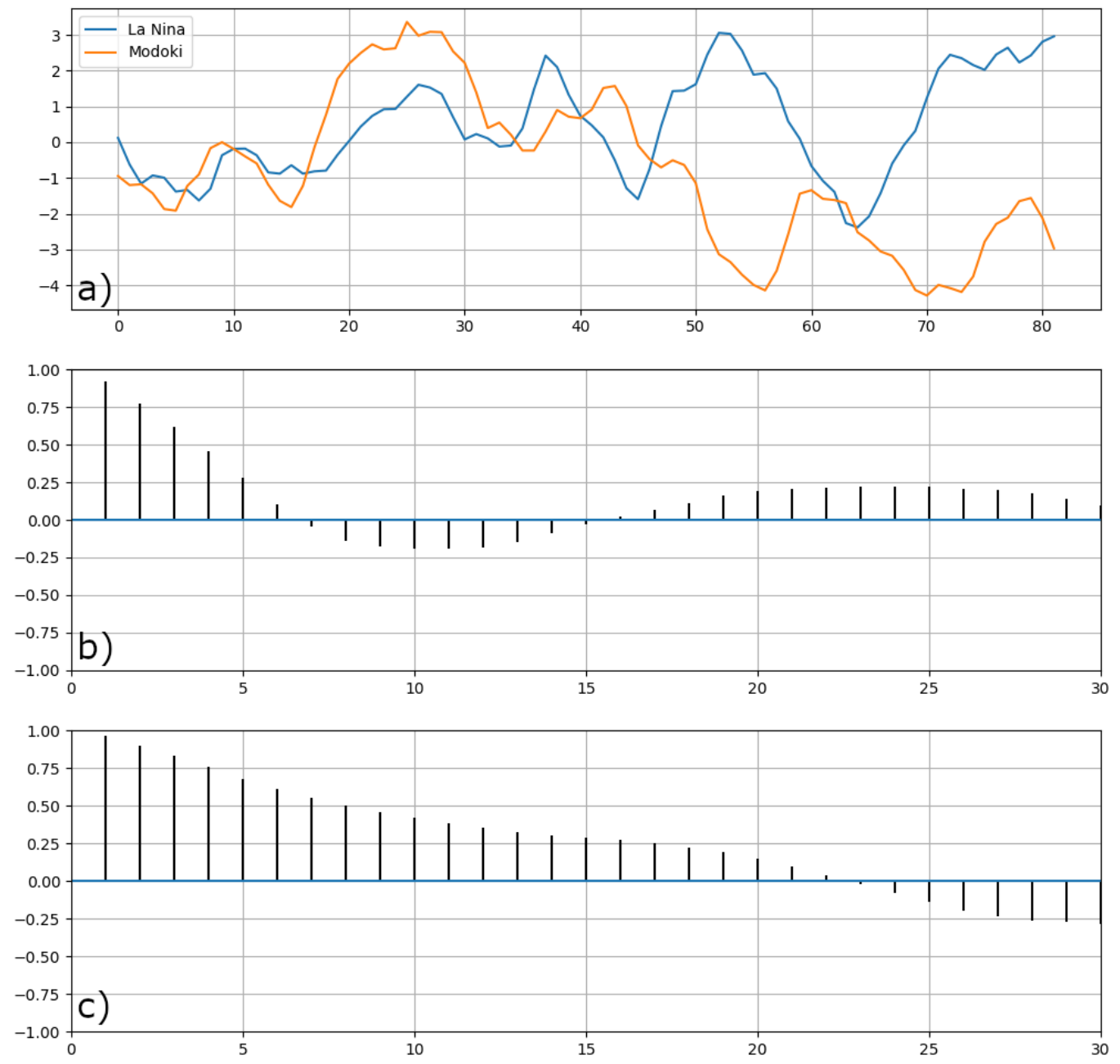

Figure B.5: As in Figure B.1, except comparing La Niña (blue) values to Modoki (orange). Graphs b) and c) show the autocorrelation of Maximum Temperature for Binghamton for conventional La Niña and Modoki, respectively. 
B.6 - Comparison of Minimum Temperature Anomalies - La Niña vs Modoki
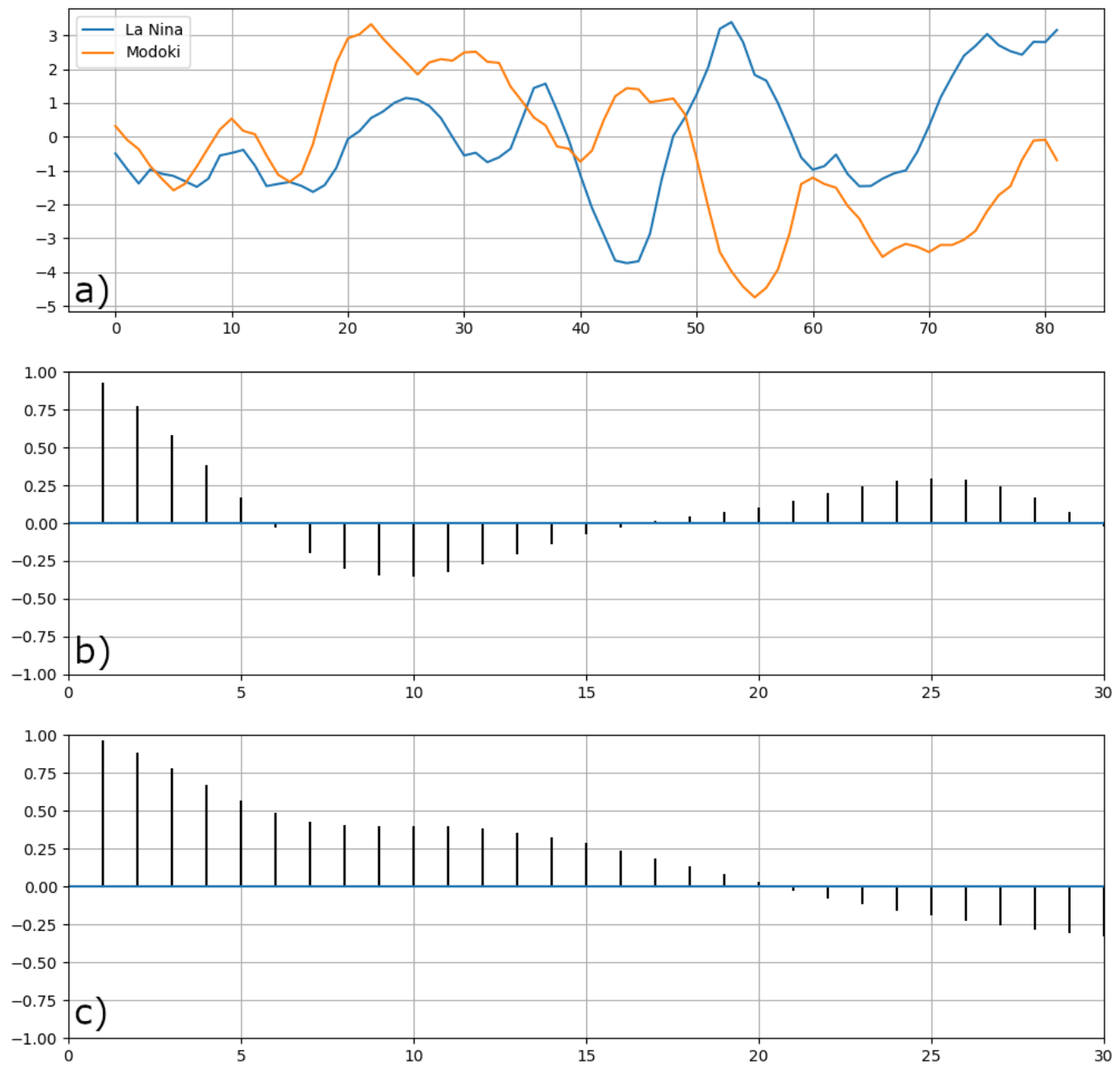

Figure B.6: As in Figure B.5, except for Minimum Temperature (F). 
B.7 - Comparison of Precipitation Anomalies - La Niña vs Modoki
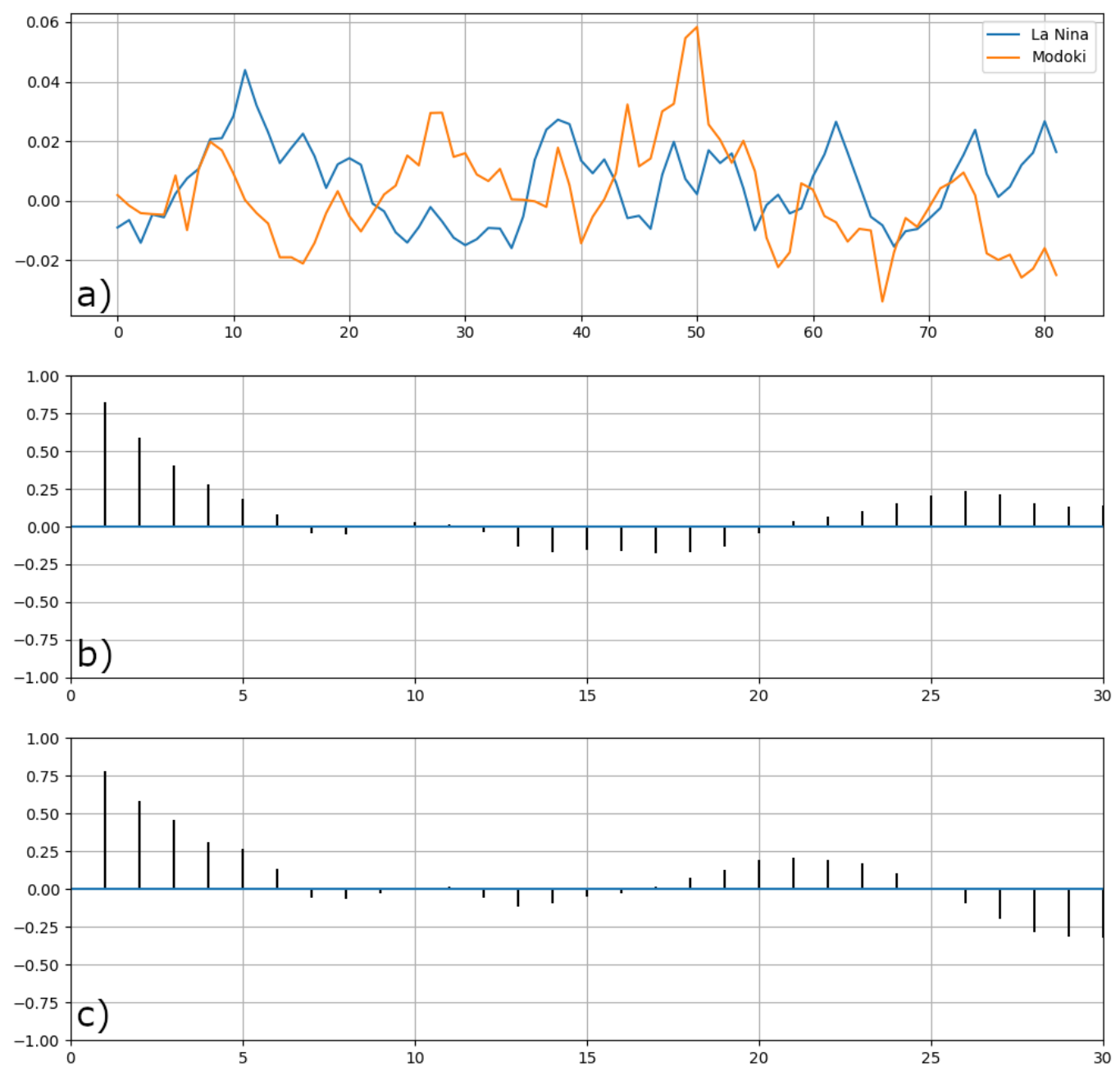

Figure B.7: As in Figure B.5, except for Precipitation (in). 
B.8 - Comparison of Snow Anomalies - La Niña vs Modoki
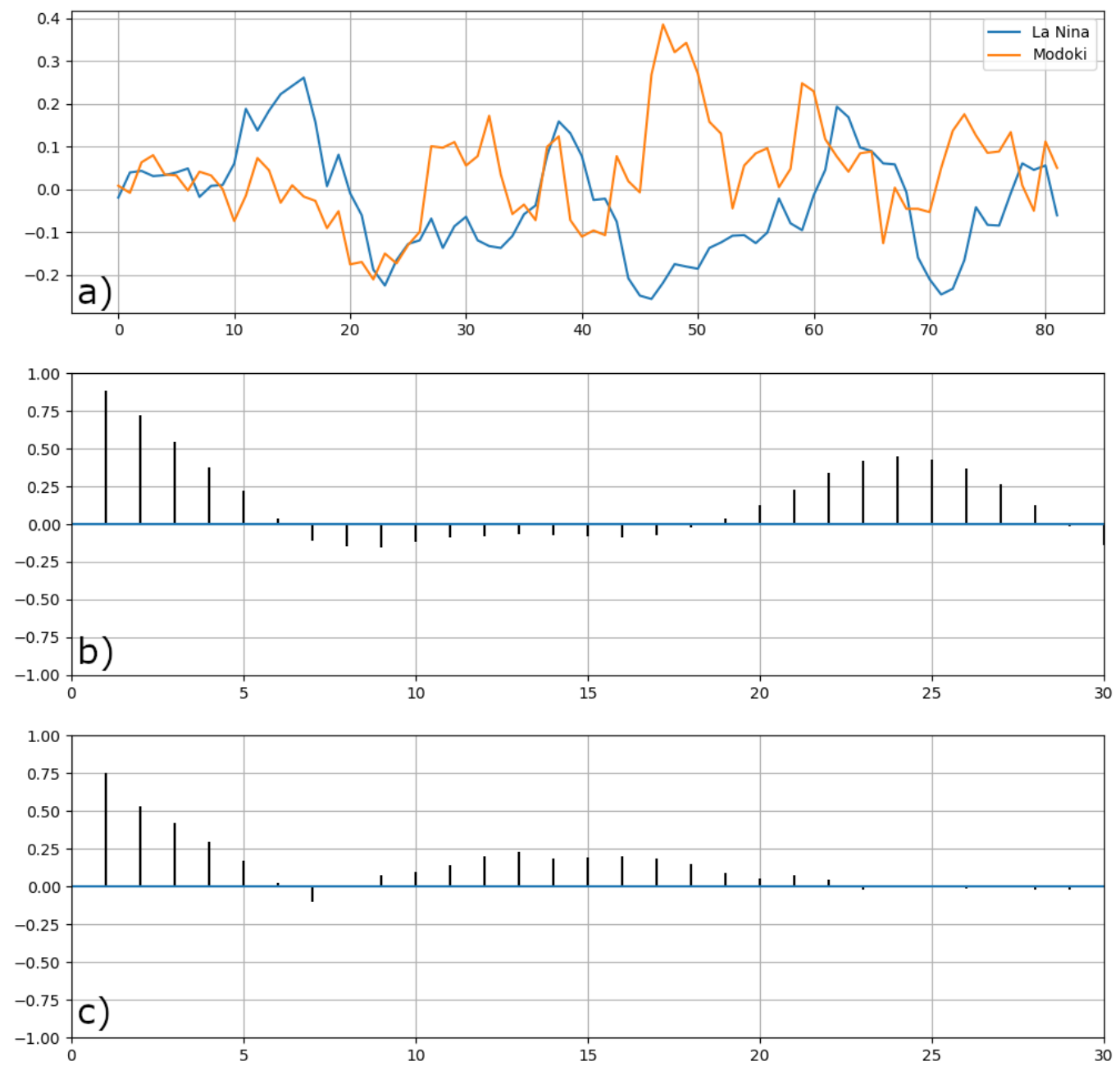

Figure B.8: As in Figure B.5, except for Snowfall (in). 


\section{Appendix C - Albany Data}

C.1 - Comparison of Maximum Temperature Anomalies - Conventional El Niño vs Modoki
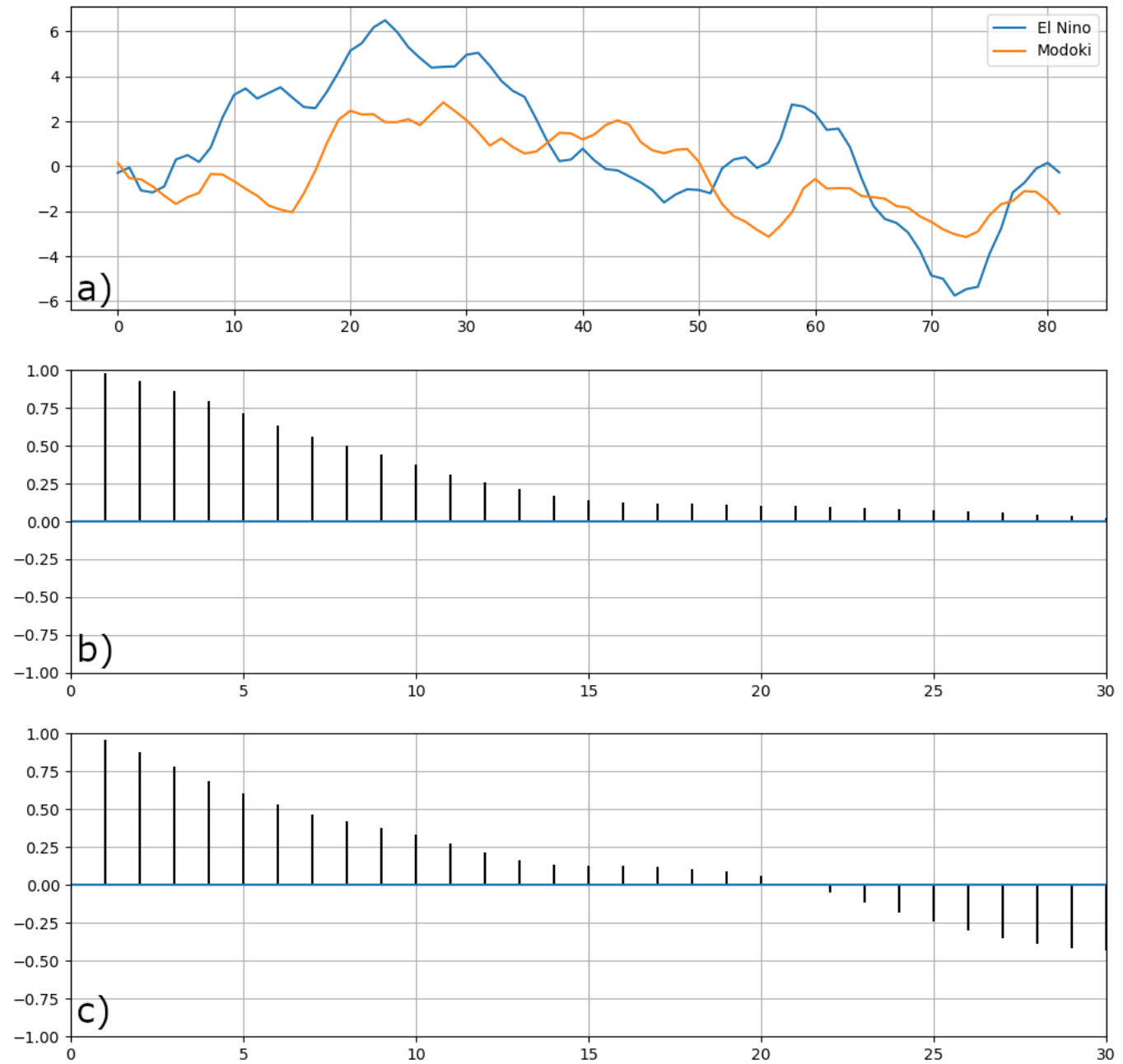

Figure C.1:: a) Filtered Daily Averages of Maximum Temperature (F) for Albany, comparing conventional El Niño values(blue) against Modoki values(orange). Graphs $b$ ) and c) show the autocorrelation of Maximum Temperature for Albany for conventional El Niño and Modoki, respectively. 

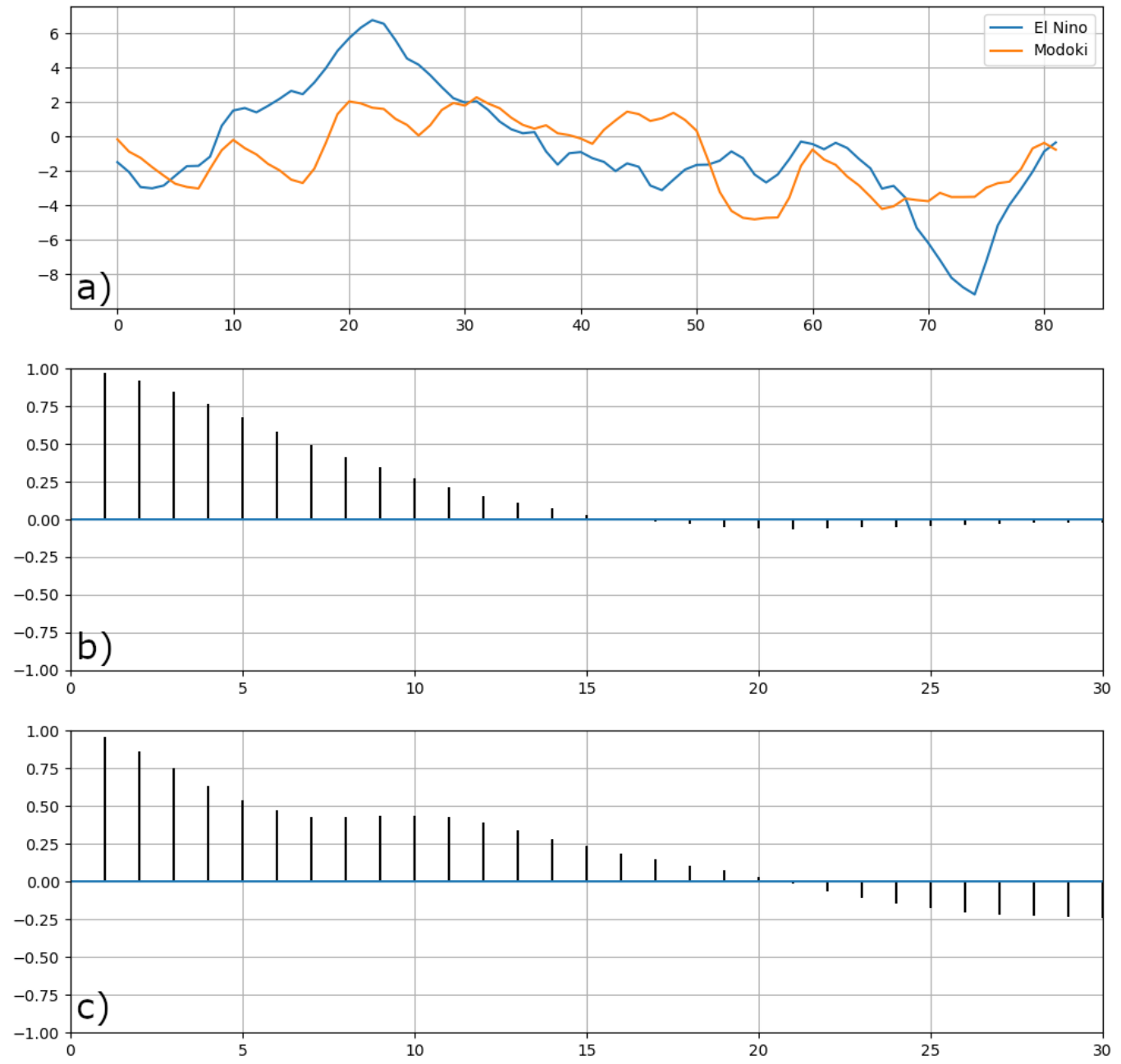

Figure C.2: As in Figure C.1, except for Minimum Temperature (F). 
C.3 - Comparison of Precipitation Anomalies - Conventional El Niño vs Modoki
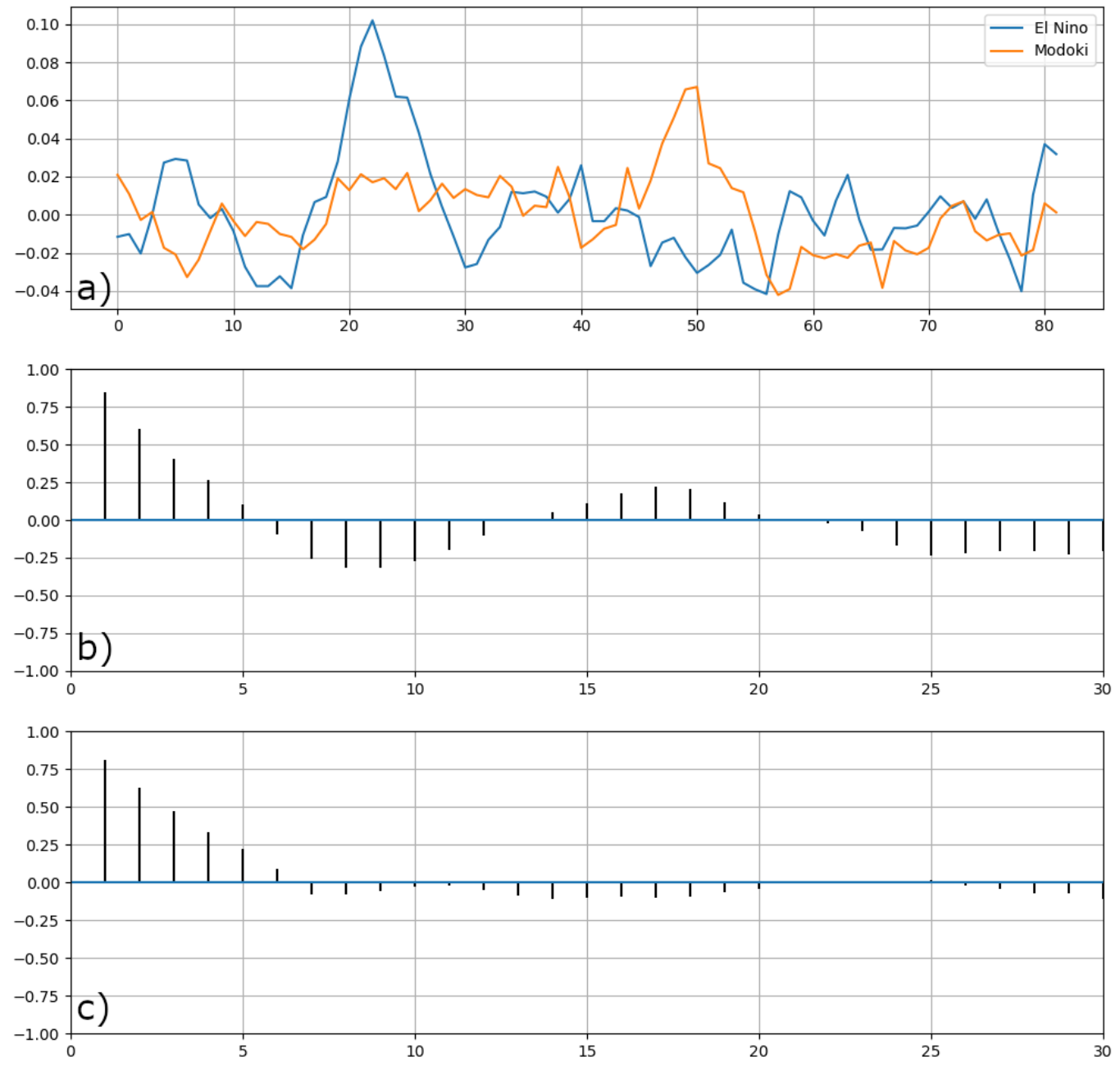

Figure C.3: As in Figure C.1, except for Precipitation (in). 
C.4 - Comparison of Snow Anomalies - Conventional El Niño vs Modoki
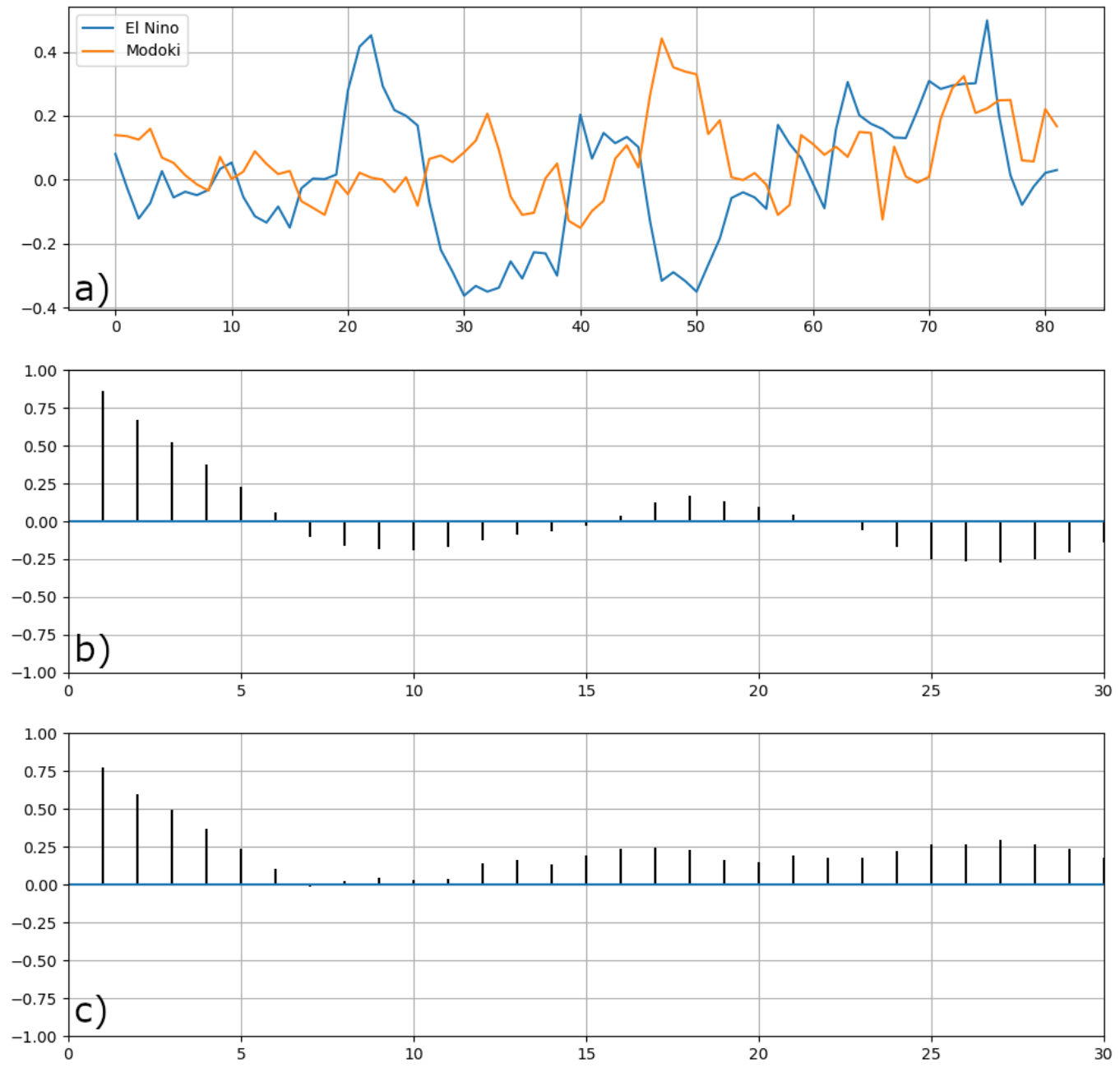

Figure C.4: As in Figure C.1, except for Snowfall (in). 
C.5 - Comparison of Maximum Temperature Anomalies - La Niña vs Modoki


Figure C.5: As in Figure C.1, except comparing La Niña (blue) values to Modoki (orange). Graphs b) and c) show the autocorrelation of Maximum Temperature for Albany for conventional La Niña and Modoki, respectively. 
C.6 - Comparison of Minimum Temperature Anomalies - La Niña vs Modoki
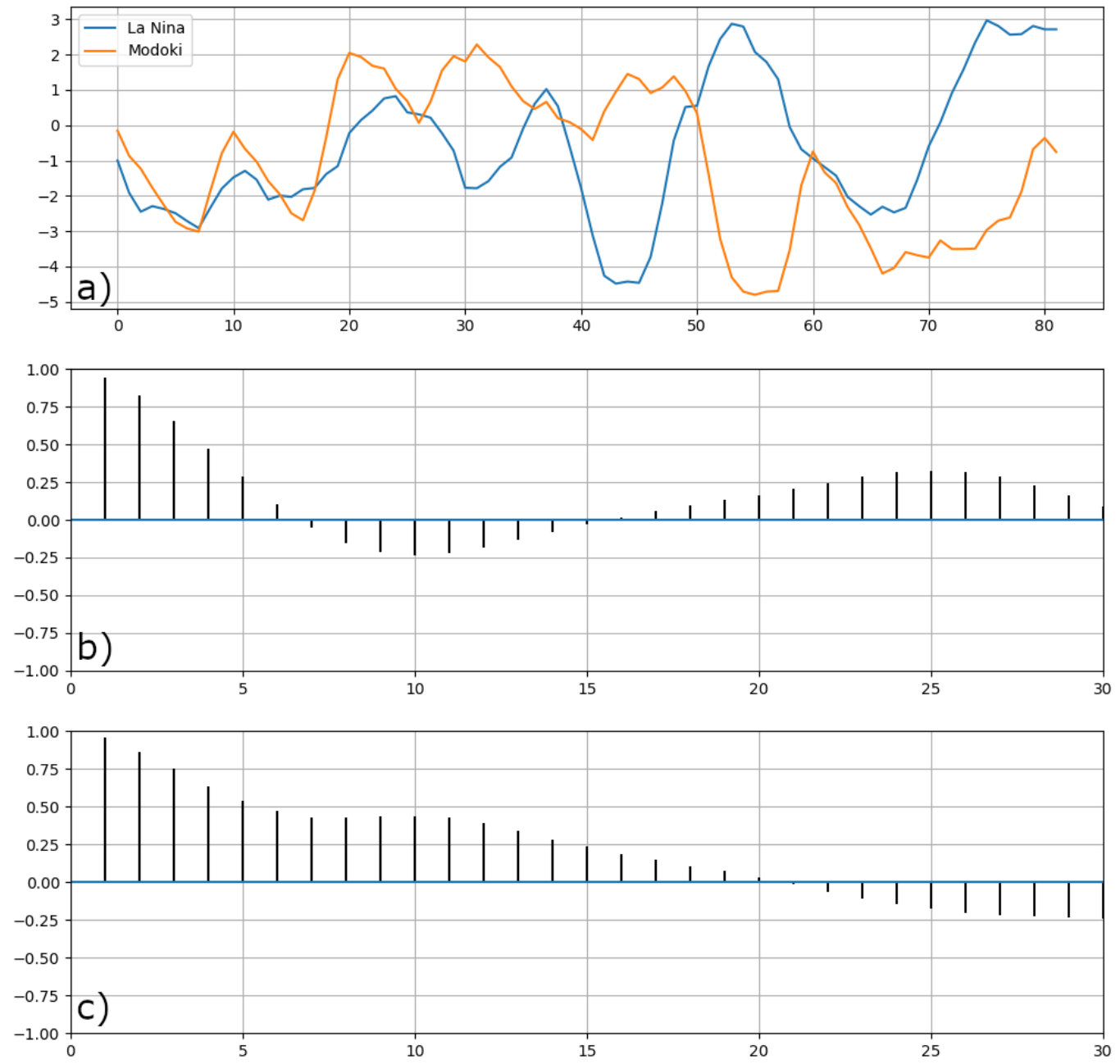

Figure C.6: As in Figure C.5, except for Minimum Temperature (F). 
C.7 - Comparison of Precipitation Anomalies - La Niña vs Modoki


Figure C.7: As in Figure C.5, except for Precipitation (in). 
C.8 - Comparison of Snow Anomalies - La Niña vs Modoki
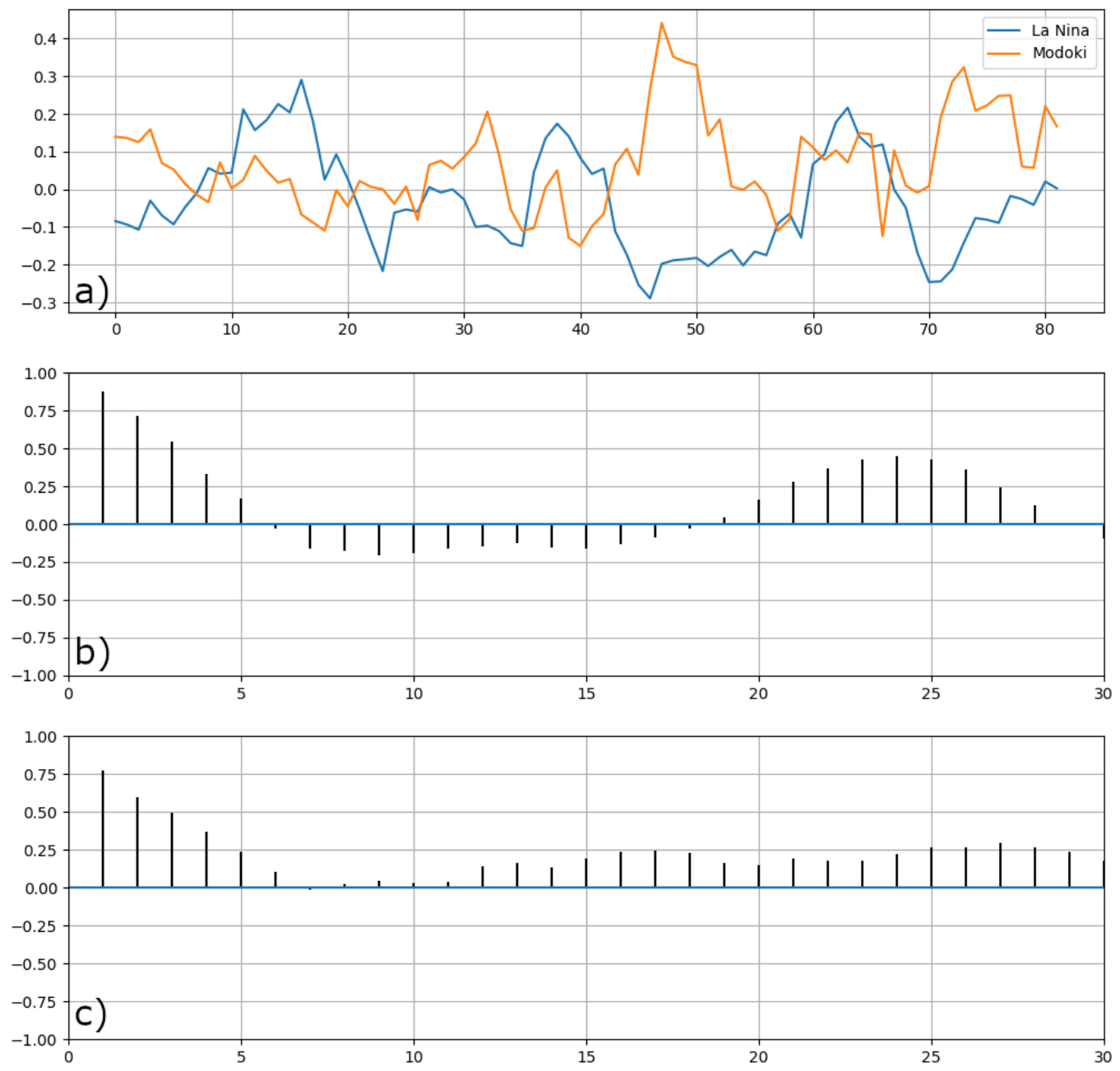

Figure C.8: As in Figure C.5, except for Snowfall (in). 


\section{Appendix D - Buffalo Data}

D.1 - Comparison of Maximum Temperature Anomalies - Conventional El Niño vs Modoki
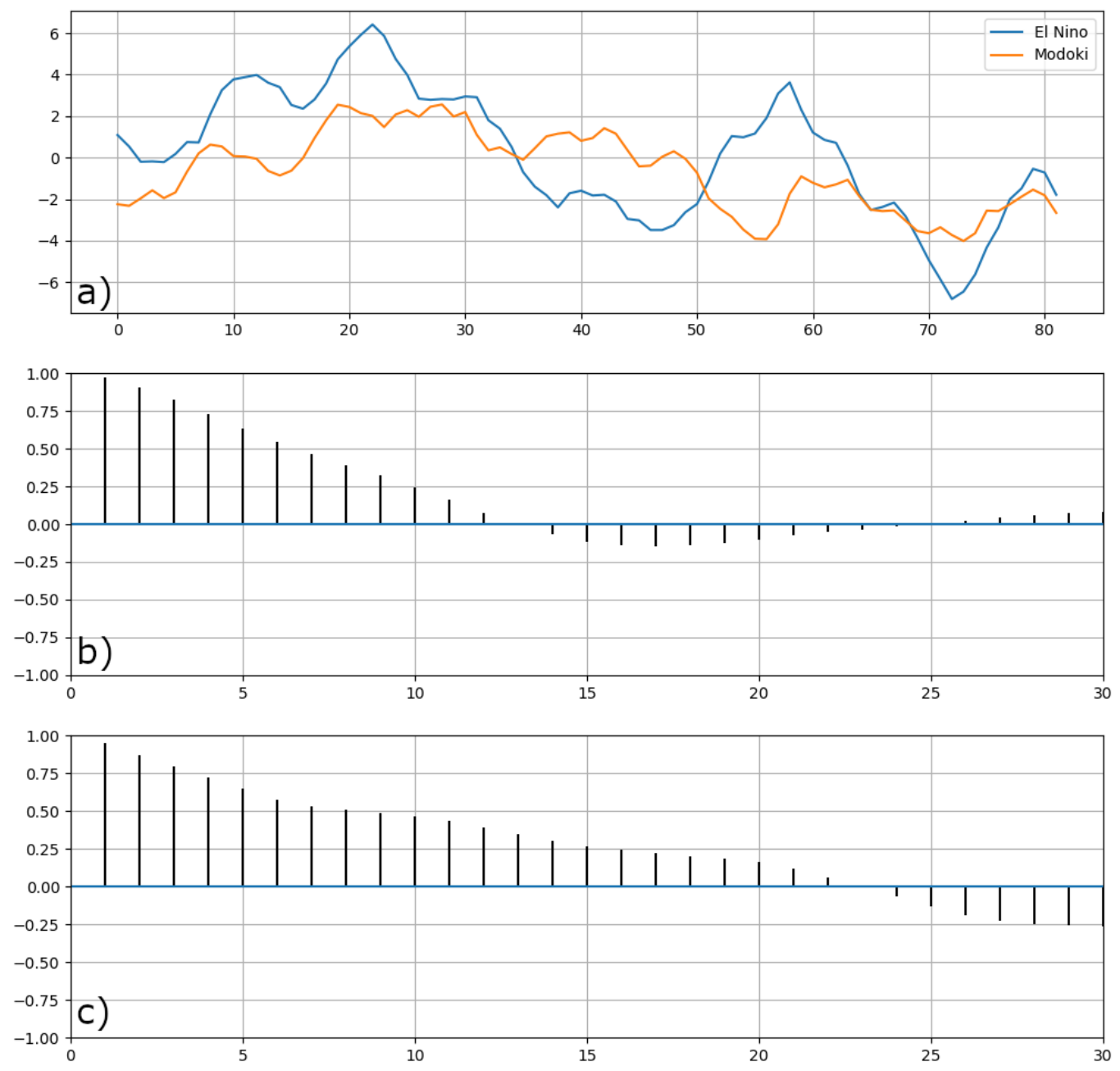

Figure D.1: a) Filtered Daily Averages of Maximum Temperature (F) for Buffalo, comparing conventional El Niño values(blue) against Modoki values(orange). Graphs b) and c) show the autocorrelation of Maximum Temperature for Buffalo for conventional El Niño and Modoki, respectively. 
D.2 - Comparison of Minimum Temperature Anomalies - Conventional El Niño vs Modoki
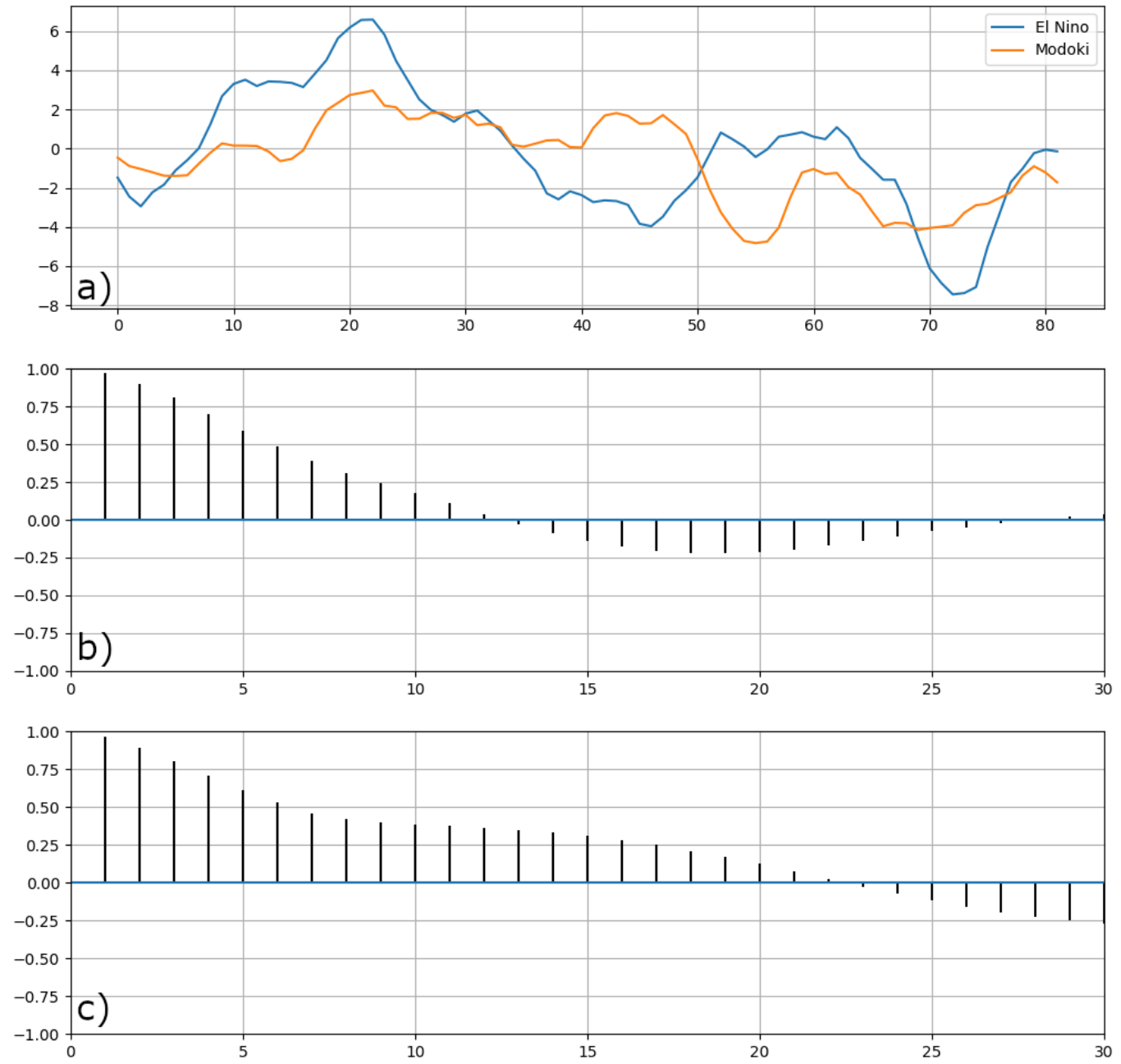

Figure D.2: As in Figure D.1, except for Minimum Temperature (F). 
D.3 - Comparison of Precipitation Anomalies - Conventional El Niño vs Modoki
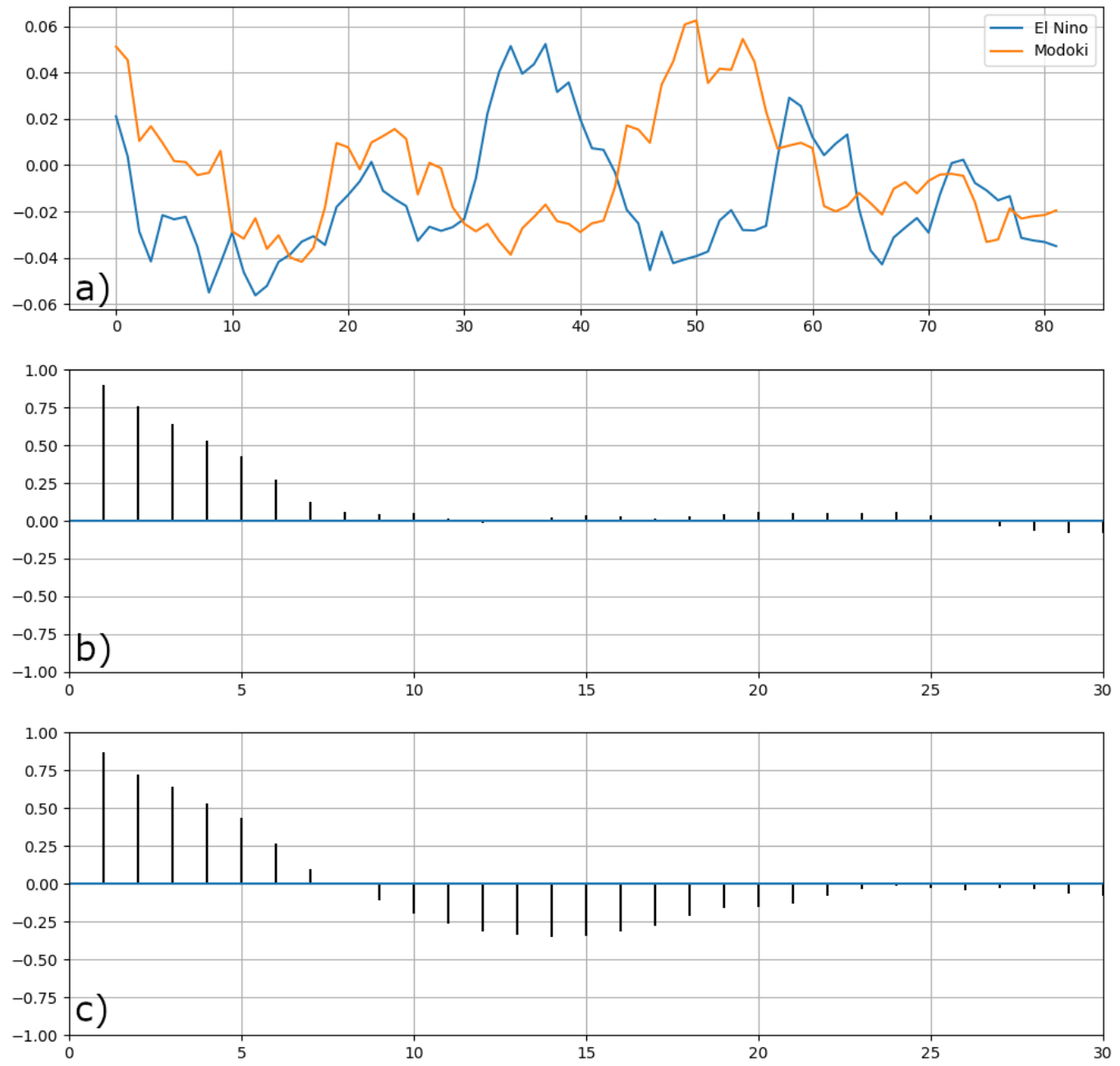

Figure D.3: As in Figure D.1, except for Precipitation (in). 
D.4 - Comparison of Snow Anomalies - Conventional El Niño vs Modoki
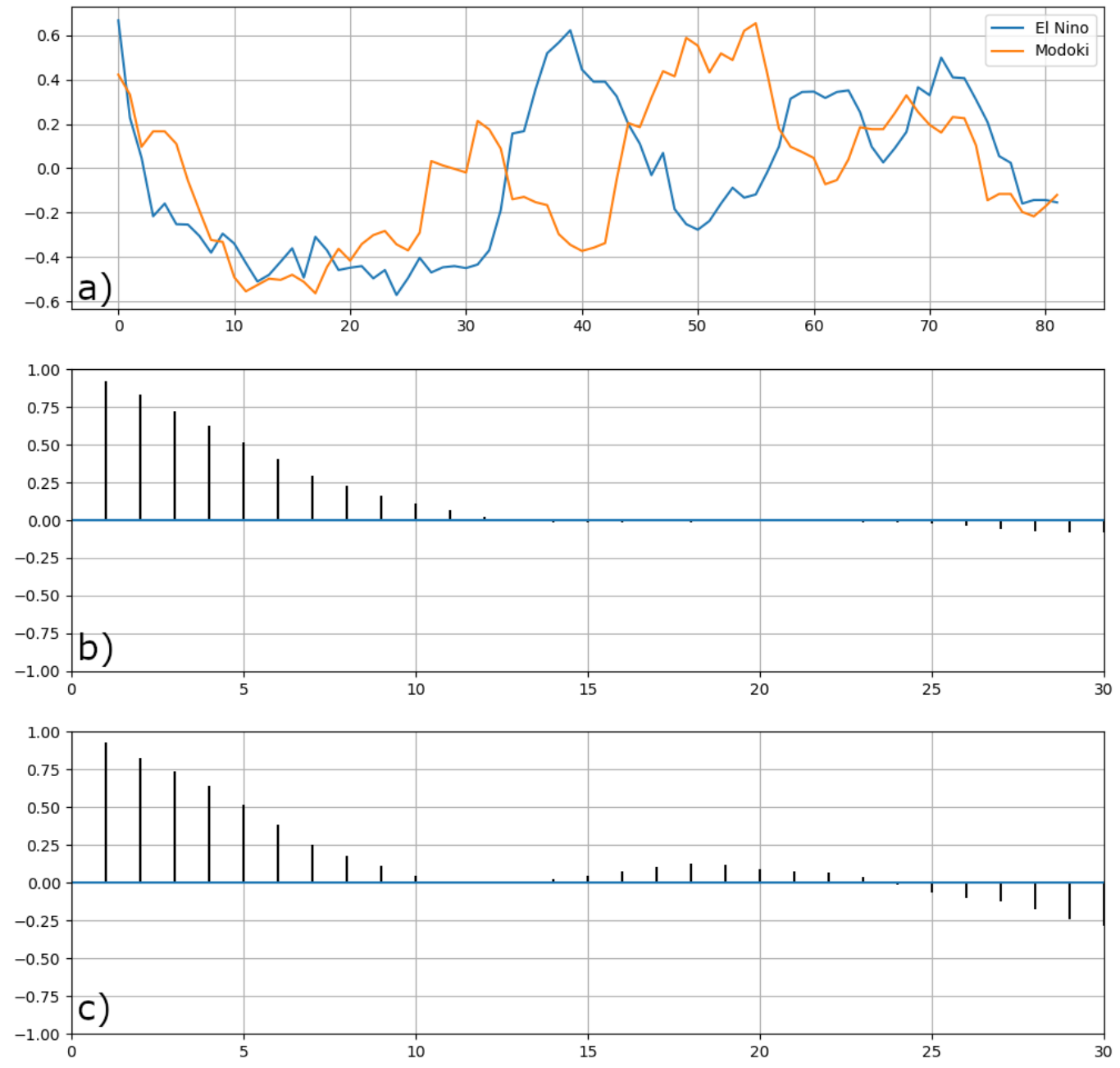

Figure D.4: As in Figure D.1, except for Snowfall (in). 
D.5 - Comparison of Maximum Temperature Anomalies - La Niña vs Modoki
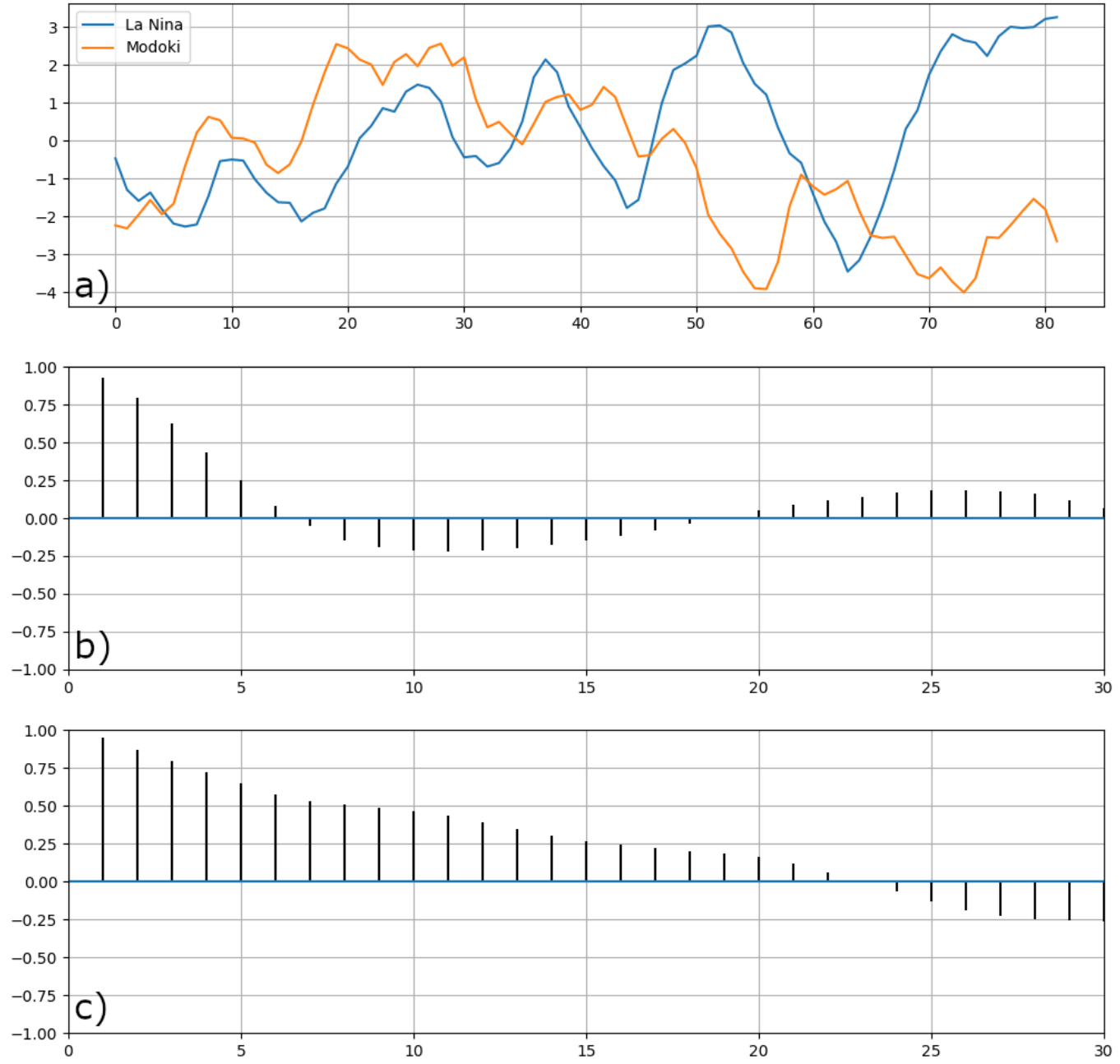

Figure D.5: As in Figure D.1, except comparing La Niña (blue) values to Modoki (orange). Graphs b) and c) show the autocorrelation of Maximum Temperature for Buffalo for conventional La Niña and Modoki, respectively. 
D.6 - Comparison of Minimum Temperature Anomalies - La Niña vs Modoki
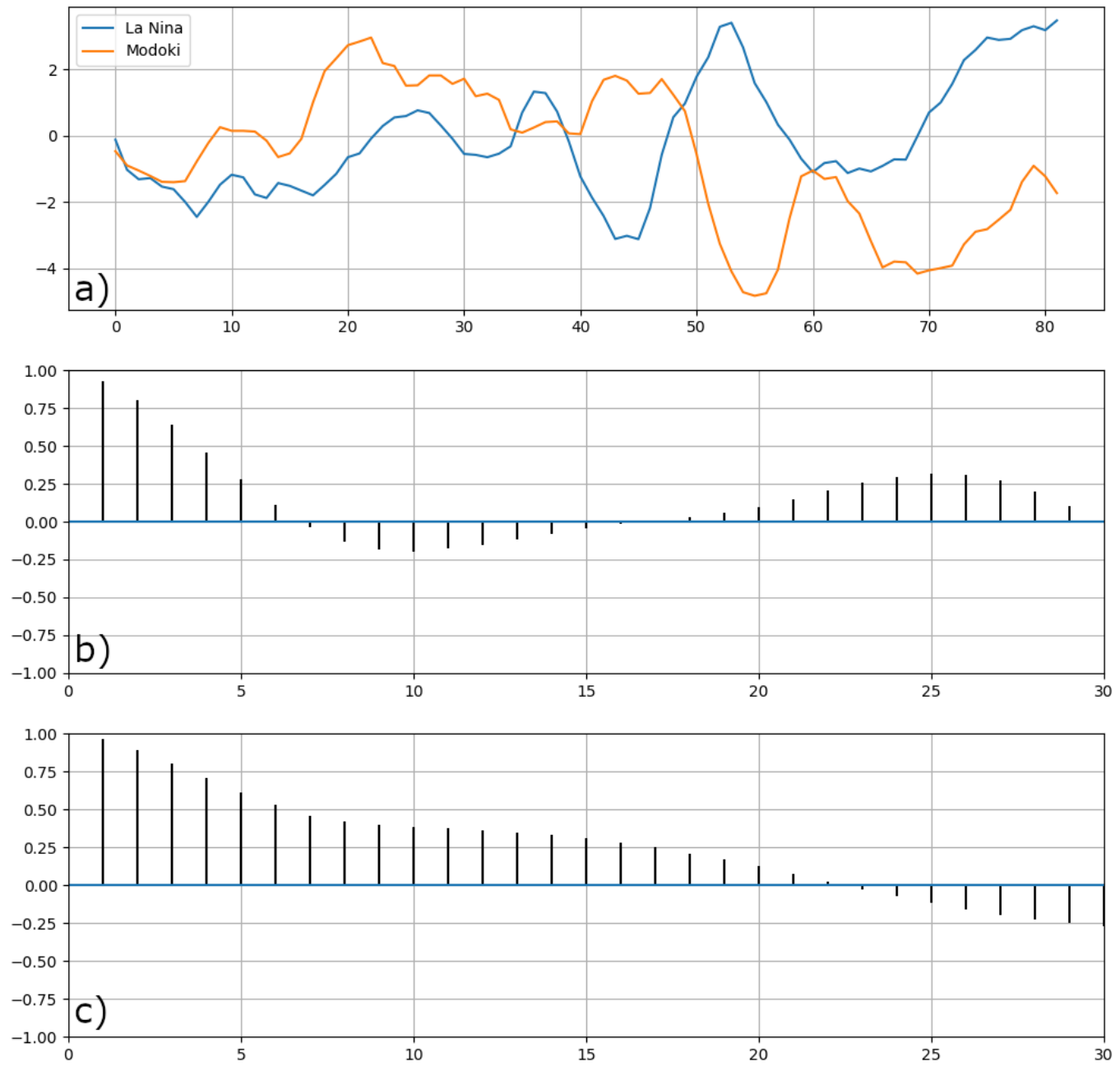

Figure D.6: As in Figure D.5, except for Minimum Temperature (F). 
D.7 - Comparison of Precipitation Anomalies - La Niña vs Modoki
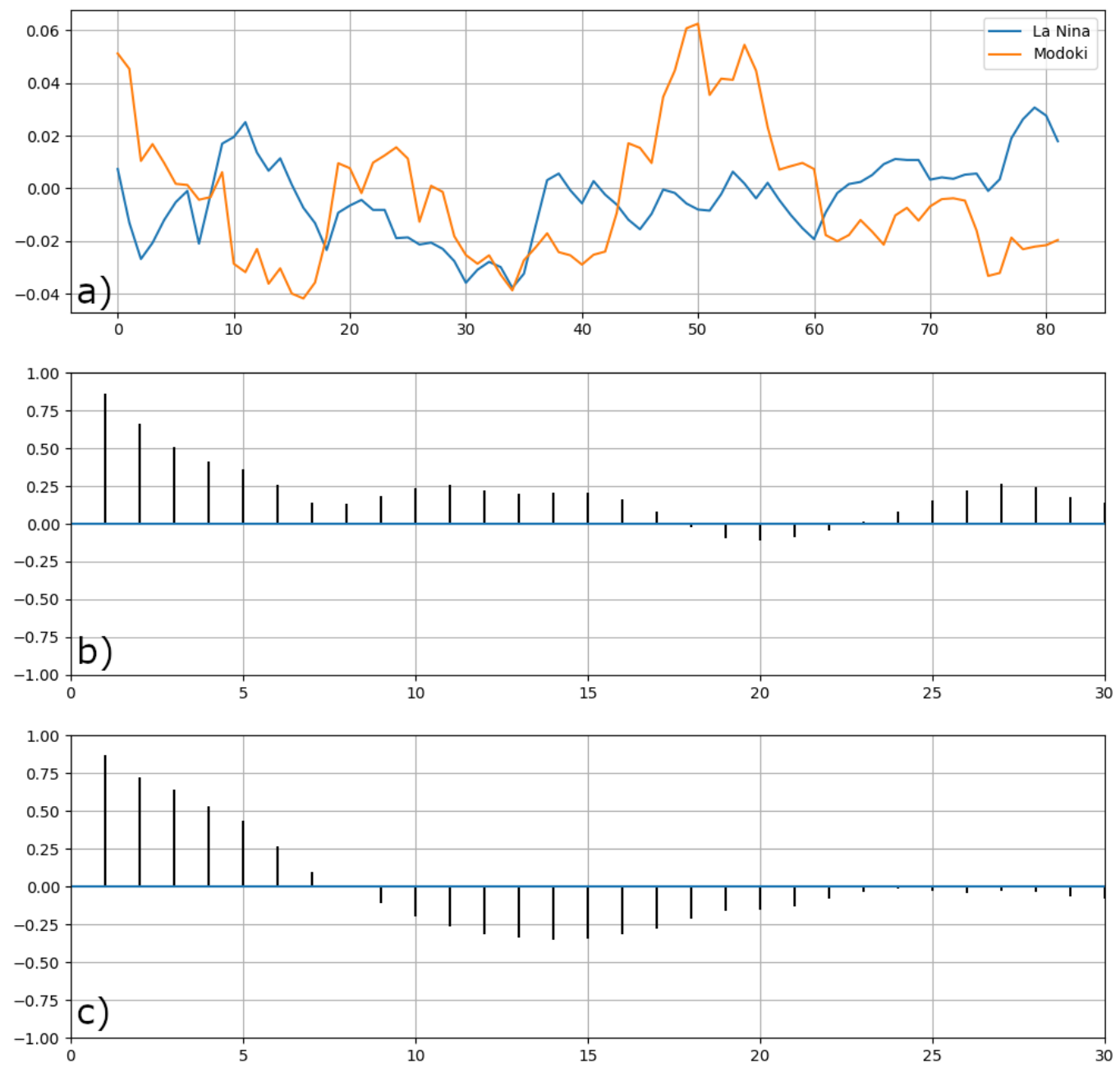

Figure D.7: As in Figure D.5, except for Precipitation (in). 
D.8 - Comparison of Snow Anomalies - La Niña vs Modoki
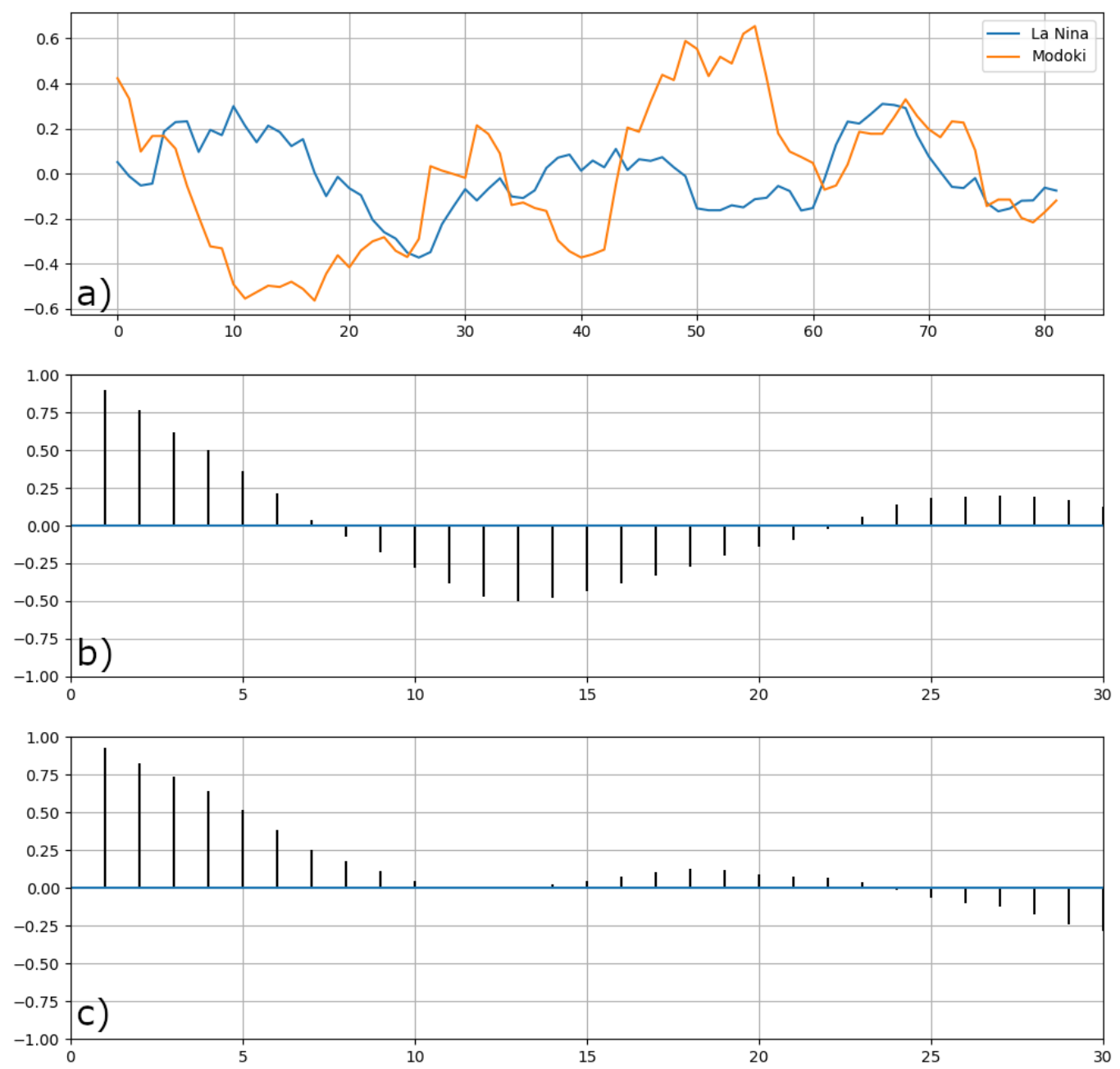

Figure D.8: As in Figure D.5, except for Snowfall (in). 


\section{Appendix E - White Plains Data}

E.1 - Comparison of Maximum Temperature Anomalies - Conventional El Niño vs Modoki
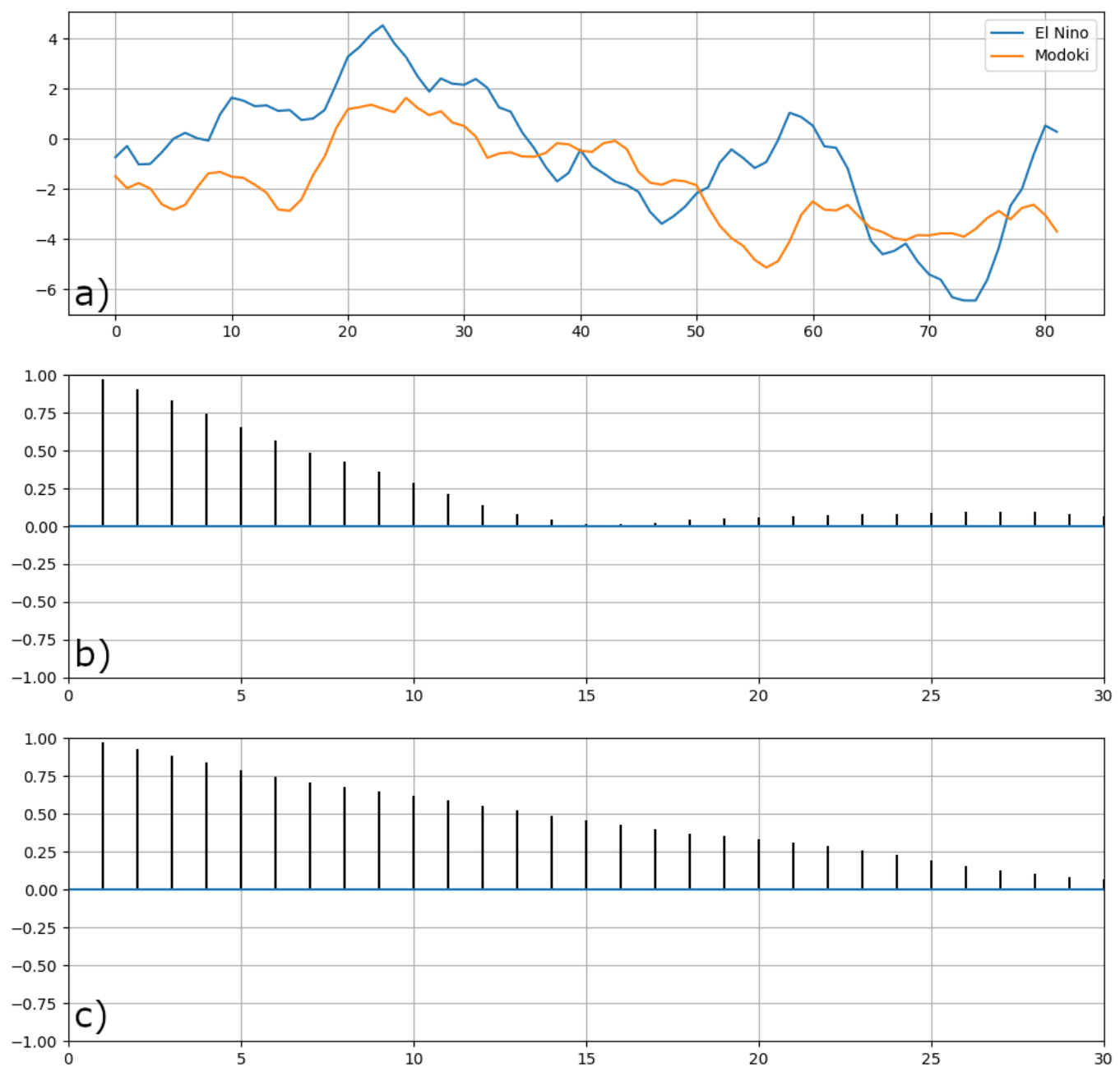

FigureE.1: a) Filtered Daily Averages of Maximum Temperature (F) for White Plains, comparing conventional El Niño values(blue) against Modoki values(orange). Graphs b) and c) show the autocorrelation of Maximum Temperature for White Plains for conventional El Niño and Modoki, respectively. 
E.2 - Comparison of Minimum Temperature Anomalies - Conventional El Niño vs Modoki
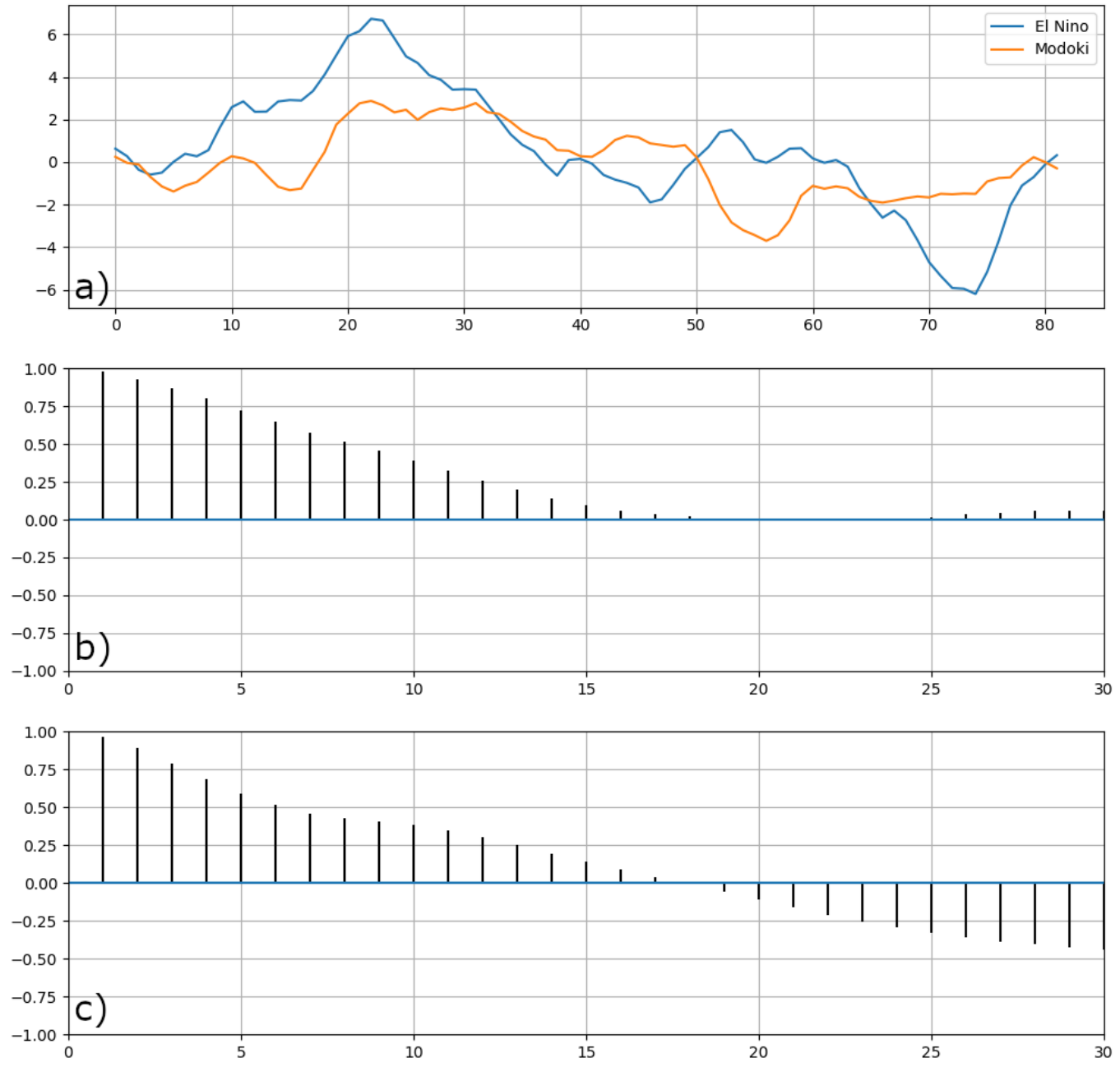

Figure E.2: As in Figure E.1, except for Minimum Temperature (F). 
E.3 - Comparison of Precipitation Anomalies - Conventional El Niño vs Modoki
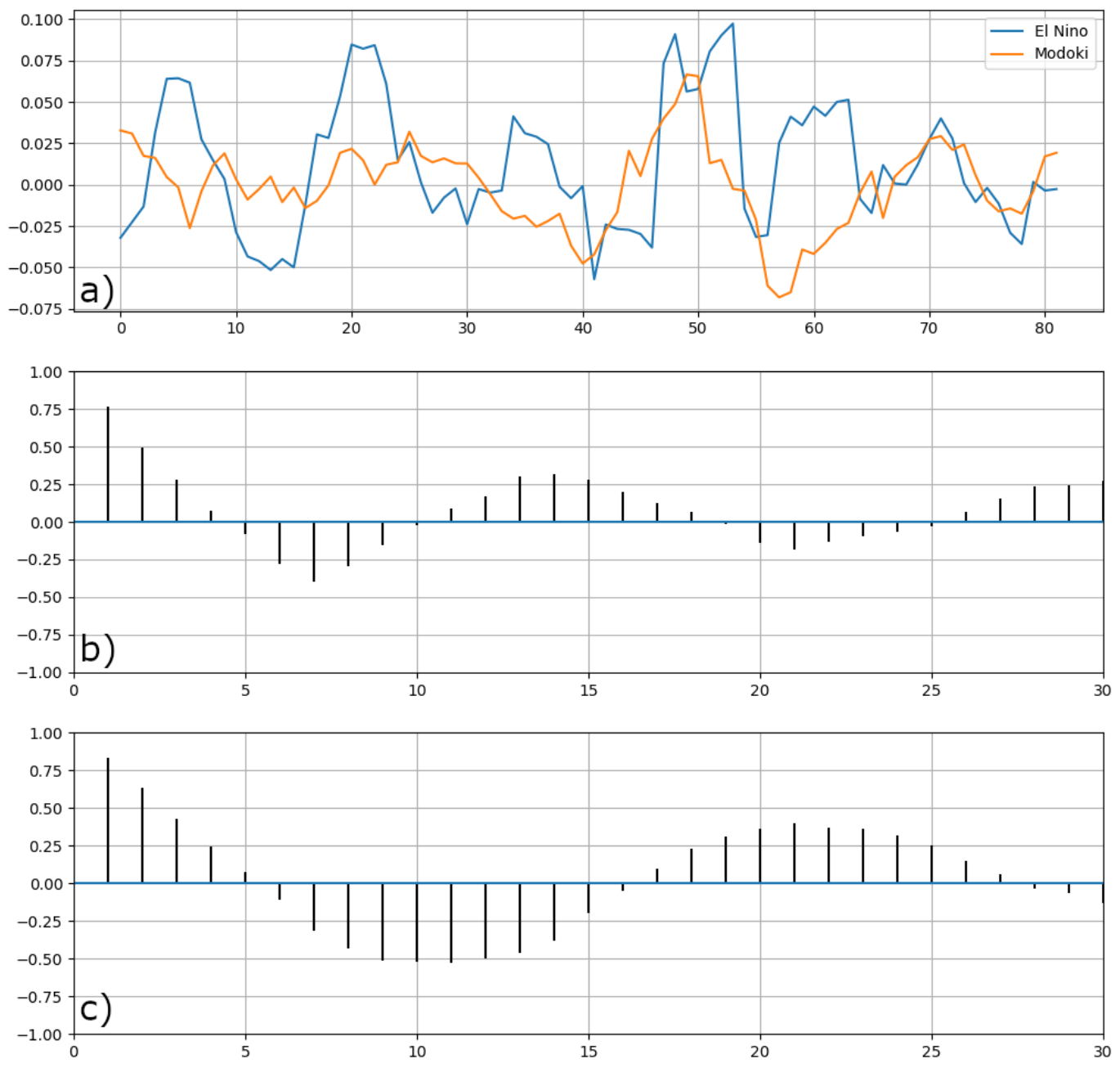

Figure E.3: As in Figure E.1, except for Precipitation (in). 
E.4 - Comparison of Snow Anomalies - Conventional El Niño vs Modoki
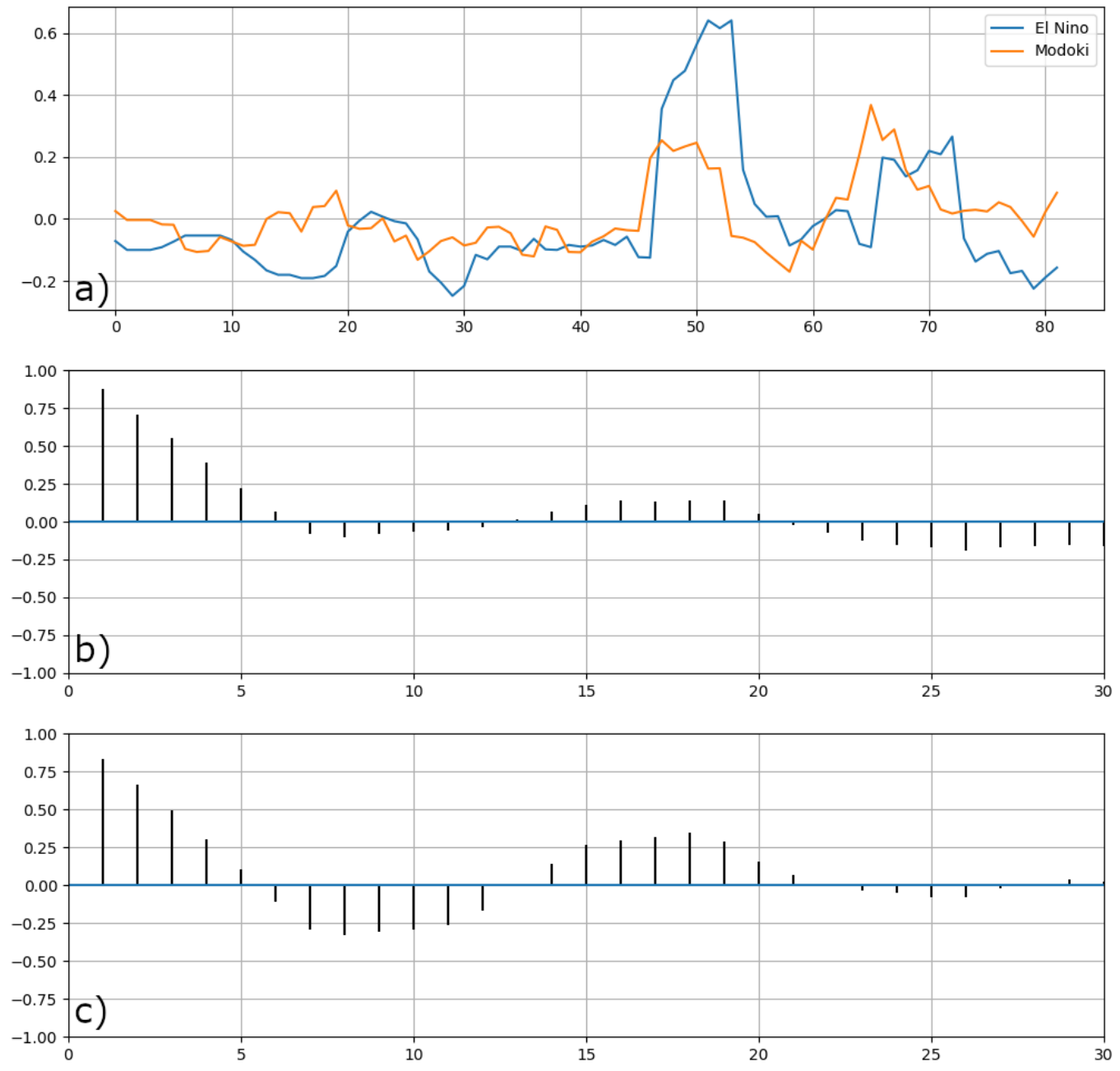

Figure E.4: As in Figure E.1, except for Snowfall (in). 

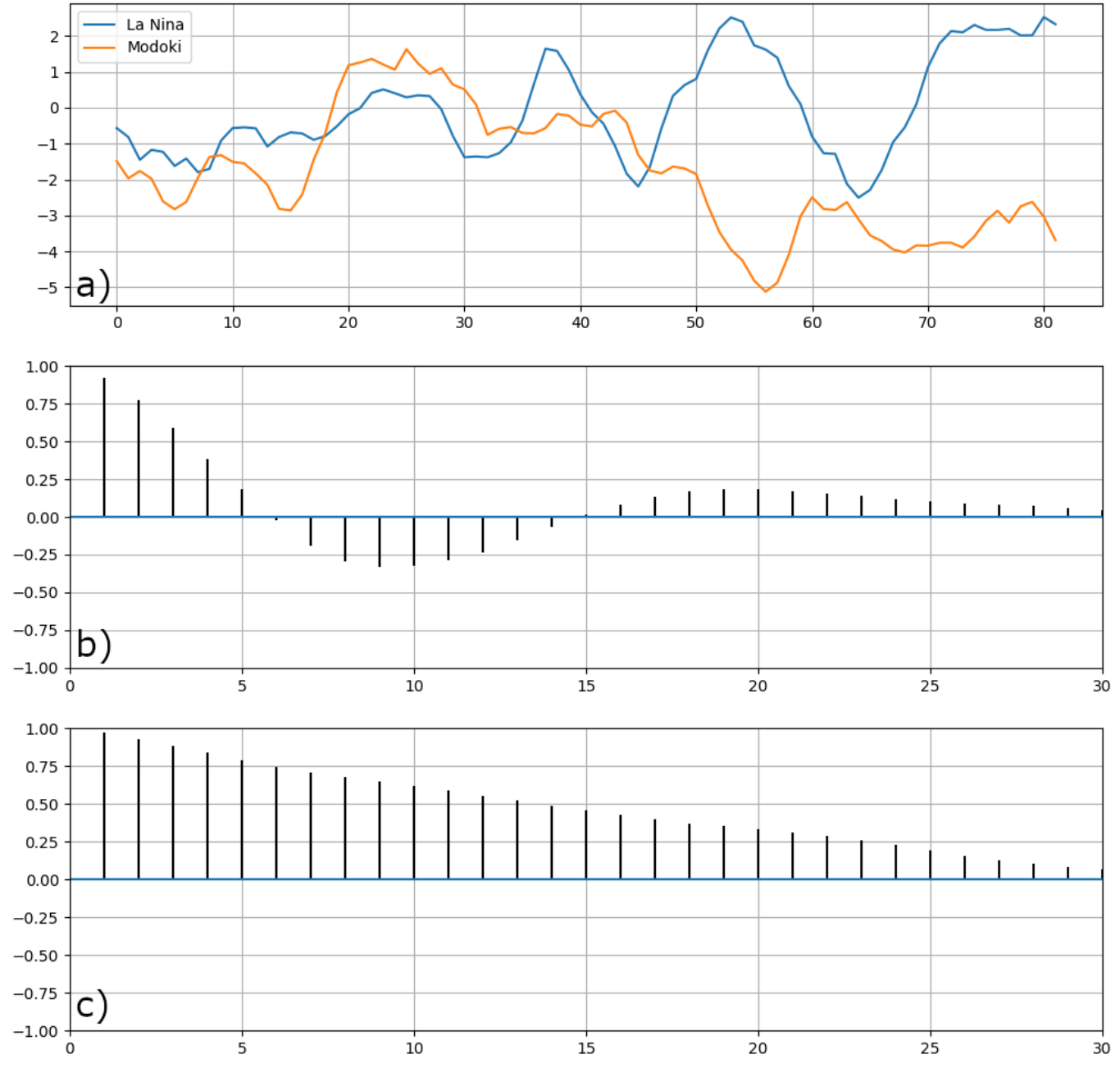

Figure E.5: As in Figure E.1, except comparing La Niña (blue) values to Modoki (orange). Graphs b) and c) show the autocorrelation of Maximum Temperature for White Plains for conventional La Niña and Modoki, respectively. 
E.6 - Comparison of Minimum Temperature Anomalies - La Niña vs Modoki
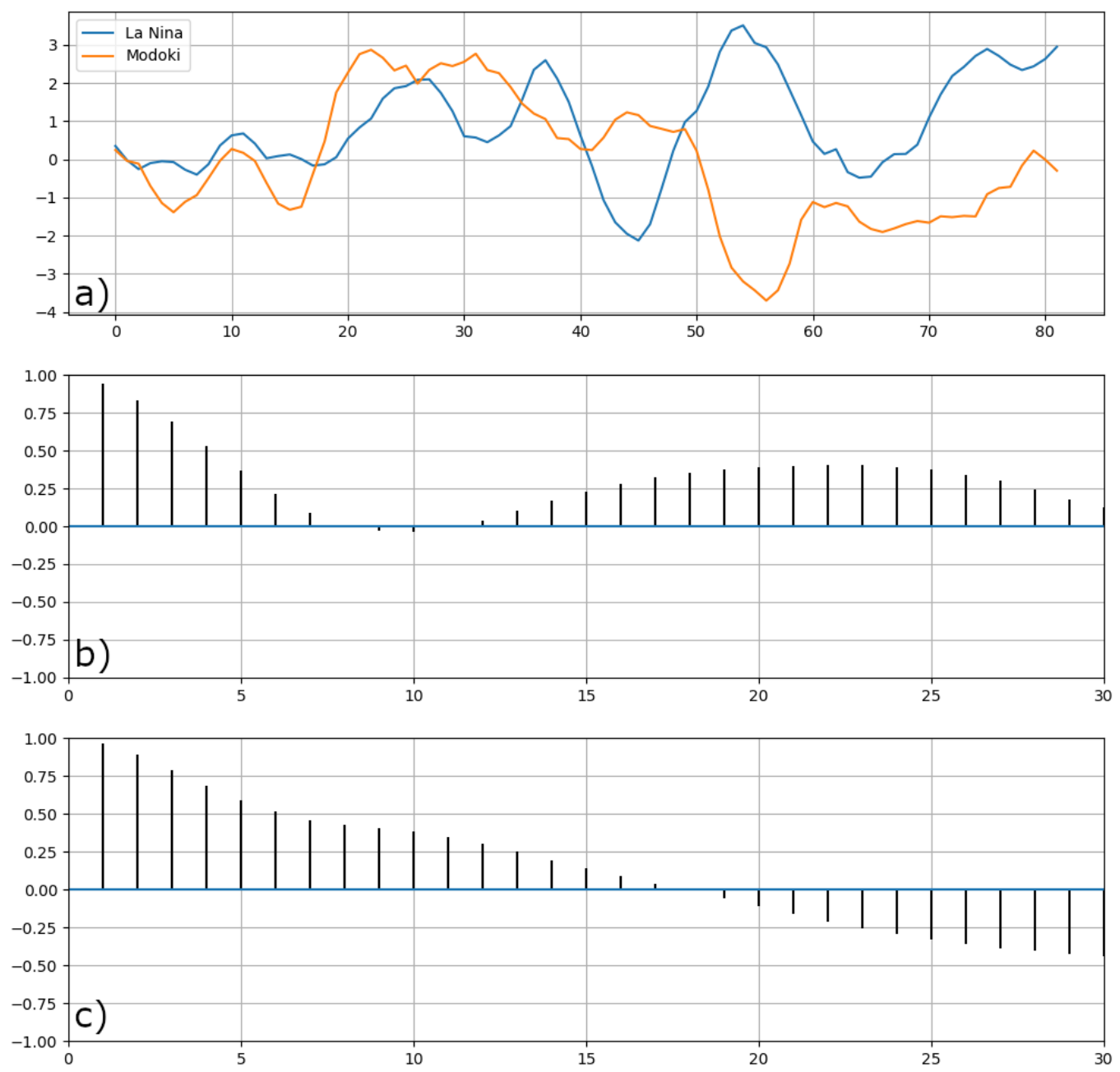

Figure E.6: As in Figure E.5, except for Minimum Temperature (F). 
E.7 - Comparison of Precipitation Anomalies - La Niña vs Modoki
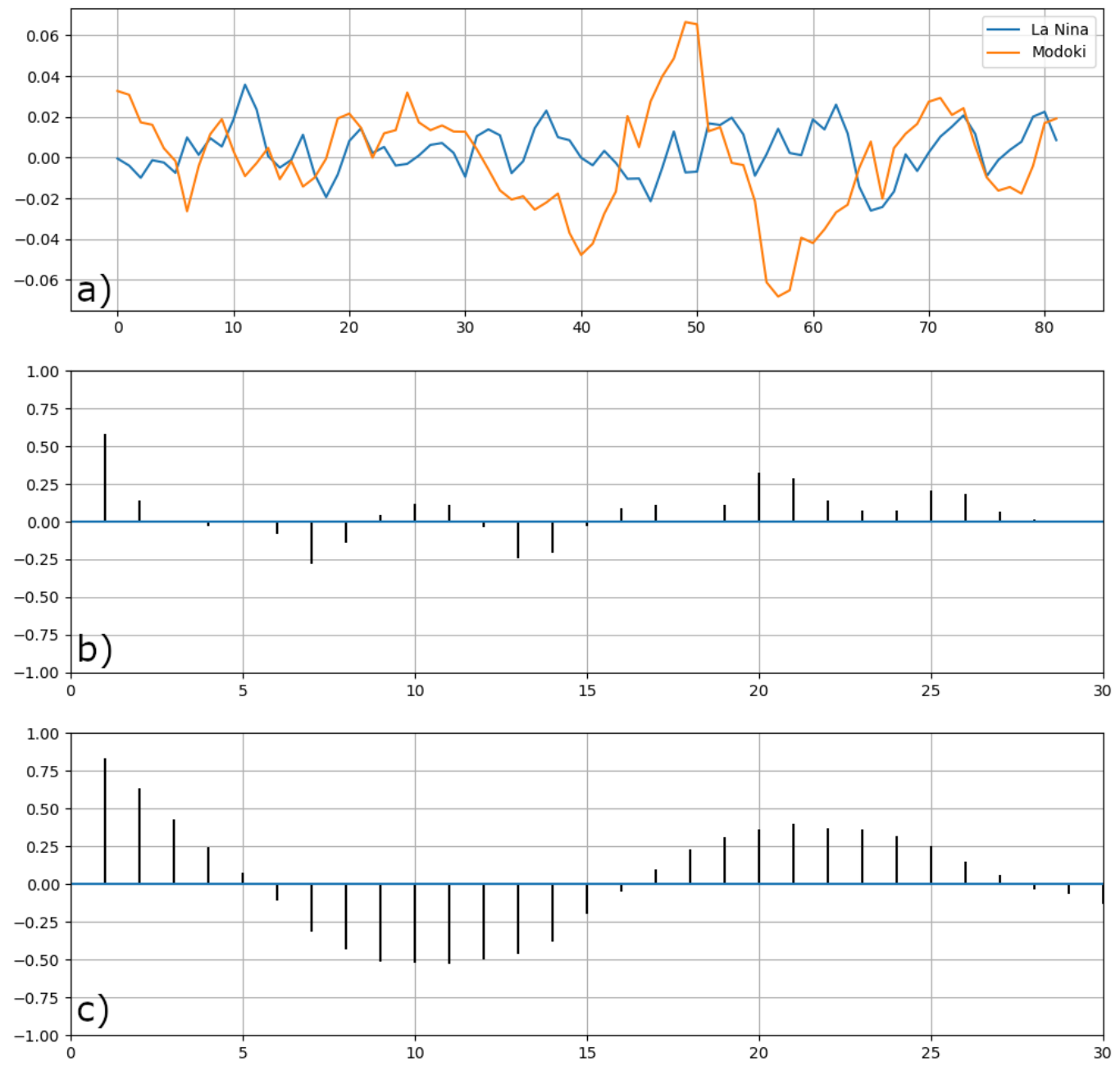

Figure E.7: As in Figure E.5, except for Precipitation (in). 
E.8 - Comparison of Snow Anomalies - La Niña vs Modoki
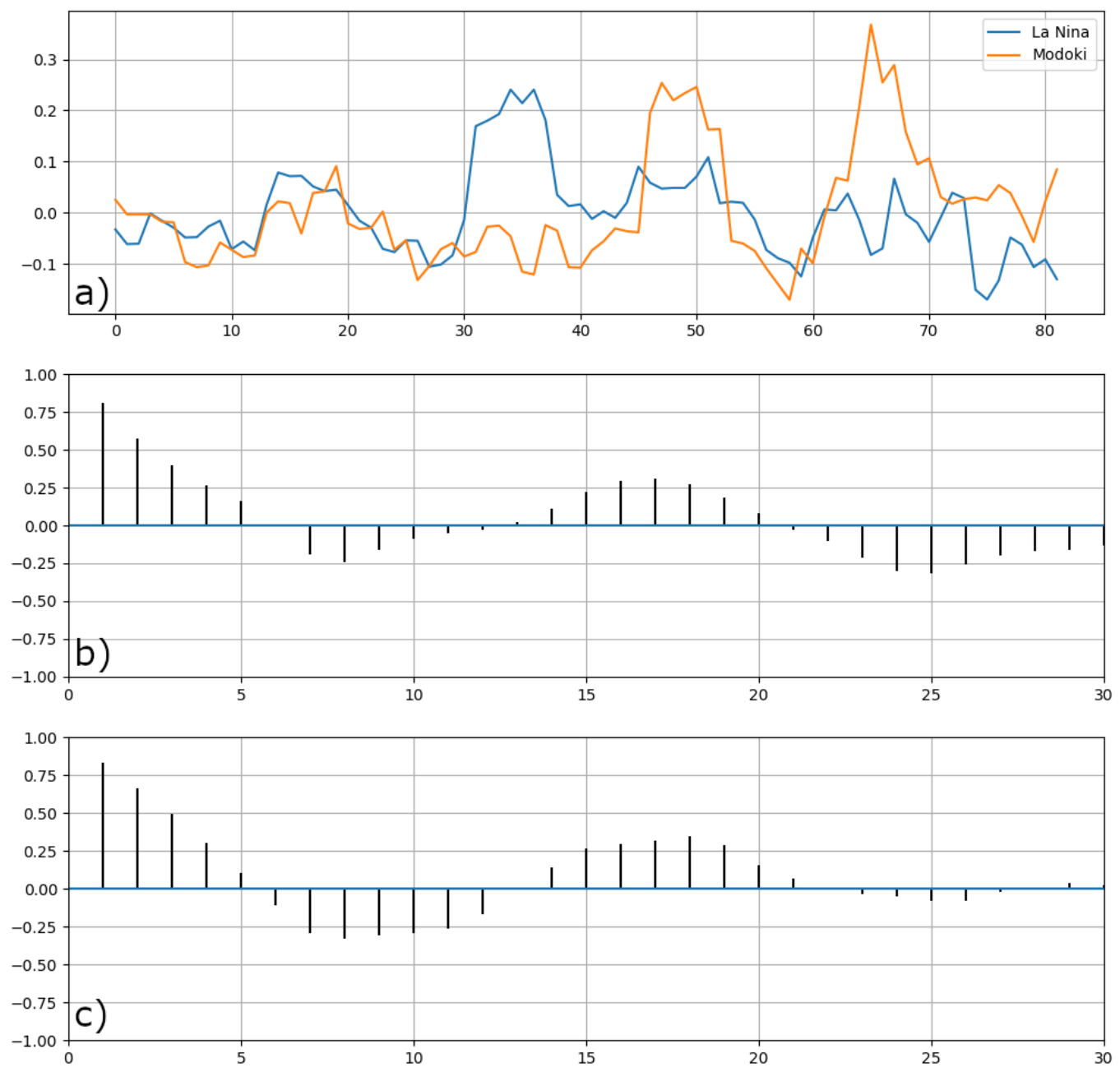

Figure E.8: As in Figure E.5, except for Snowfall (in). 


\section{Appendix F - Watertown Data}

F.1 - Comparison of Maximum Temperature Anomalies - Conventional El Niño vs Modoki
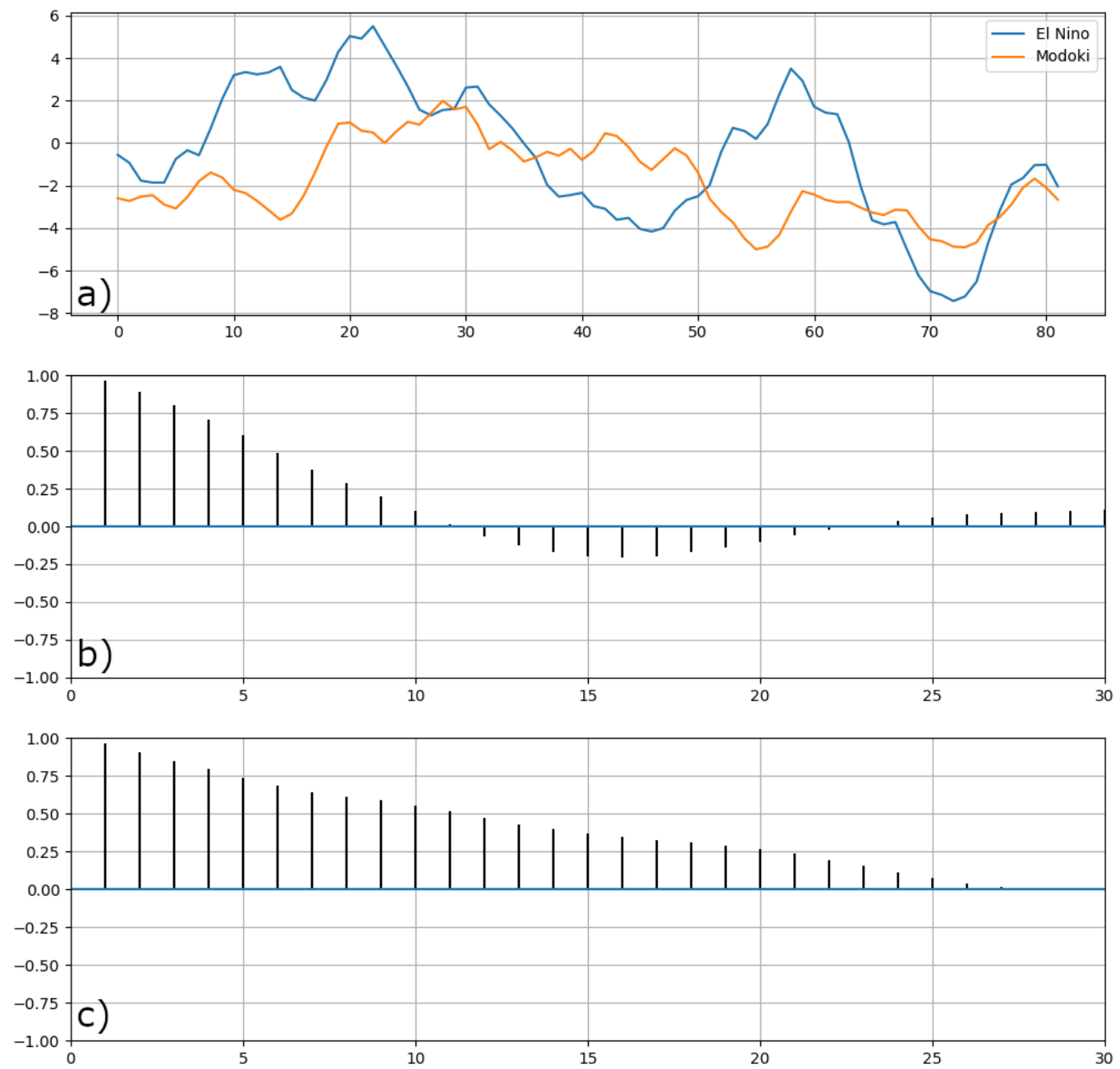

Figure F.1: a) Filtered Daily Averages of Maximum Temperature (F) for Watertown, comparing conventional El Niño values(blue) against Modoki values(orange). Graphs $b$ ) and c) show the autocorrelation of Maximum Temperature for Watertown for conventional El Niño and Modoki, respectivly. 
F.2 - Comparison of Minimum Temperature Anomalies - Conventional El Niño vs Modoki
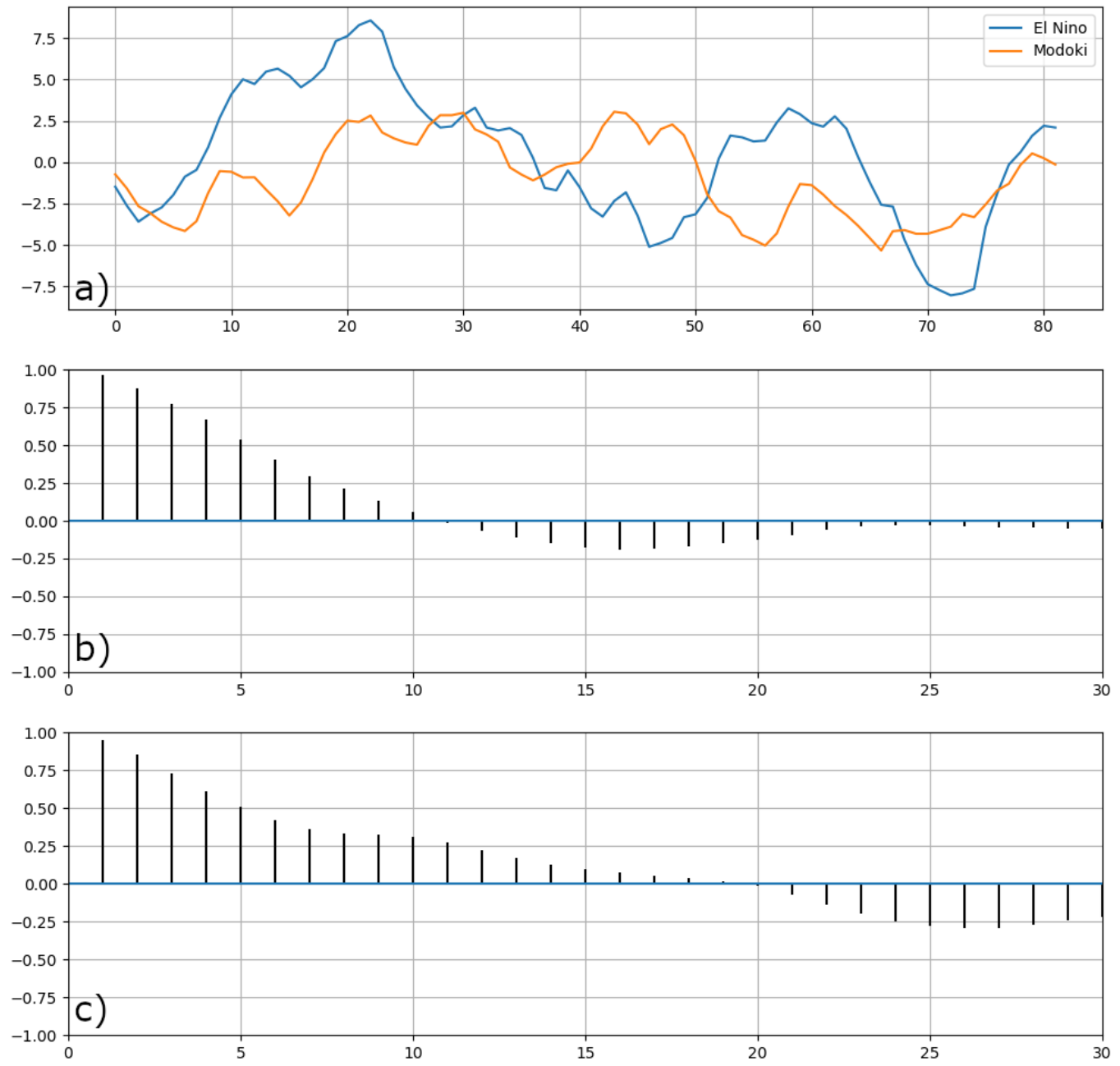

Figure F.2: As in Figure F.1, except for Minimum Temperature (F). 
F.3 - Comparison of Precipitation Anomalies - Conventional El Niño vs Modoki
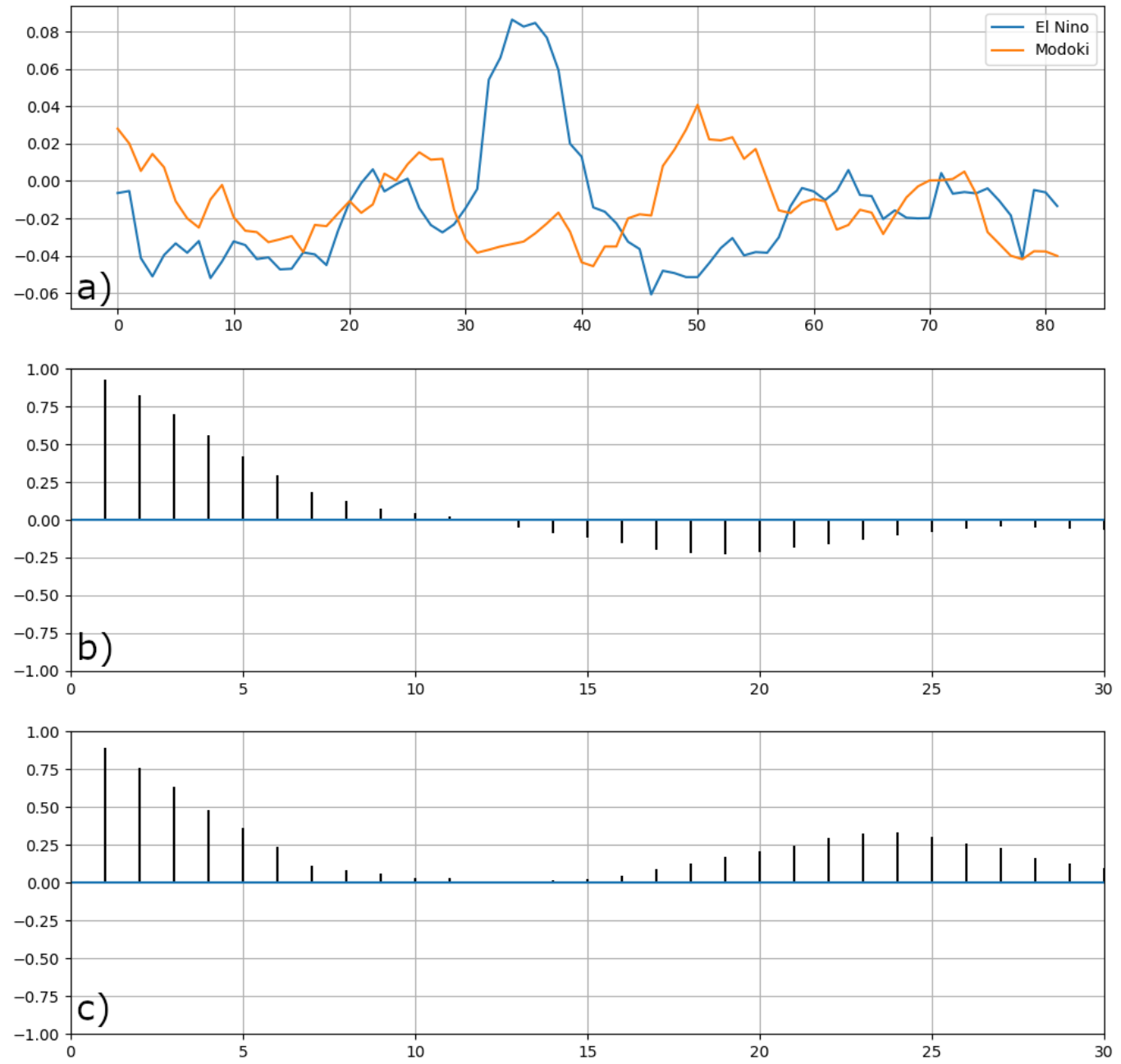

Figure F.3: As in Figure F.1, except for Precipitation (in). 
F.4 - Comparison of Snow Anomalies - Conventional El Niño vs Modoki
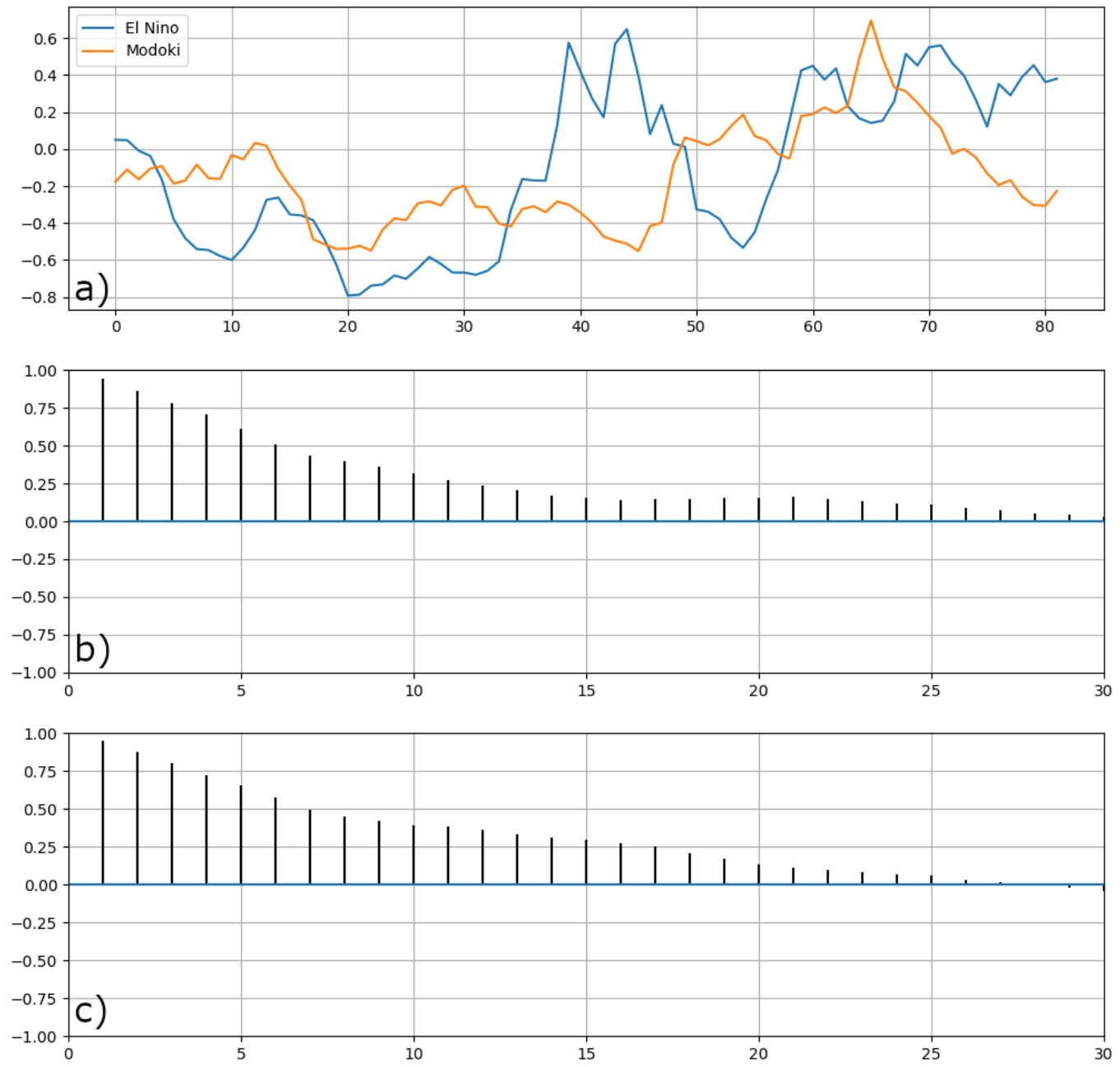

Figure F.4: As in Figure F.1, except for Snowfall (in). 

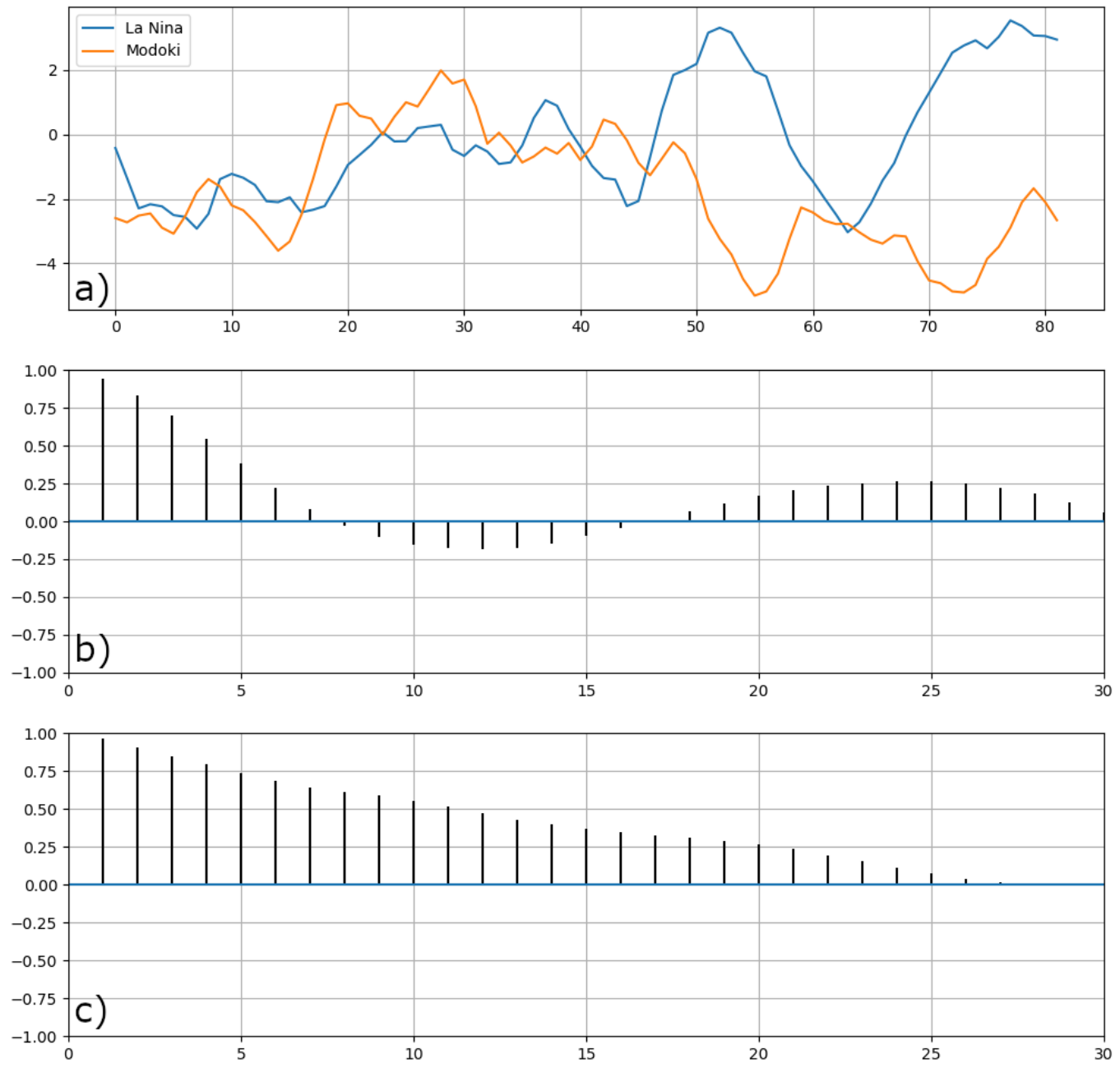

Figure F.5: As in Figure F.1, except comparing La Niña (blue) values to Modoki (orange). Graphs b) and c) show the autocorrelation of Maximum Temperature for Watertown for conventional La Niña and Modoki, respectively. 
F.6 - Comparison of Minimum Temperature Anomalies - La Niña vs Modoki
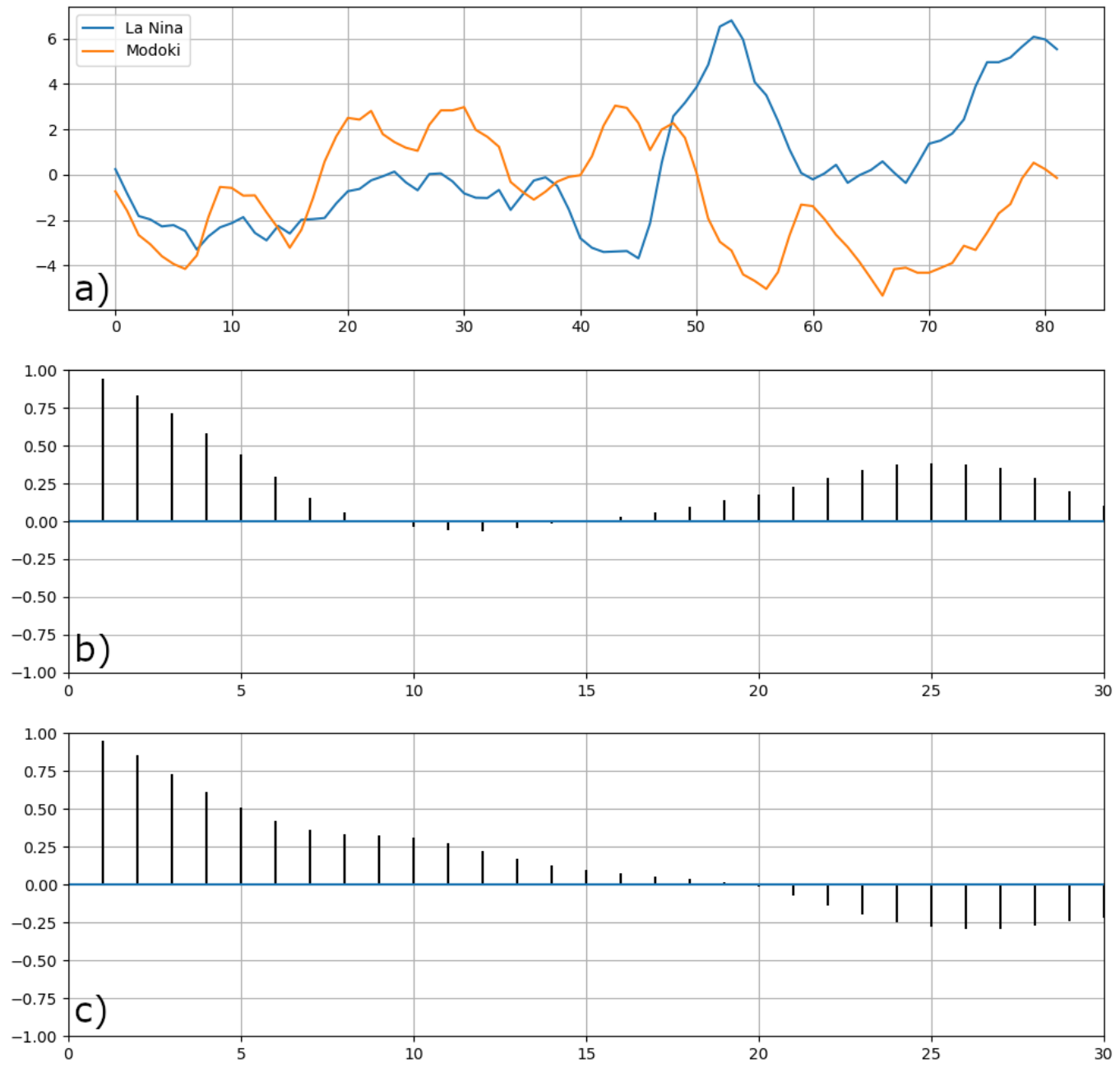

Figure F.6: As in Figure F.5, except for Minimum Temperature (F). 
F.7 - Comparison of Precipitation Anomalies - La Niña vs Modoki
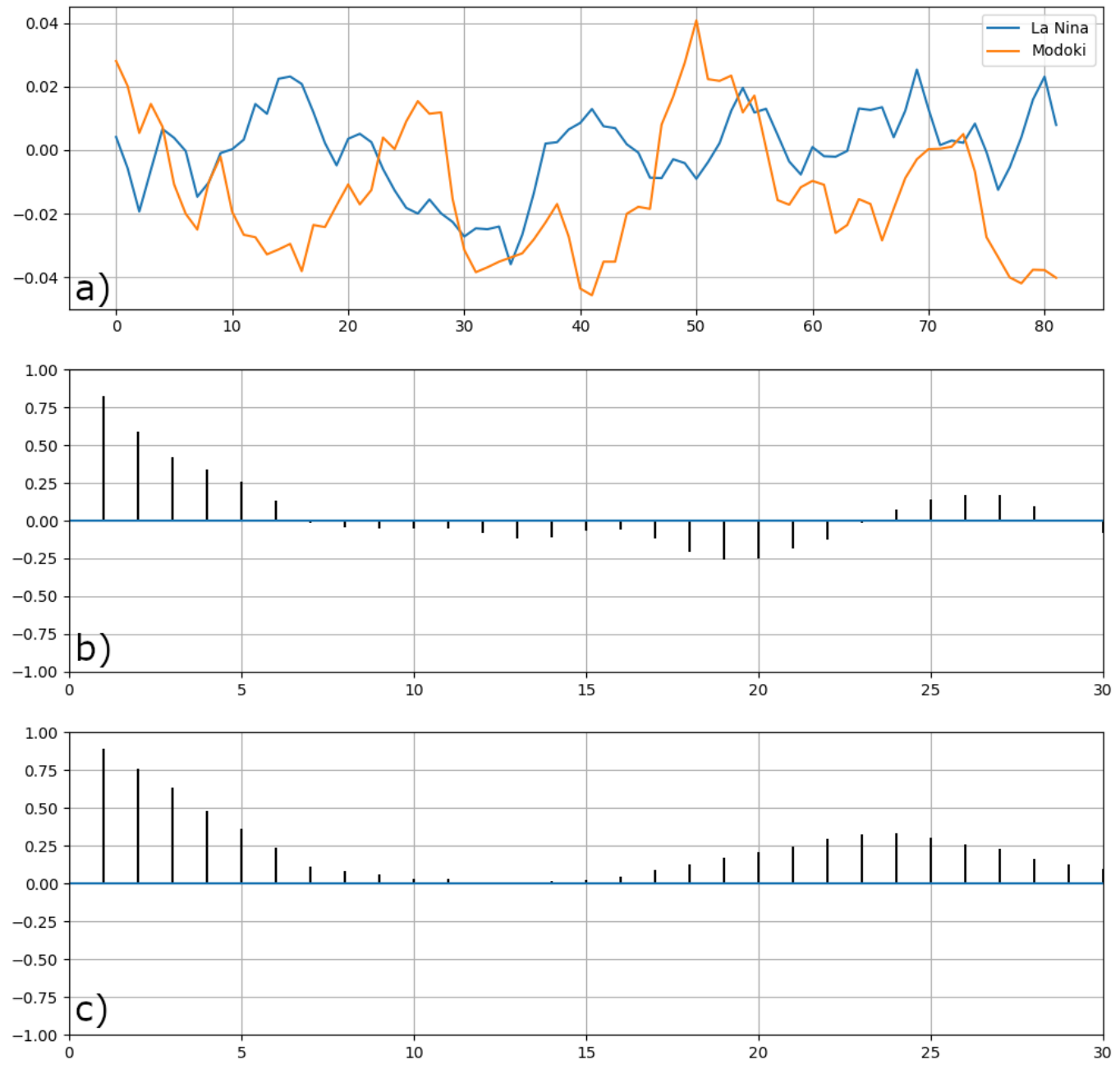

Figure F.7: As in Figure F.5, except for Precipitation (in). 
F.8 - Comparison of Snow Anomalies - La Niña vs Modoki
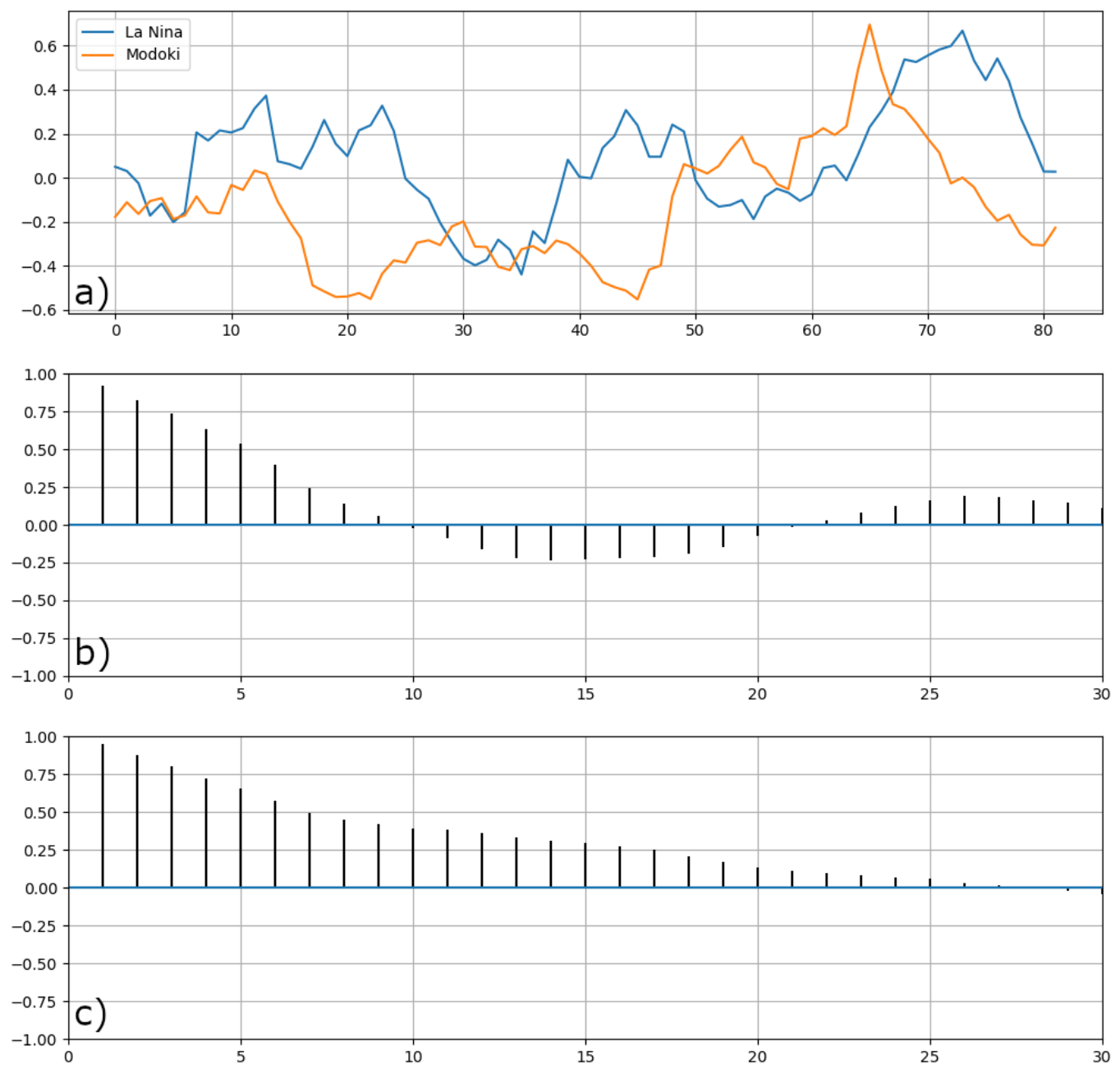

Figure F.8: As in Figure F.5, except for Snowfall (in). 


\section{Appendix G - Syracuse Data}

G.1 - Comparison of Maximum Temperature Anomalies - Conventional El Niño vs Modoki
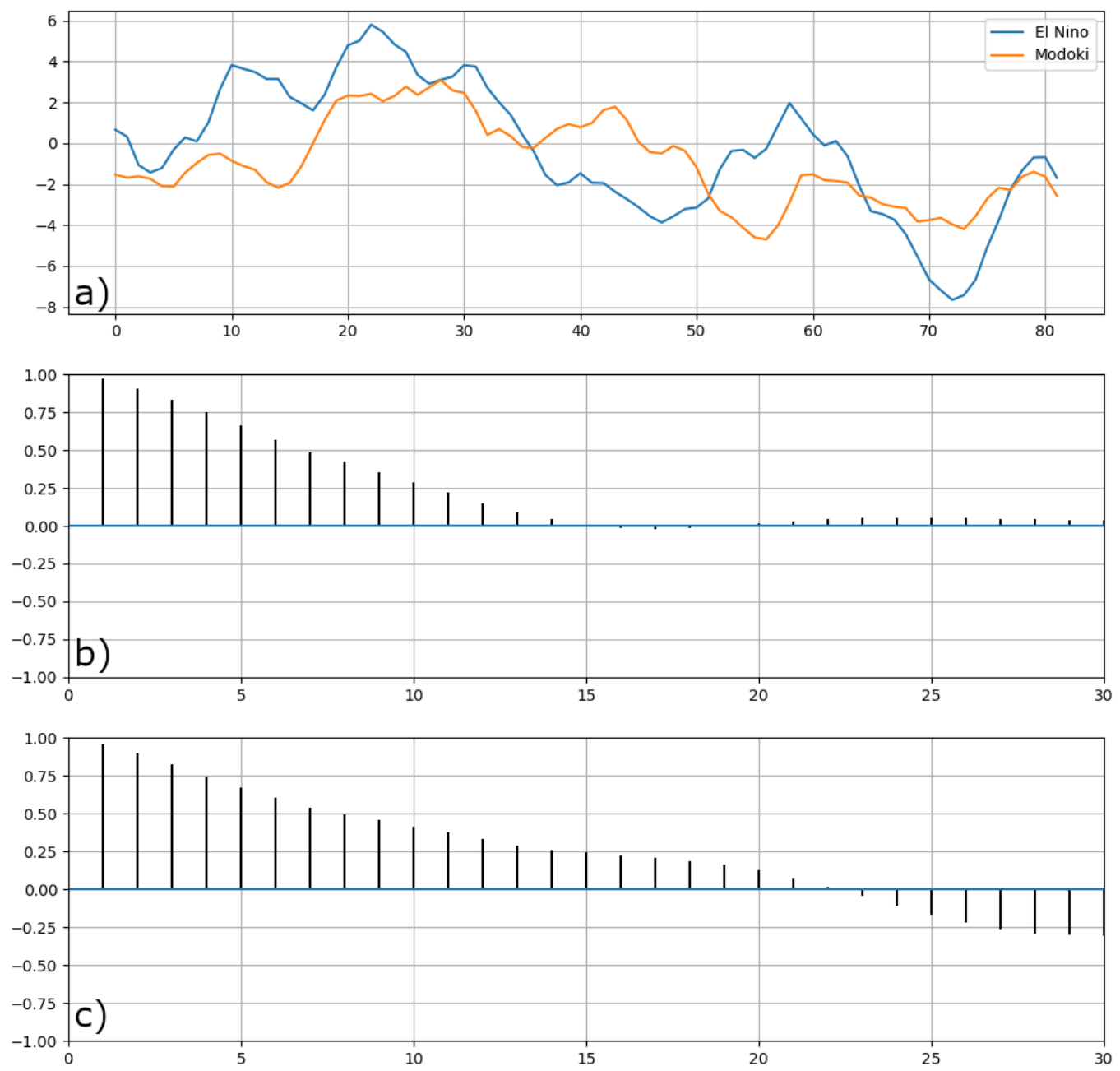

Figure G.1: a) Filtered Daily Averages of Maximum Temperature (F) for Syracuse, comparing conventional El Niño values(blue) against Modoki values(orange). Graphs $b$ ) and c) show the autocorrelation of Maximum Temperature for Syracuse for conventional El Niño and Modoki, respectively. 
G.2 - Fig G.2: As in Figure G.1, except for Minimum Temperature (F).
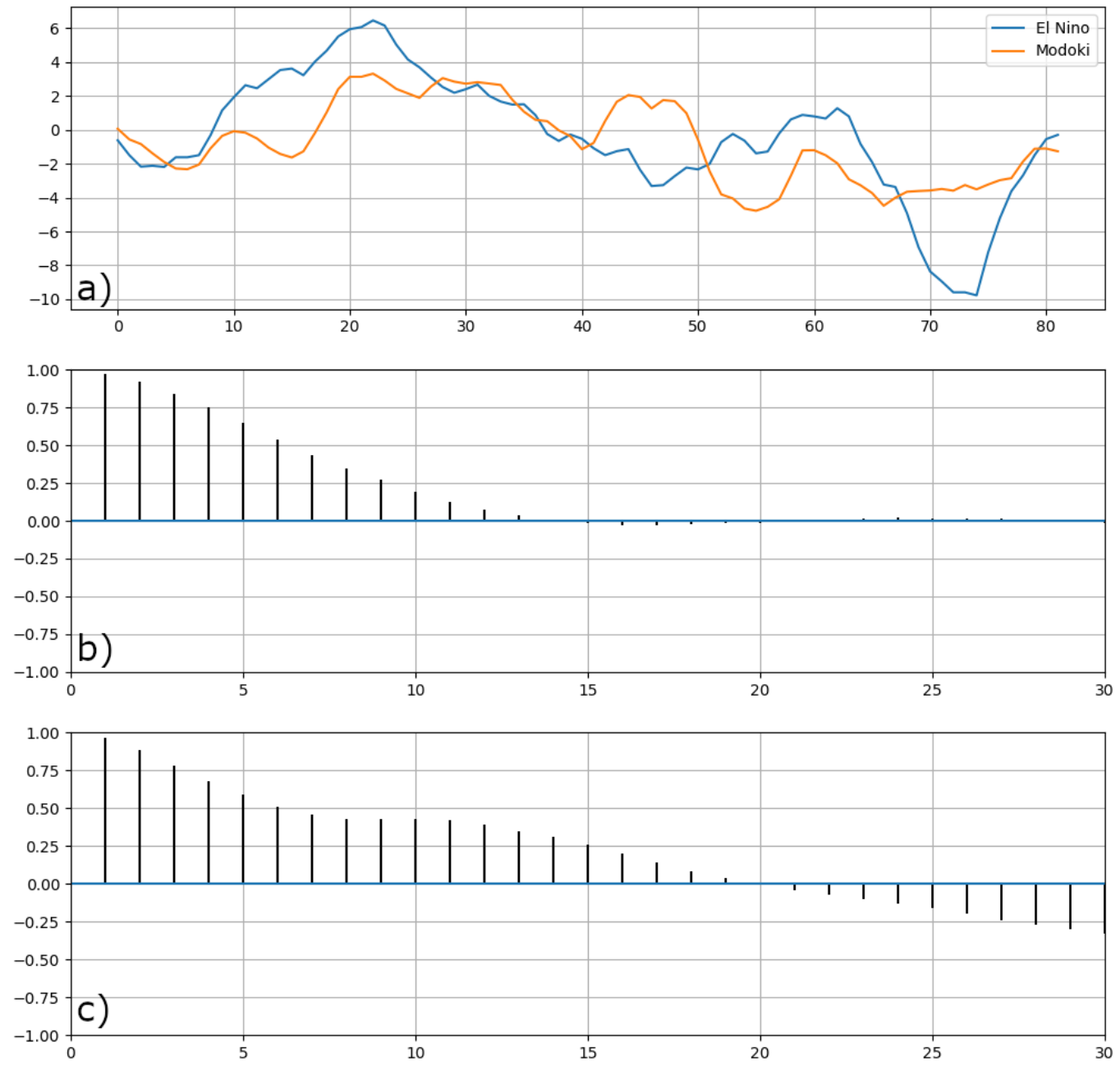

Figure G.2: As in Figure G.1, except for Minimum Temperature (F). 
G.3 - Comparison of Precipitation Anomalies - Conventional El Niño vs Modoki
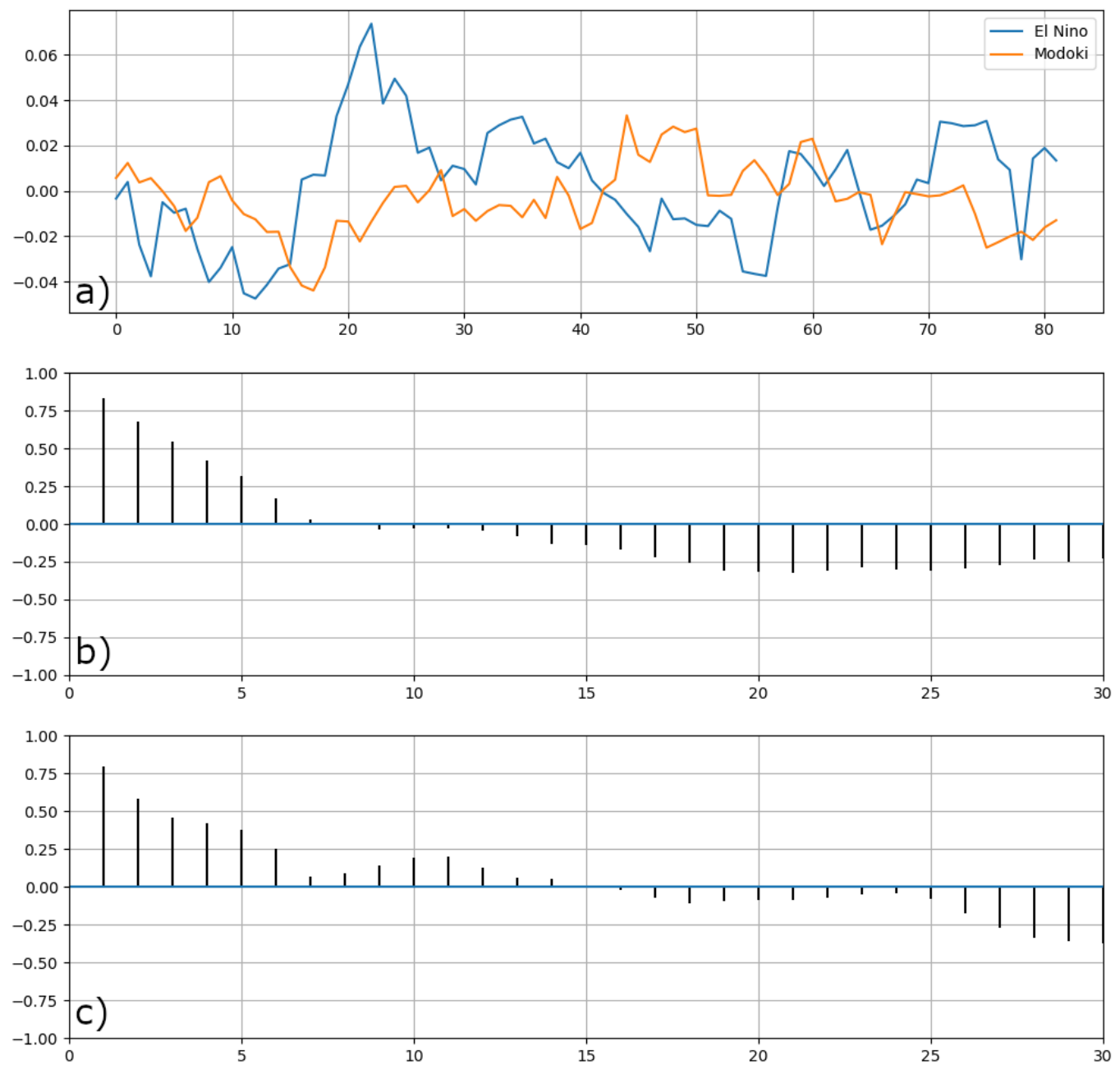

Figure G.3: As in Figure G.1, except for Precipitation (in). 
G.4 - Comparison of Snow Anomalies - Conventional El Niño vs Modoki
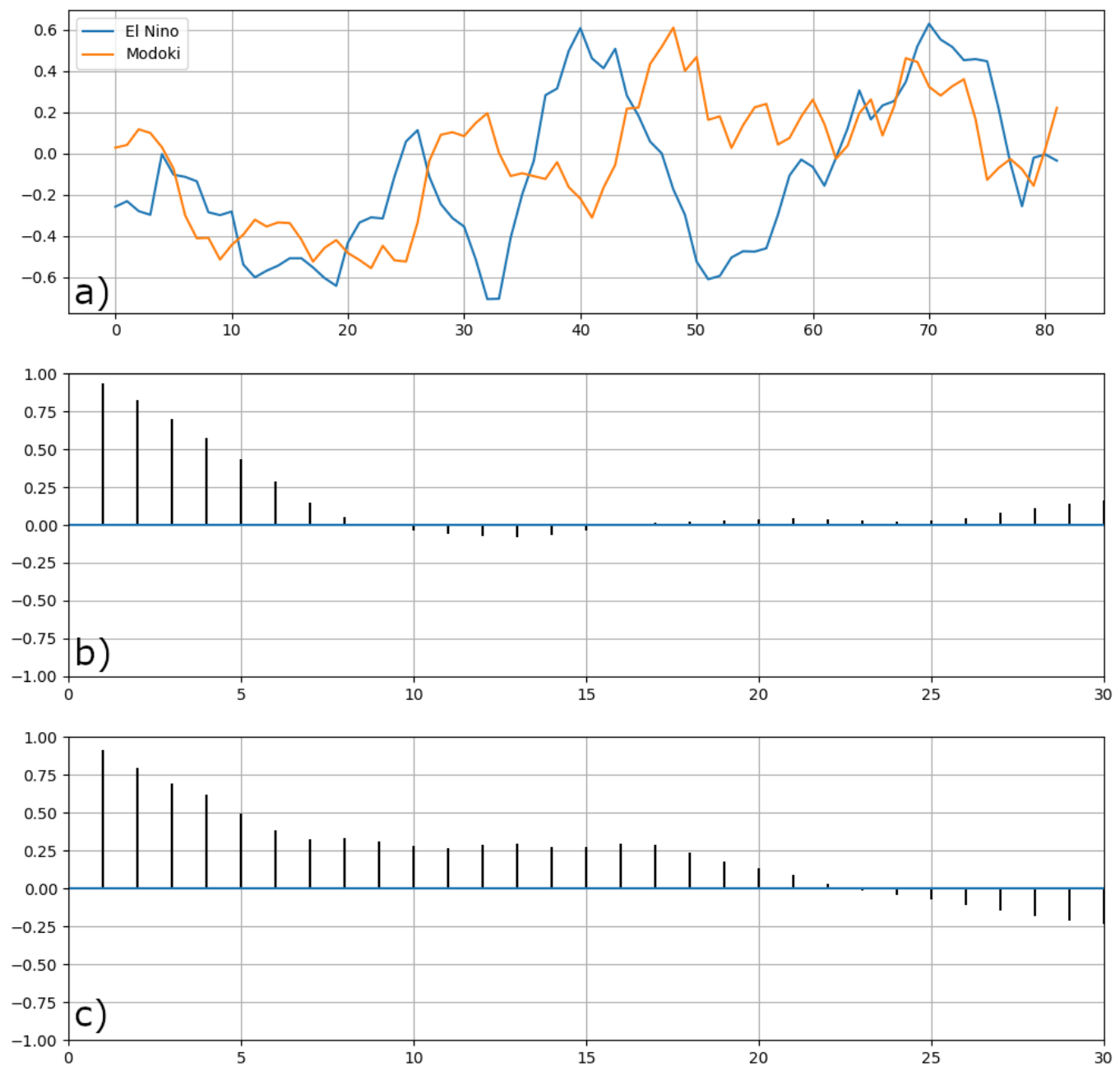

Figure G.4: As in Figure G.1, except for Snowfall (in). 
G.5 - Comparison of Maximum Temperature Anomalies - La Niña vs Modoki
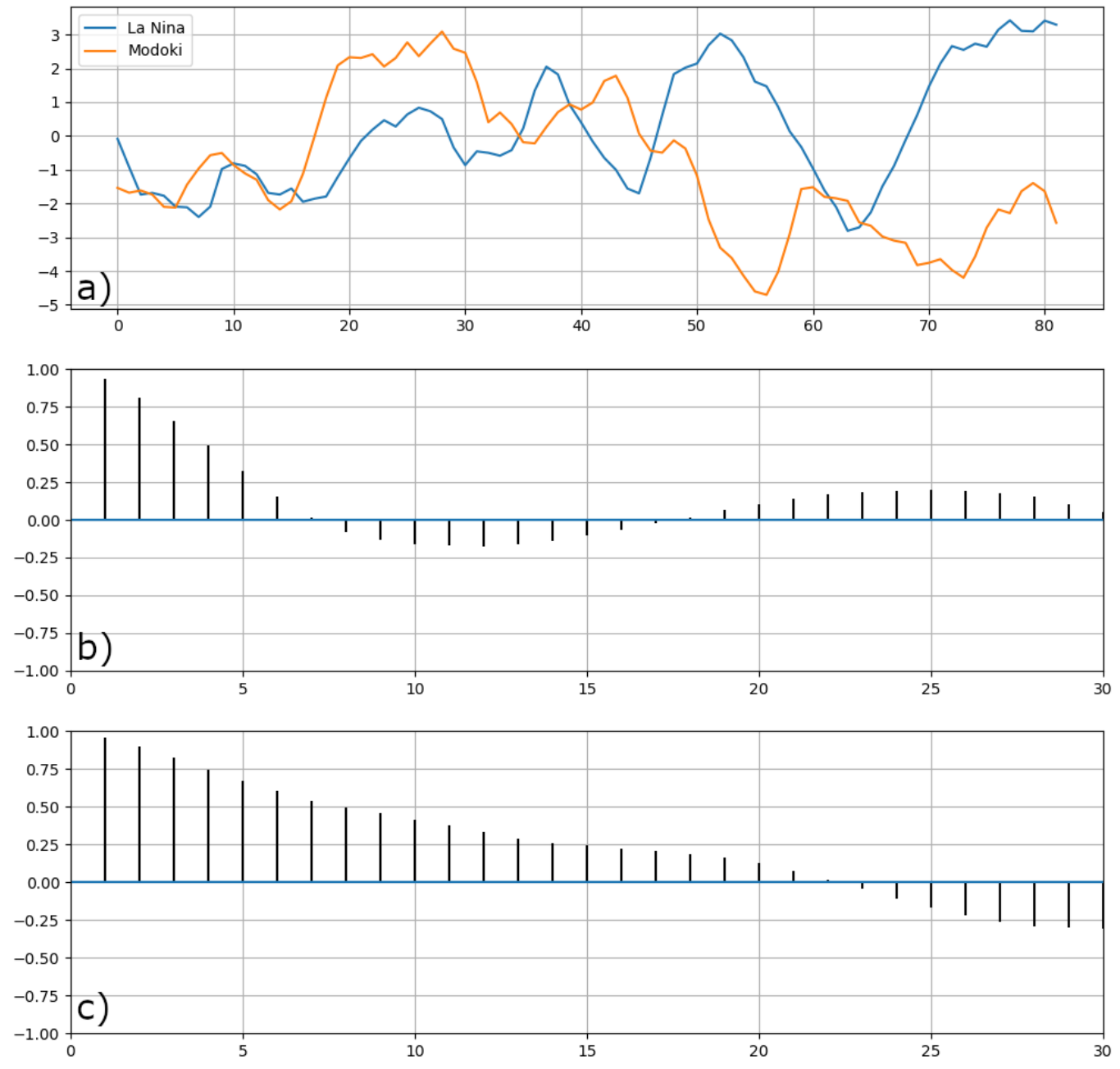

Figure G.5: As in Figure G.1, except comparing La Niña (blue) values to Modoki (orange). Graphs b) and c) show the autocorrelation of Maximum Temperature for Syracuse for conventional La Niña and Modoki, respectively. 
G.6 - Comparison of Minimum Temperature Anomalies - La Niña vs Modoki
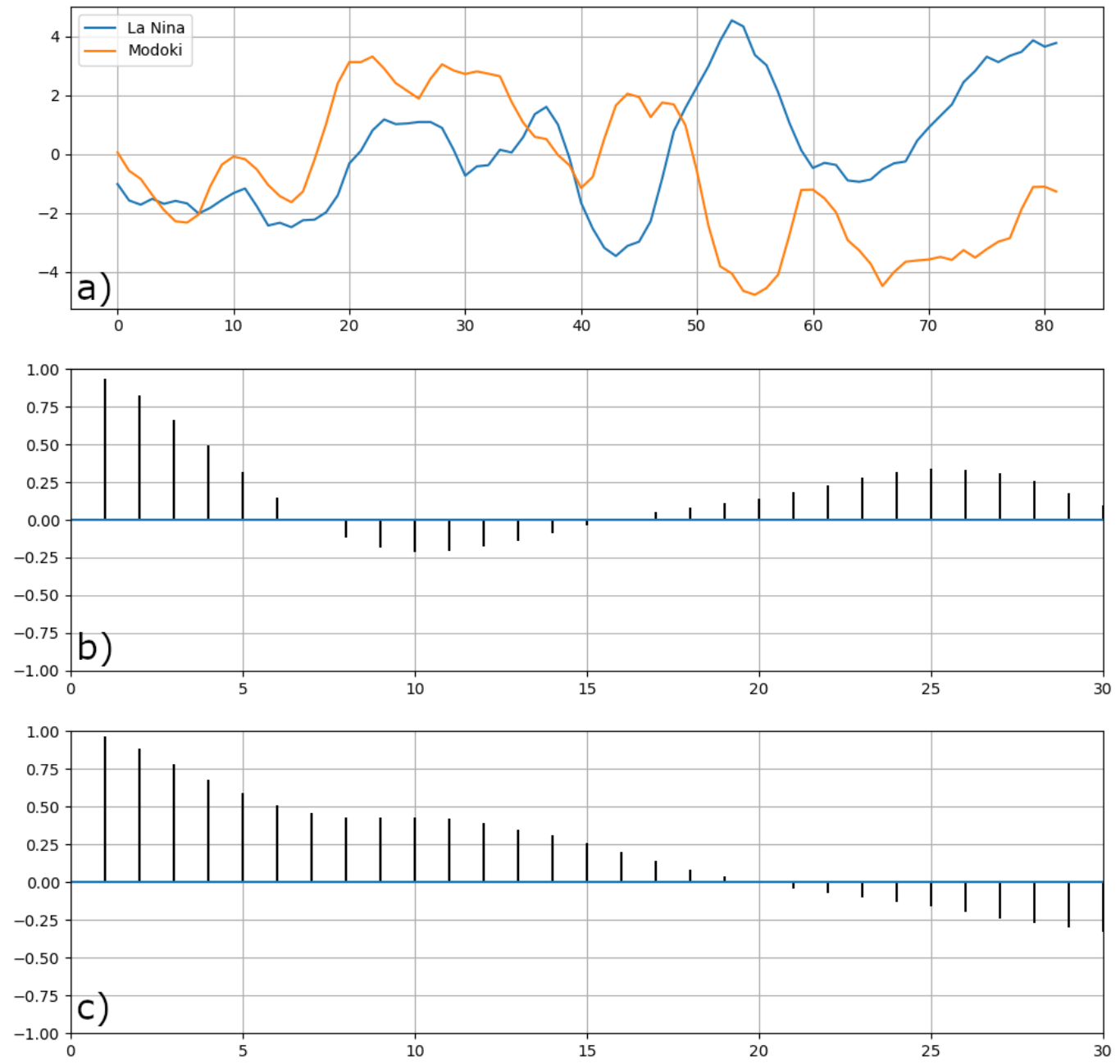

Figure G.6: As in Figure G.5, except for Minimum Temperature (F). 
G.7 - Comparison of Precipitation Anomalies - La Niña vs Modoki
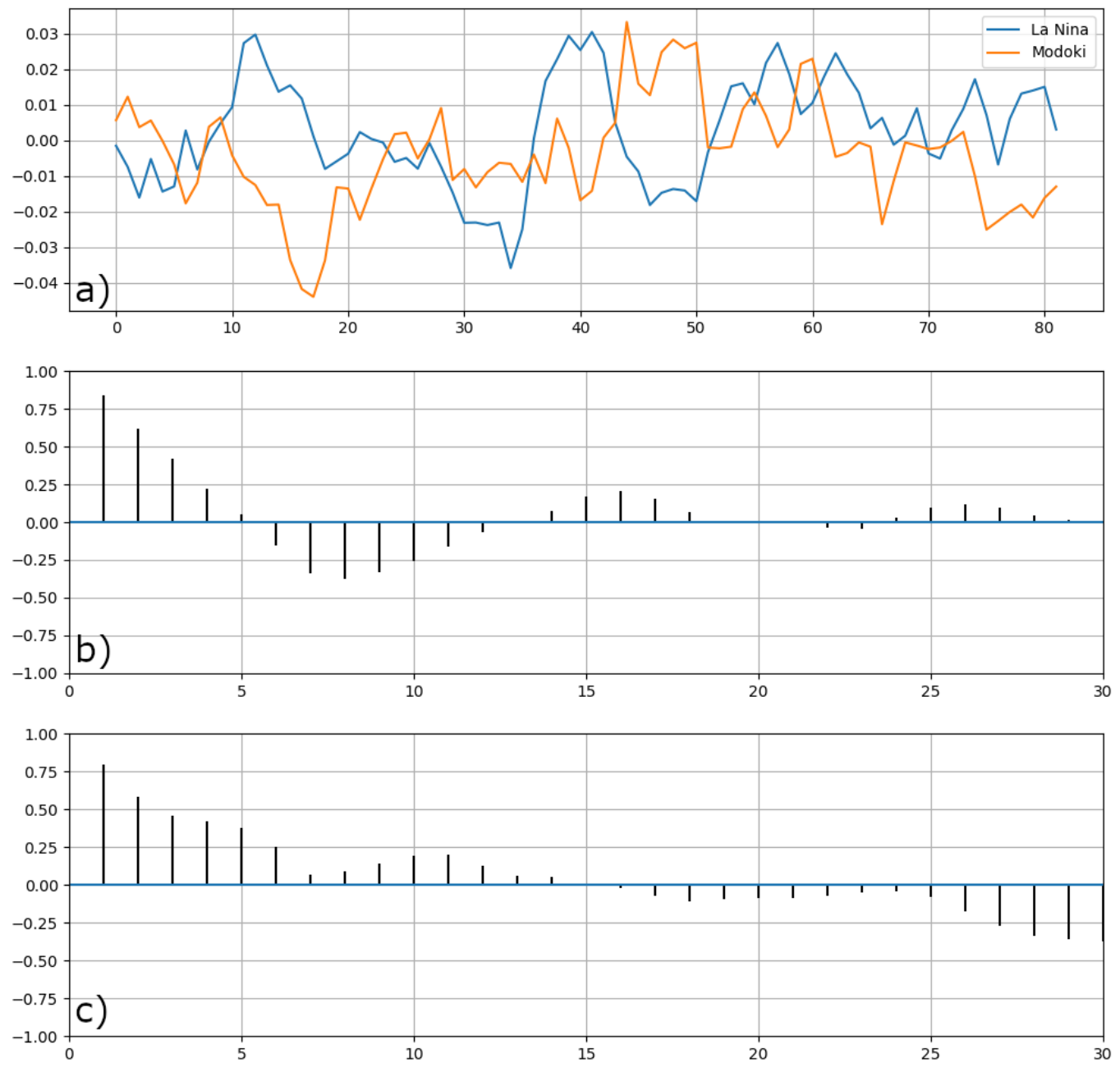

Figure G.7: As in Figure G.5, except for Precipitation (in). 
G.8 - Comparison of Snow Anomalies - La Niña vs Modoki
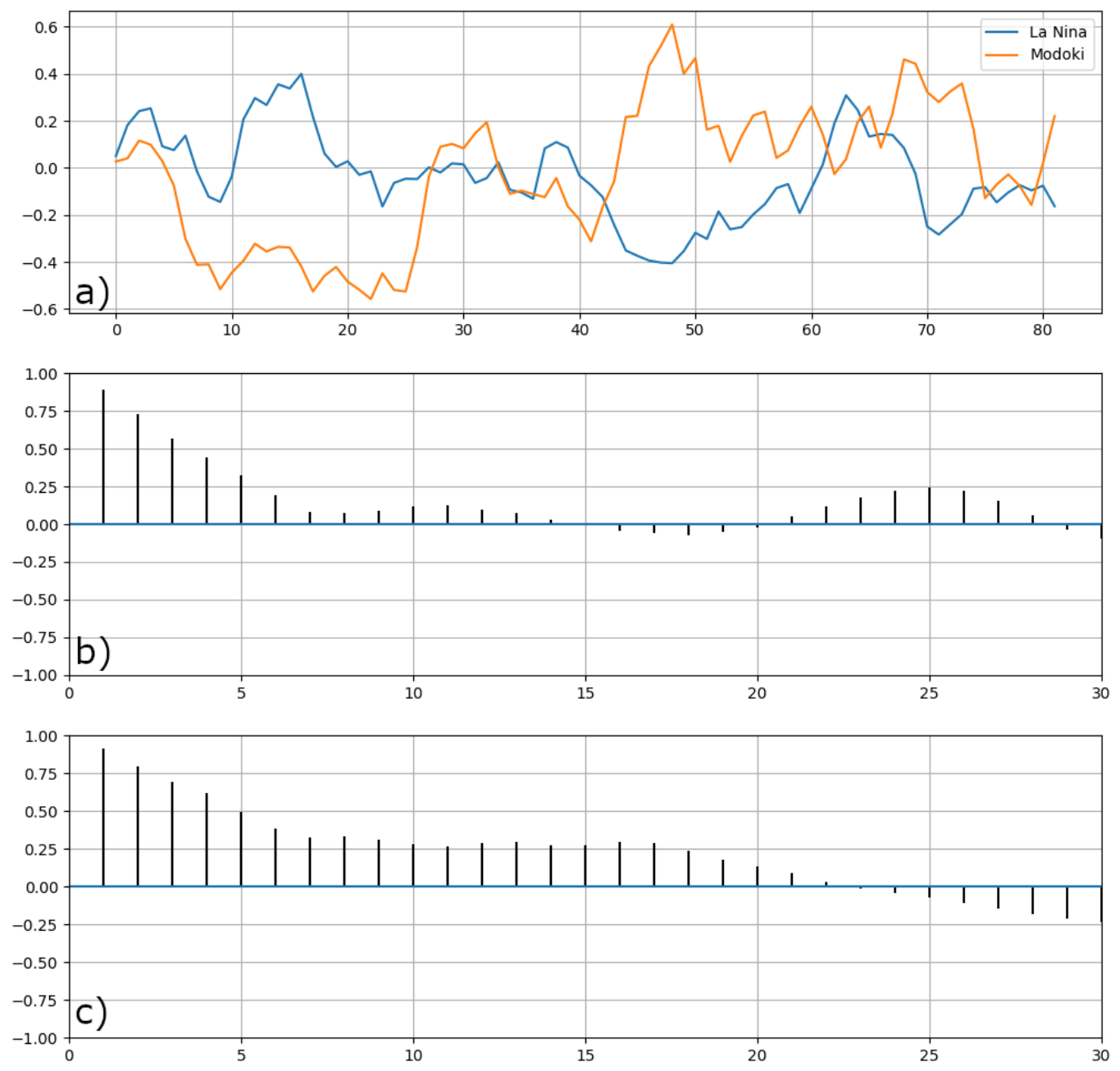

Figure G.8: As in Figure G.5, except for Snowfall (in). 


\section{Appendix $\mathrm{H}$ - Tables}

Table H.1 - Results of El Niño City Result comparisons to the overall average curves (Figures 8-11). Maximum and Minimum Temperature results were combined due to similarity of results.

\begin{tabular}{|c|c|c|c|}
\hline $\mathbf{x}$ & Temps & Precip & Snow \\
\hline Massena & $\begin{array}{l}\text { Fits curve very } \\
\text { well, very strong } \\
\text { signal }\end{array}$ & $\begin{array}{l}\text { Fits average curve well. } \\
\text { Strong signal. }\end{array}$ & $\begin{array}{l}\text { High anomalies past } 60 \text { day mark, but } \\
\text { otherwise does not fit average. Lots of snow } \\
\text { early on. }\end{array}$ \\
\hline Watertown & $\begin{array}{l}\text { Fits curve very } \\
\text { well, strong } \\
\text { signal }\end{array}$ & $\begin{array}{l}\text { Decent fit to curve, } \\
\text { regular signal }\end{array}$ & Fits curve very well, strong signal \\
\hline NYC & $\begin{array}{l}\text { Fits curve, } \\
\text { decent signal, } \\
\text { very regular } \\
\text { cycle }\end{array}$ & $\begin{array}{l}\text { Massive spike against } \\
\text { curve early on and at } 50 \\
\text { days }\end{array}$ & Near neutral until massive spike at 50 days \\
\hline Binghamton & $\begin{array}{l}\text { Fits curve very } \\
\text { well, very strong } \\
\text { signal }\end{array}$ & $\begin{array}{l}\text { Big spike after } 20 \text { days, } \\
\text { dry after } 50 \text {. Exactly how } \\
\text { the curve goes. }\end{array}$ & $\begin{array}{l}\text { Roughly } 20 \text { day cycle, heavy spike early, but } \\
\text { otherwise good fit }\end{array}$ \\
\hline Buffalo & $\begin{array}{l}\text { Fits curve, } \\
\text { decent signal, } \\
\text { very regular } \\
\text { cycle }\end{array}$ & $\begin{array}{l}\text { Fits decently, no spike at } \\
25 \text { days }\end{array}$ & $\begin{array}{l}\text { BIG spike at start (lake snow season is early } \\
\text { here), strong throughout, fits well, matches } \\
\text { with negative min temp anomalies }\end{array}$ \\
\hline Syracuse & $\begin{array}{l}\text { Fits curve very } \\
\text { well, very strong } \\
\text { signal }\end{array}$ & $\begin{array}{l}\text { Fits curve very well, } \\
\text { strong signal }\end{array}$ & Fits curve, decent signal \\
\hline Albany & $\begin{array}{l}\text { Fits curve, } \\
\text { decent signal }\end{array}$ & $\begin{array}{l}\text { Fits curve except no } 40 \\
\text { day spike. Strong signal }\end{array}$ & $\begin{array}{l}\text { Roughly } 20 \text { day cycle, heavy spike early, but } \\
\text { otherwise good fit }\end{array}$ \\
\hline
\end{tabular}


TableH.2 - Same as H.1, only for La Niña Results.

\begin{tabular}{|l|l|l|l|}
\hline & Temps & Precip & Snow \\
\hline Massena & $\begin{array}{l}\text { Fits curve very } \\
\text { well, strong } \\
\text { signal }\end{array}$ & $\begin{array}{l}\text { Fits curve well, strong } \\
\text { spike near end, probably } \\
\text { outlier }\end{array}$ & Lots of early snow and then quiet, fits curve \\
\hline Watertown & $\begin{array}{l}\text { Fits curve very } \\
\text { signal }\end{array}$ & Nearly neutral & Big 70 day spike, otherwise average \\
\hline NYC & $\begin{array}{l}\text { Fits curve very } \\
\text { well, strong } \\
\text { signal }\end{array}$ & $\begin{array}{l}\text { Nearly neutral } \\
\text { Bits curve, decent }\end{array}$ & Fits curve, decent signal \\
\hline signal
\end{tabular}


Table H.3 - Same as H.1, only for Modoki results.

\begin{tabular}{|c|c|c|c|}
\hline & Temps & Precip & Snow \\
\hline Massena & $\begin{array}{l}\text { Fits curve very } \\
\text { well, strong } \\
\text { signal }\end{array}$ & $\begin{array}{l}\text { Fits pattern before } \\
\text { halfway, but breaks down } \\
\text { after. Weak signal. }\end{array}$ & $\begin{array}{l}\text { Not very good fit, weak signal, avg } 20 \text { day } \\
\text { cycle }\end{array}$ \\
\hline Watertown & $\begin{array}{l}\text { Fits curve very } \\
\text { well, strong } \\
\text { signal }\end{array}$ & $\begin{array}{l}\text { Decent fit to curve, } \\
\text { regular signal }\end{array}$ & Fits curve very well, strong signal \\
\hline NYC & $\begin{array}{l}\text { Fits curve, } \\
\text { average signal }\end{array}$ & $\begin{array}{l}\text { Big spike in late January, } \\
\text { fits curve well }\end{array}$ & Near neutral until spike at 50 days and 70 \\
\hline Binghamton & $\begin{array}{l}\text { Fits curve, } \\
\text { average signal }\end{array}$ & $\begin{array}{l}\text { Big spike in late January, } \\
\text { fits curve well }\end{array}$ & Decent fit to curve, regular signal \\
\hline Buffalo & $\begin{array}{l}\text { Fits curve very } \\
\text { well, strong } \\
\text { signal }\end{array}$ & $\begin{array}{l}\text { Big spike in late January, } \\
\text { fits curve well }\end{array}$ & Decent fit to curve, moderate/strong signal \\
\hline Syracuse & $\begin{array}{l}\text { Fits curve, } \\
\text { average signal }\end{array}$ & Fits curve, weak signal & Fits curve, decent signal \\
\hline Albany & $\begin{array}{l}\text { Fits curve very } \\
\text { well, strong } \\
\text { signal }\end{array}$ & Fits curve, average signal & Not present until 50 day spike, then 70 \\
\hline
\end{tabular}


Table H.4 - Analysis of all city-based autocorrelation results.

\begin{tabular}{|c|c|c|c|}
\hline & Temps & Precip & Snow \\
\hline Massena & $\begin{array}{l}\text { La Niña: Full } \\
\text { Cycle in } 24 \text { days. }\end{array}$ & $\begin{array}{l}\text { El Niño: } 2 \text { cycles in } 24 \\
\text { days. La Niña: Weak } \\
\text { signal, } 26 \text { days per cycle }\end{array}$ & El Niño: Full cycle in 15 days. \\
\hline Watertown & $\begin{array}{l}\text { La Niña: roughly } \\
20-24 \text { day cycle, } \\
\text { strong signal }\end{array}$ & $\begin{array}{l}\text { Modoki: strong positive } \\
\text { half-cycle at 24ish days }\end{array}$ & La Niña: 26 day cycle, weak signal \\
\hline NYC & $\begin{array}{l}\text { La Niña: roughly } \\
20-24 \text { day cycle, } \\
\text { strong signal }\end{array}$ & $\begin{array}{l}\text { El Niño: moderate signal, } \\
\text { 14-day cycle }\end{array}$ & $\begin{array}{l}\text { La Niña AND Modoki: Full cycle in } 18 \text { days, } \\
\text { strong signal }\end{array}$ \\
\hline Binghamton & $\begin{array}{l}\text { La Niña: } 23 \text { day } \\
\text { cycle, weak signal }\end{array}$ & $\begin{array}{l}\text { El Niño: strong negative } 26 \\
\text { day signal. La Niña: weak } \\
\text { to moderate } 25 \text { day cycle. }\end{array}$ & $\begin{array}{l}\text { La Niña: VERY strong positive signal after } 25 \\
\text { days }\end{array}$ \\
\hline Buffalo & $\begin{array}{l}\text { La Niña: } 25 \text { day } \\
\text { cycle, moderate } \\
\text { signal }\end{array}$ & $\begin{array}{l}\text { Modoki: moderate negative } \\
\text { half-cycle at } 15 \text { days La } \\
\text { Niña: } 27 \text { day weak cycle }\end{array}$ & $\begin{array}{l}\text { La Niña: } 24 \text { day cycle, moderate to strong } \\
\text { signal }\end{array}$ \\
\hline Syracuse & $\begin{array}{l}\text { La Niña: } 25 \text { day } \\
\text { cycle, moderate } \\
\text { signal }\end{array}$ & $\begin{array}{l}\text { La Niña: } 16 \text { day cycle, } \\
\text { weak signal El Niño: } \\
\text { moderate signal, half cycle, } \\
\text { negative }\end{array}$ & La Niña: 24 day cycle, weak signal \\
\hline Albany & $\begin{array}{l}\text { La Niña: Full } \\
\text { Cycle in } 24 \text { days. }\end{array}$ & $\begin{array}{l}\text { El Niño: } 16 \text { day cycle, } \\
\text { weak to moderate signal } \\
\text { La Niña: negative } \\
\text { moderate signal at } 19 \text { days }\end{array}$ & $\begin{array}{l}\text { El Niño: Weak } 18 \text { day signal La Niña: } 24 \text { day } \\
\text { cycle, moderate to strong signal }\end{array}$ \\
\hline
\end{tabular}




\section{References}

Ashok, S. K. Behera, S. A. Rao, H. Weng, and T. Yamagata, 2007: El Niño Modoki and its possible teleconnection. Journal of Geophysical Research:

Oceans, 112, https://doi.org/10.1029/2006JC003798.

— C.-Y. Tam, and W.-J. Lee, 2009: ENSO Modoki impact on the Southern Hemisphere storm track activity during extended austral winter. Geophysical Research

Letters, 36, https://doi.org/10.1029/2009GL038847.

Birk, K., A. R. Lupo, P. Guinan, and C. E. Barbieri, 2010: The interannual variability of midwestern temperatures and precipitation as related to the ENSO and PDO. Atmósfera, 23. Branstator, G., 1987: A Striking Example of the Atmosphere's Leading Traveling Pattern. $J$. Atmos. Sci., 44, 2310-2323, https://doi.org/10.1175/15200469(1987)044<2310:ASEOTA>2.0.CO;2.

Chen, S., W. Chen, and B. Yu, 2018: Modulation of the relationship between spring AO and the subsequent winter ENSO by the preceding November AO. Scientific Reports, 8 , 6943, https://doi.org/10.1038/s41598-018-25303-0.

Cook, A. R., and J. T. Schaefer, 2008: The Relation of El Niño-Southern Oscillation (ENSO) to Winter Tornado Outbreaks. Mon. Wea. Rev., 136, 31213137, https://doi.org/10.1175/2007MWR2171.1.

Dogar, M. M., F. Kucharski, T. Sato, S. Mehmood, S. Ali, Z. Gong, D. Das, and J. Arraut, 2019: Towards understanding the global and regional climatic impacts of Modoki magnitude. Global and Planetary Change, 172, 223-241, https://doi.org/10.1016/j.gloplacha.2018.10.004.

Eichler, T., and W. Higgins, 2006: Climatology and ENSO-Related Variability of North American Extratropical Cyclone Activity. J. Climate, 19, 20762093, https://doi.org/10.1175/JCLI3725.1.

Feng, J., W. Chen, C.-Y. Tam, and W. Zhou, 2011: Different impacts of El Niño and El Niño Modoki on China rainfall in the decaying phases. International Journal of Climatology, 31, 2091-2101, https://doi.org/10.1002/joc.2217.

Kim, D.-W., K.-S. Choi, and H.-R. Byun, 2012: Effects of El Niño Modoki on winter precipitation in Korea. Clim Dyn, 38, 1313-1324, https://doi.org/10.1007/s00382-011-1114-1.

Kug, J.-S., F.-F. Jin, and S.-I. An, 2009: Two Types of El Niño Events: Cold Tongue El Niño and Warm Pool El Niño. J. Climate, 22, 1499-1515, https://doi.org/10.1175/2008JCLI2624.1.

—, J. Choi, S.-I. An, F.-F. Jin, and A. T. Wittenberg, 2010: Warm Pool and Cold Tongue El Niño Events as Simulated by the GFDL 2.1 Coupled GCM. J. Climate, 23, 12261239, https://doi.org/10.1175/2009JCLI3293.1. 
Larkin, N. K., and D. E. Harrison, 2005: On the definition of El Niño and associated seasonal average U.S. weather anomalies. Geophysical Research

Letters, 32, https://doi.org/10.1029/2005GL022738.

L'Heureux, M. L., M. K. Tippett, A. Kumar, A. H. Butler, L. M. Ciasto, Q. Ding, K. J. Harnos, and N. C. Johnson, 2017: Strong Relations Between ENSO and the Arctic Oscillation in the North American Multimodel Ensemble. Geophysical Research Letters, 44, 11,65411,662, https://doi.org/10.1002/2017GL074854.

Li, F., H. Wang, and J. Liu, 2014: The strengthening relationship between Arctic Oscillation and ENSO after the mid-1990s. International Journal of Climatology, 34, 25152521, https://doi.org/10.1002/joc.3828.

Lim, Y.-K., and S. D. Schubert, 2011: The impact of ENSO and the Arctic Oscillation on winter temperature extremes in the southeast United States. Geophysical Research

Letters, 38, https://doi.org/10.1029/2011GL048283.

Linkin, M. E., and S. Nigam, 2008: The North Pacific Oscillation-West Pacific Teleconnection Pattern: Mature-Phase Structure and Winter Impacts. J. Climate, 21, 1979-

1997, https://doi.org/10.1175/2007JCLI2048.1.

May, W., and L. Bengtsson, 1998: The signature of ENSO in the Northern Hemisphere midlatitude seasonal mean flow and high-frequency intraseasonal variability. Meteorl. Atmos. Phys., 69, 81-100, https://doi.org/10.1007/BF01025185.

Oort, A. H., and J. J. Yienger, 1996: Observed Interannual Variability in the Hadley Circulation and Its Connection to ENSO. J. Climate, 9, 2751-2767, https://doi.org/10.1175/15200442(1996)009<2751:OIVITH>2.0.CO;2.

Overland, J. E., J. M. Adams, and N. A. Bond, 1999: Decadal Variability of the Aleutian Low and Its Relation to High-Latitude Circulation. J. Climate, 12, 15421548, https://doi.org/10.1175/1520-0442(1999)012<1542:DVOTAL>2.0.CO;2.

Preethi, B., T. P. Sabin, J. A. Adedoyin, and K. Ashok, 2015: Impacts of the ENSO Modoki and other Tropical Indo-Pacific Climate-Drivers on African Rainfall. Scientific Reports, $\mathbf{5}$, 16653, https://doi.org/10.1038/srep16653.

Seager, R., Y. Kushnir, J. Nakamura, M. Ting, and N. Naik, 2010: Northern Hemisphere winter snow anomalies: ENSO, NAO and the winter of 2009/10. Geophysical Research

Letters, 37, https://doi.org/10.1029/2010GL043830.

Straus, D. M., and J. Shukla, 2002: Does ENSO Force the PNA? J. Climate, 15, 2340-

2358, https://doi.org/10.1175/1520-0442(2002)015<2340:DEFTP>2.0.CO;2.

Takahashi, K., A. Montecinos, K. Goubanova, and B. Dewitte, 2011: ENSO regimes: Reinterpreting the canonical and Modoki El Niño. Geophysical Research

Letters, 38, https://doi.org/10.1029/2011GL047364. 
Timmermann, A., F.-F. Jin, and J. Abshagen, 2003: A Nonlinear Theory for El Niño Bursting. J. Atmos. Sci., 60, 152-165, https://doi.org/10.1175/15200469(2003)060<0152:ANTFEN>2.0.CO;2.

Wang, X., M. Chen, C. Wang, S.-W. Yeh, and W. Tan, 2019: Evaluation of performance of CMIP5 models in simulating the North Pacific Oscillation and El Niño Modoki. Clim Dyn, 52, 1383-1394, https://doi.org/10.1007/s00382-018-4196-1.

Weng, H., K. Ashok, S. K. Behera, S. A. Rao, and T. Yamagata, 2007: Impacts of recent El Niño Modoki on dry/wet conditions in the Pacific rim during boreal summer. Clim Dyn, 29, 113129, https://doi.org/10.1007/s00382-007-0234-0.

— S. K. Behera, and T. Yamagata, 2009: Anomalous winter climate conditions in the Pacific rim during recent El Niño Modoki and El Niño events. Clim Dyn, 32, 663674, https://doi.org/10.1007/s00382-008-0394-6.

Yu, L., S. Zhong, W. E. Heilman, and X. Bian, 2017: A comparison of the effects of El Niño and El Niño Modoki on subdaily extreme precipitation occurrences across the contiguous United States. Journal of Geophysical Research: Atmospheres, 122, 74017415, https://doi.org/10.1002/2017JD026683. 